\title{
Avian Occupancy Dynamics and Canada Warbler (Cardellina canadensis) Environmental Correlates on a Central Appalachian Elevation Gradient in West Virginia
}

Gordon W. Dimmig

West Virginia University, gwd0005@mix.wvu.edu

Follow this and additional works at: https://researchrepository.wvu.edu/etd

Part of the Biodiversity Commons, and the Ornithology Commons

\section{Recommended Citation}

Dimmig, Gordon W., "Avian Occupancy Dynamics and Canada Warbler (Cardellina canadensis) Environmental Correlates on a Central Appalachian Elevation Gradient in West Virginia" (2019). Graduate Theses, Dissertations, and Problem Reports. 3778.

https://researchrepository.wvu.edu/etd/3778

This Thesis is protected by copyright and/or related rights. It has been brought to you by the The Research Repository @ WVU with permission from the rights-holder(s). You are free to use this Thesis in any way that is permitted by the copyright and related rights legislation that applies to your use. For other uses you must obtain permission from the rights-holder(s) directly, unless additional rights are indicated by a Creative Commons license in the record and/ or on the work itself. This Thesis has been accepted for inclusion in WVU Graduate Theses, Dissertations, and Problem Reports collection by an authorized administrator of The Research Repository @ WVU. For more information, please contact researchrepository@mail.wvu.edu. 
Avian Occupancy Dynamics and Canada Warbler (Cardellina canadensis)

Environmental Correlates on a Central Appalachian Elevation Gradient in West Virginia

\author{
Gordon W. Dimmig
}

Thesis submitted to the Davis College of Agriculture, Natural Resources, and Design at West Virginia University

in partial fulfillment of the requirements for the degree of

Master of Science in

Wildlife and Fisheries Resources

Christopher T. Rota, Ph.D. Chair

Christopher M. Lituma, Ph.D.

Petra B. Wood, Ph.D.

Division of Forestry and Natural Resources

Morgantown, West Virginia

2019

Keywords: Canada Warbler, Cardellina canadensis, multi-species occupancy, avian dynamics, forest songbirds, Appalachian Mountains, Monongahela National Forest, elevation gradient

Copyright 2019 Gordon W. Dimmig 


\begin{abstract}
Avian Occupancy Dynamics and Canada Warbler (Cardellina canadensis)

Environmental Correlates on a Central Appalachian Elevation Gradient in West Virginia
\end{abstract}

\title{
Gordon Dimmig
}

Mountains are important areas for avian diversity and conservation since they have steep elevational and environmental gradients. In the central Appalachian Mountains, several songbird species have trailing edge populations that are restricted to high elevations. Climate change and other factors can cause species distributions to change, which is of particular concern for birds in restricted trailing edge populations. Additionally, the Canada Warbler (Cardellina canadensis) breeds throughout the Appalachian Mountains and is species of conservation concern due to range-wide population declines. For this project, I used avian point count data from the central Appalachian Mountains to: (1) evaluate the spatial and temporal dynamics of a group of songbirds, and (2) assess fine-scale environmental correlates of the Canada Warbler. To assess avian dynamics, I used a 26-year (1993-2018) historic dataset of 5922 point count surveys conducted in the Monongahela National Forest, West Virginia to model colonization and persistence rates for 16 songbird species in a Bayesian framework. Colonization and persistence rates were modeled as a function of year, elevation, and harvest, with interactive effects between year and elevation. I then derived equilibrium occupancy for each species to evaluate the change in occupancy over the 26-year period and across the elevation gradient. Five species expanded upwards, 3 species expanded downwards, 1 species contracted downwards, 1 species shifted downwards, and 6 species had no directional change in equilibrium occupancy. None of the 16 species contracted upwards and there was little evidence of climate-induced elevational movement. Varying responses along the elevation gradient are likely due to a combination of several factors, including changing forest conditions and regional population trends. Spruce restoration and regeneration of northern hardwood and spruce forests are likely driving the upward and downward expansions observed in 5 species, which suggests that climate-induced movements may be alleviated by more direct changes to forest conditions. In chapter 2, I evaluate Canada Warbler space use and environmental correlates using 840 point count surveys conducted in 2017 and 2018. I assessed Canada Warbler occupancy in a multi-species occupancy modelling framework that accounted for potential interactions between Black-throated Blue Warbler (Setophaga caerulescens) and Hermit Thrush (Catharus guttatus). I found that Canada Warblers were more likely to occur in mid-elevations, in areas with high Rhododendron (Rhododendron maximum) stem density, closer to riparian areas, and in northern hardwood forests. Canada Warblers were also positively associated with Black-throated Blue Warblers. Conservation actions for Canada Warblers in its southern breeding distribution should span across a range of elevations in northern hardwood forests. Additionally, protection of riparian areas, especially those with dense Rhododendron thickets, will likely benefit Canada Warblers in their Appalachian distribution. 


\section{ACKNOWLEDGMENTS}

This work was supported by the USDA National Institute of Food and Agriculture, McIntire Stennis project WVA00124. This project would not have been possible without the countless number of technicians from the U.S. Forest Service and West Virginia University that conducted nearly 6000 point count surveys in the past 2.5 decades. Dr. Petra Wood and Dr. Thomas DeMeo played integral roles in establishing and conducting many of first historic point count transects. Thank you to the U.S. Forest Service, particularly Catherine Johnson and Kyle Crafts, for their technical and logistical support in the field. Thank you to my thesis advisor, Dr. Christopher Rota, for his knowledgeable guidance and encouragement in every step of this project. Thanks to my thesis committee, Dr. Petra Wood and Dr. Christopher Lituma, for their support and direction in forming this thesis. Finally, thank you to my wife, Allison, and my family and friends for their constant encouragement along the way. 


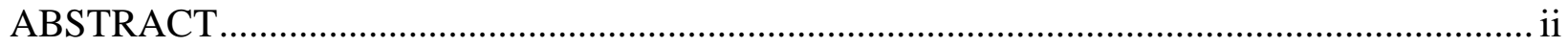

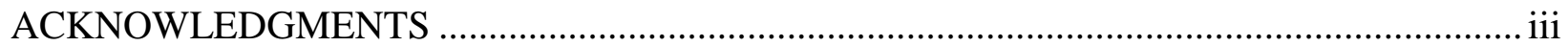

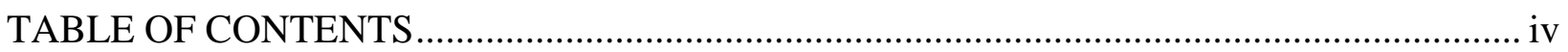

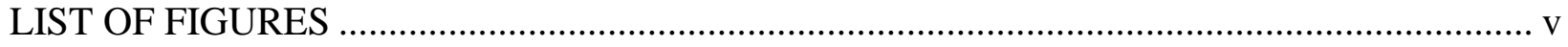

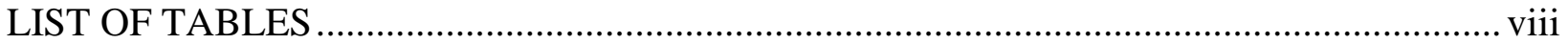

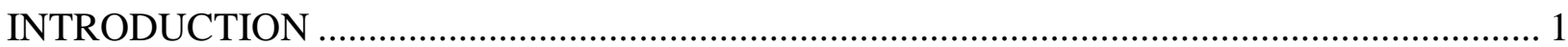

CHAPTER 1: Spatial and temporal avian occupancy dynamics on a Central Appalachian

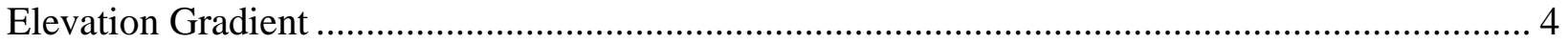

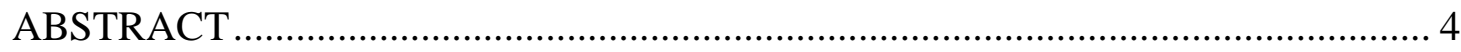

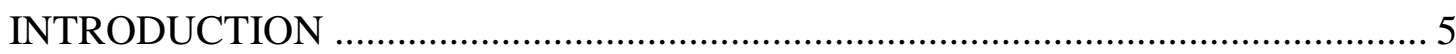

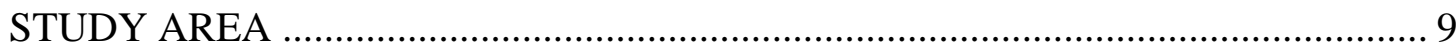

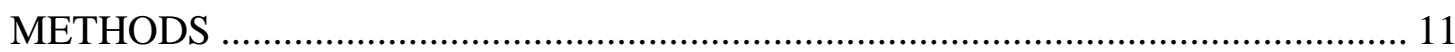

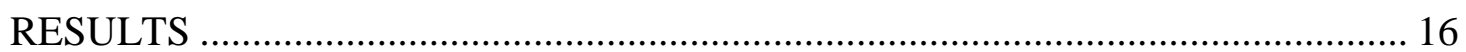

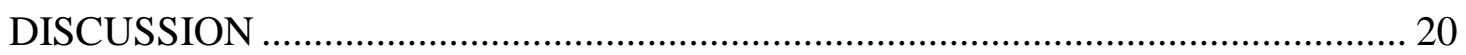

CHAPTER 2: Evaluating Canada Warbler Environmental Correlates on a Central Appalachian

Elevation Gradient in its Southern Breeding Distribution .......................................................... 43

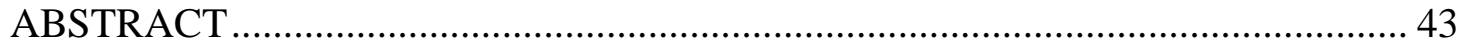

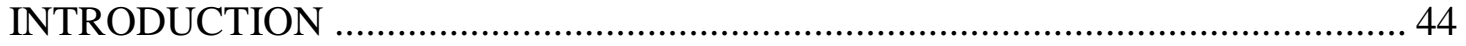

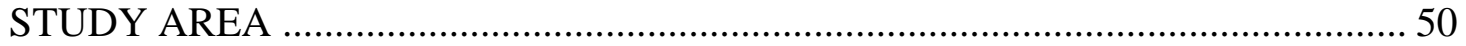

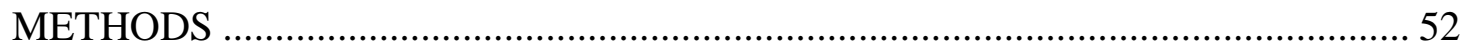

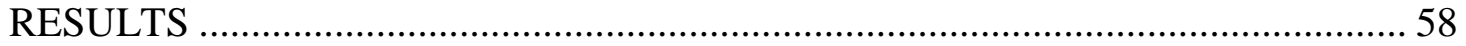

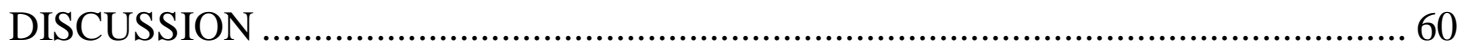

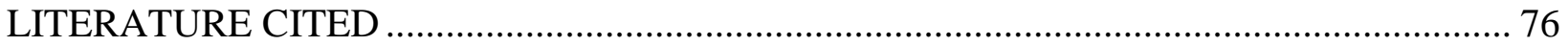

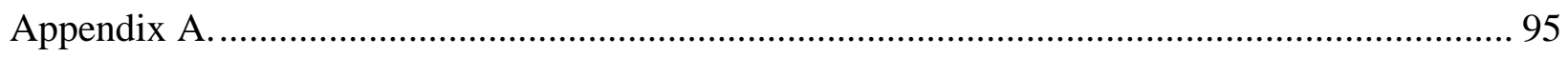

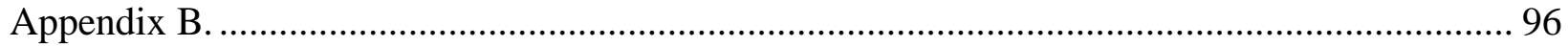

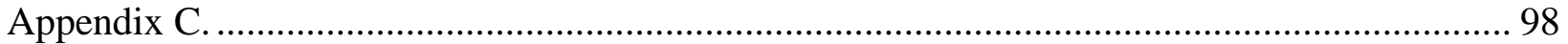




\section{LIST OF FIGURES}

Figure 1.1 Average daily high temperature (A) and total rainfall in centimeters (B) for May through July in Elkins, West Virginia, USA (NOAA 2018). The blue line is the best fit linear regression, where mean expected temperature is significantly increasing ( 0.06 degrees C/year) and total May-July rainfall has no significant change over time. ...25

Figure 1.2. The Monongahela National Forest study site in West Virginia, USA where 5922 avian point count surveys were conducted in public land between 1993 and 2018. The forest is 688,000 hectares in size with about half publicly owned.

Figure 1.3. The locations of all avian point count surveys conducted on public land in the Monongahela National Forest, West Virginia, USA, 1993-2018. A total of 5922 point count surveys were conducted at 1651 locations. Detection/non-detection data for 16 bird species was used to model occupancy dynamics over the 26-year study period.

Figure 1.4. Point count transects were established along gravel roads and trails on public land in the Monongahela National Forest, West Virginia between 1993 and 2018. Points randomly generated along roads (A) started 100 meters from the road and subsequent points were placed perpendicular to the road spaced at least 250 meters apart. Points randomly generated along trails (B) began 100 meters from the trailhead and subsequent points were placed along the trail spaced 300 meters apart. A total of 5922 ten-minute unlimited radius point count surveys were conducted at 1651 locations.

Figure 1.5. The yearly point count survey effort throughout public land in the Monongahela National Forest, West Virginia between 1993 and 2018. Over the 26-year period, a total of 5922 unlimited radius point count surveys were conducted. Detection/non-detection data for 16 songbird species was used to model spatial and temporal avian occupancy dynamics.

Figure 1.6. The change in equilibrium occupancy between 1994 and 2018 at high elevation (A) and low elevation (B) for 16 avian species in the Monongahela National Forest, West Virginia, 1994-2018. The $90^{\text {th }}$ percentile of the surveyed elevational distribution was used for high elevations $(1250 \mathrm{~m})$ and the $10^{\text {th }}$ percentile of the surveyed elevational distribution was used for low elevations $(700 \mathrm{~m})$. Dots indicate the point estimate and vertical bars indicate $95 \%$ credible intervals. Detection/non-detection data was obtained from 5922 unlimited radius point count surveys was used to model equilibrium occupancy, colonization, and persistence of species that were detected at > $15 \%$ of all point count surveys. Refer to Table 1.1 for a species code key.

Figure 1.7. Equilibrium occupancy for the 8 species that expanded upwards or increased uniformly between 1994 and 2018 in the Monongahela National Forest, West Virginia, USA. Plots show how average occupancy varies by elevation in 1994 (solid line) and 2018 (dashed line). Red and blue areas indicate 95\% credible intervals. Vertical dotted lines are the $10^{\text {th }}$ and $90^{\text {th }}$ percentiles of the surveyed elevational distribution that were used to represent low $(700 \mathrm{~m})$ and high elevations $(1250 \mathrm{~m})$. I calculated equilibrium occupancy from species-specific colonization and persistence rates that were evaluated in a dynamic multi-species occupancy model. Detection/non-detection data was obtained from 5922 unlimited radius point count surveys conducted at 1651 locations.

Figure 1.8. Equilibrium occupancy for the 9 species that expanded downwards, contracted downwards, decreased uniformly (Red-eyed Vireo), or remained constant between 1994 and 2018 in the Monongahela National Forest, West Virginia, USA. Plots show how average occupancy varies by elevation in 1994 (solid line) and 2018 (dashed line). Red and blue areas indicate $95 \%$ credible intervals. Vertical dotted lines are the $10^{\text {th }}$ and $90^{\text {th }}$ percentiles of the surveyed elevational distribution that were used to represent low $(700 \mathrm{~m})$ and high elevations $(1250 \mathrm{~m})$. I calculated equilibrium occupancy from species-specific colonization and persistence rates that were evaluated in a dynamic multi-species occupancy model. Detection/non-detection data was obtained from 5922 unlimited radius point count surveys conducted at 1651 locations. 
Figure 1.9. Equilibrium occupancy probability in young harvest ( $0-19$ years), old harvest (20-40 years), and nonharvest stands ( $>40$ years) for the 16 species analyzed (Table 1) throughout the Monongahela National Forest, West Virginia, USA, 1994-2018. Dots indicate the point estimate and vertical lines indicate $95 \%$ credible intervals. Letters indicate levels whose $95 \%$ credible interval for $\Delta \Psi_{\mathrm{s}}$ does not overlap 0 . All other covariates were held at their mean. Equilibrium occupancy was derived from colonization and persistence rates calculated in a dynamic multi-species occupancy model (Royle and Kery 2007) using avian detection/non-detection data from 5922 point count surveys conducted at 1651 locations.

Figure 1.10. Estimated density of Red Spruce trees (A) and three northern hardwood species (B) in three elevation classes throughout the Monongahela National Forest, West Virginia in 2000 and 2017. Density estimates were obtained from Forest Inventory Analysis (FIA) data (USDA Forest Service: Northern Research Station 2018). .......34

Figure 2.1. Locations of point count transects in the Monongahela National Forest, West Virginia, 2017-2018. I stratified points across the three elevation zones. Each transect consists of 10-15 point count sites where detection/non-detection sampling occurred for Canada Warbler (Cardellina canadensis), Black-throated Blue Warbler (Setophaga caerulescens), and Hermit Thrush (Catharus guttatus).

Figure 2.2. Placement of point count sites in harvested stands in the Monongahela National Forest, West Virginia, to assess occupancy of Canada Warbler (Cardellina canadensis), Black-throated Blue Warbler (Setophaga caerulescens), and Hermit Thrush (Catharus guttatus). Harvest sale areas were randomly selected among 3 elevation strata $(<850 \mathrm{~m}, 850-1150 \mathrm{~m},>1150 \mathrm{~m})$ and 3 age classes $(<10 \mathrm{yr}, 10-20 \mathrm{yr},>20 \mathrm{yr})$, and stands that retained some residual trees were delineated using historic aerial imagery. Points were spaced at least $250 \mathrm{~m}$ apart. In the summer of 2018, 90 point count sites were surveyed in harvested stands.

Figure 2.3. The canopy position classification system adapted from Jennings et al. (1999) used to sample vertical diversity of trees at each point count site in the Monongahela National Forest, West Virginia, 2017-2018. Codominant trees (C) form the main forest canopy. Dominant trees (D) have their crown above the main canopy formed by codominant trees. Intermediate trees (I) are shorter than codominant trees but still receive some direct sunlight. Suppressed trees (S) are well-below the canopy and receive little or no direct sunlight. Open growth trees $(\mathrm{O})$ are found in unforested areas that have broken canopy. Legacy trees $(\mathrm{L})$ are uncut dominant/codominant trees in timber harvests where the canopy layer is broken.

Figure 2.4. Marginal occupancy probability of Canada Warbler (Cardellina canadensis) in the Monongahela National Forest, West Virginia, 2017 - 2018 obtained from detection/non-detection data at 840 unlimited radius point count surveys. Black lines/dots represent the point estimate, and gray areas/error bars represent the $95 \%$ confidence interval. Elevation was modeled with a quadratic effect, and Rhododendron density and distance to riparian were modeled with pseudo-threshold effects. Forest types are mixed mesophytic, northern hardwood, oak/pine, and spruce. For each covariate of interest, all other continuous covariates were held at their mean, and forest type was held at northern hardwood.

Figure 2.5. Marginal occupancy probability of Black-throated Blue Warbler (Setophaga caerulescens) in the Monongahela National Forest, West Virginia, 2017 - 2018 obtained from detection/non-detection data at 840 unlimited radius point count surveys. Black lines/dots represent the point estimate, and gray areas/error bars represent the $95 \%$ confidence interval. Elevation was modeled with a quadratic effect. Distance to stream was modeled with a pseudo-threshold effect. Forest types are mixed mesophytic, northern hardwood, oak/pine, and spruce. For each covariate of interest, all other continuous covariates were held at their mean, forest type was set to northern hardwood, and year was held at 2017.

Figure 2.6. Marginal occupancy probability of Hermit Thrush (Catharus guttatus) in the Monongahela National Forest, West Virginia, 2017 - 2018 obtained from detection/non-detection data at 840 unlimited radius point count surveys. Black lines/dots represent the point estimate, and gray areas/error bars represent $95 \%$ confidence intervals. Forest types are mixed mesophytic, northern hardwood, oak/pine, and spruce. Forest age classes are young harvest (0-19 yr), old harvest (20-40 yr), mature forest (40-120 yr) and old-age forest (>120 yr). For each covariate of interest, all other continuous covariates were held at their mean, forest type was held at northern hardwood, and forest age was held at mature. 
Figure 2.7. Occupancy probability of the Canada Warbler (Cardellina canadensis) conditional on Black-throated Blue Warbler (Setophaga caerulescens) presence (A) and absence (B) in the Monongahela National Forest, West Virginia, 2017 - 2018 obtained from detection/non-detection data at 840 unlimited radius point count surveys. Black lines represent the point estimate, and gray areas represent the $95 \%$ confidence interval. All other continuous covariates were held at their mean and forest type was held at northern hardwood.

Figure 2.8. Effect of survey date and hours after sunrise on Canada Warbler (Cardellina canadensis) detection probability (A-B). Effect of hours after sunrise and wind speed on Black-throated Blue Warbler (Setophaga caerulescens) detection probability (C-D). Detection/non-detection data was obtained from 840 unlimited radius point count surveys in the Monongahela National Forest, West Virginia, 2017 - 2018. Black lines represent the point estimate, and gray areas represent the $95 \%$ confidence interval. For each covariate of interest, all other covariates were held at their mean. 


\section{LIST OF TABLES}

Table 1.1. Detection and occupancy covariates used in the dynamic multi-species occupancy model of 16 forest songbirds. Detection/non-detection data was obtained from 5922 unlimited radius point count surveys at 1651 locations in the Monongahela National Forest, West Virginia, 1993-2018. Levels describe the categories for categorical variables and the units for continuous variables. For continuous variables, I report the mean and range, and for categorical variables I report the proportion of point count surveys that fell in each level.

Table 1.2. Summary of the 16 species included in the dynamic multi-species occupancy model to evaluate the changes in occupancy through time along an elevation gradient in the Monongahela National Forest, West Virginia, 1993-2018. Detection/non-detection data was obtained from 5922 unlimited radius avian point count surveys conducted at 1651 locations. Mean elevation and $10^{\text {th }}$ and $90^{\text {th }}$ percentiles $(\mathrm{p} 10, \mathrm{p} 90)$ are shown for each species. Detections is the number of point count surveys that each species was detected with the percent of total in parentheses.

Table 1.3. Criteria for categorizing occupancy dynamics given changes in equilibrium occupancy between 1994 and 2018 at low $(700 \mathrm{~m})$ and high $(1250 \mathrm{~m})$ elevations. Zero indicates no change in occupancy, - indicates a decrease in occupancy over the study period, and + indicates an increase in occupancy over the study period. Direction and trends are categorized for each of the 16 species included in the dynamic occupancy model that used avian point count surveys in the Monongahela National Forest, West Virginia, 1993-2018.

Table 1.4. A total of 5922 avian point count surveys were conducted at 1651 locations on public land in the Monongahela National Forest, West Virginia between 1993 and 2018. Point count sites received varying levels of effort, and 1651 locations were surveyed between 1 and 16 times over the 26-year study period.

Table 1.5. Posterior log odds ratios of initial occupancy parameters for the 16 species included in the dynamic multi-species occupancy model. Initial occupancy was modeled using avian detection/non-detection data from 60 point count surveys conducted in 1993 throughout the Monongahela National Forest, West Virginia. Initial occupancy in 1993 was modeled as a function of elevation (linear and quadratic) and categorical forest type. Estimates for the four forest types (mixed mesophytic, northern hardwood, spruce, open) are relative to oak/pine forest. Values in bold have $95 \%$ credible intervals that do not overlap zero.

Table 1.6. Posterior log odds ratios of colonization parameters for the 16 species included in the dynamic multi-species occupancy model. Local colonization probability was modeled as a function of elevation (linear and quadratic), year, and harvest type. The model also included interactions between elevation and year and elevation^2 and year. Log odds ratios for young harvest (0-19 years) and old harvest (20-40 years) are relative to non-harvest (> 40 years). Values in bold have $95 \%$ credible intervals that do not overlap zero. Colonization was modeled using avian detection/non-detection data from 5922 unlimited radius point count surveys conducted at 1651 locations in the Monongahela National Forest, West Virginia, 1993-2018.

Table 1.7. Posterior log odds ratios of persistence parameters for the 16 species included in the dynamic multi-species occupancy model. Local persistence probability was modeled as a function of elevation (linear and quadratic), year, and harvest type. The model also included interactions between elevation and year and elevation^2 and year. Log odds ratios for young harvest (0-19 years) and old harvest (20-40 years) are relative to non-harvest (> 40 years). Values in bold have $95 \%$ credible intervals that do not overlap zero. Persistence was modeled using avian detection/non-detection data from 5922 unlimited radius point count surveys conducted at 1651 locations in the Monongahela National Forest, West Virginia, 1993-2018.

Table 1.8. Change in equilibrium occupancy between 1994 and 2018 at high and low elevations for the 16 species (Table 1.1) included in the dynamic multi-species occupancy model. Criteria for trend and direction are outlined in Table 1.2. The 10th and 90th percentiles of the surveyed elevational distribution were used to represent low $(700 \mathrm{~m})$ and high elevations $(1250 \mathrm{~m})$. Yearly occupancy was calculated using colonization and persistence rates (Royle and Kery 2007) that were modeled using avian detection/non-detection data from 5922 unlimited radius point count surveys conducted at 1651 locations in the Monongahela National Forest, West Virginia, 1993-2018. 
Values in bold have $95 \%$ credible intervals that do not overlap zero. Direction indicates the general elevational movement of occupancy outlined in Table 1.2.

Table 2.1. Detection and occupancy covariates used to model multi-species occupancy of Canada Warbler (Cardellina canadensis), Black-throated Blue Warbler (Setophaga caerulescens), and Hermit Thrush (Catharus guttatus) in the Monongahela National Forest, West Virginia, 2017-2018. Levels describe the categories for categorical variables and the units for continuous variables. For continuous variables, I report the mean and range, and for categorical variables I report the proportion of point count surveys that fell in each level.

Table 2.2. Model selection procedure for multi-species occupancy models of Canada Warbler (Cardellina canadensis), Black-throated Blue Warbler (Setophaga caerulescens), and Hermit Thrush (Catharus guttatus) in the Monongahela National Forest, West Virginia, 2017-2018. Top model weight was 0.95. Covariates used in the global and reduced detection models are in Appendix A. Covariates used in the global and reduced $1^{\text {st }}$-order occupancy models are in Appendix B. Top model results and slope coefficients are in Appendix C.

Table 2.3. Proportion of point count surveys that Canada Warbler (Cardellina canadensis), Black-throated Blue Warbler (Setophaga caerulescens), and Hermit Thrush (Catharus guttatus) were detected for each year and forest age class. Raw detection/non-detection data was obtained from 840 unlimited radius point count surveys conducted in the Monongahela National Forest, West Virginia, 2017-2018. 


\section{INTRODUCTION}

Montane areas typically harbor high avian diversity where steep elevational and environmental gradients restrict species distributions and allow many species to exist over a small spatial extent (Able and Noon 1976). Since climatic and environmental conditions are often similar along elevational and latitudinal gradients (Rahbek 1995), many northern breeding bird species extend their range farther south along mountain ranges and create novel bird communities in these areas (Buckelew and Hall 1994, Ruggiero and Hawkins 2008). Montane bird communities are of particular conservation concern since their restricted distributions make them more vulnerable to environmental change and loss of biodiversity (Myers et al. 2000, Dirnböck et al. 2010). Understanding which factors drive the spatial and temporal dynamics of montane birds is important for maintaining biodiversity and informing landscape-scale conservation efforts (De Wan et al. 2009).

Many biotic and abiotic factors can affect avian distributions and dynamics, including climatic conditions, ecological succession, anthropogenic forces, and species interactions (Mehlman 1997, Hobson and Bayne 2000, Martin 2001, Archaux and Bakkaus 2007, Tingley and Beissinger 2013). Of these potential impacts, there is great interest in understanding the role that climate change may play, especially in montane areas where distributions are often more restricted (Shoo et al. 2006, Tingley et al. 2012). Climate change can affect bird phenology and distributions (Crick et al. 1997, Thomas and Lennon 1999, Van Buskirk et al. 2009), where high elevation montane species are at risk of being further restricted to smaller mountaintop habitats (Dirnböck et al. 2010, Freeman and Class Freeman 2014).

In eastern North America, the Appalachian Mountain range extends from Newfoundland to Alabama. A variety of forest conditions are found throughout the central Appalachians that 
support high avian diversity and trailing edge populations of several northern forest species (Buckelew and Hall 1994, Monkkonen 1994). Warming summer temperatures in the central Appalachians (NOAA 2018) may directly or indirectly cause montane avian distributions to shift along an elevation gradient and are expected cause high elevation species to contract further upwards (Sekercioglu et al. 2008, Sorte and Jetz 2010).

The Appalachian Mountains also host several species of conservation concern, including the Canada Warbler (Cardellina canadensis). This understory specialist species has experienced widespread population declines across its breeding range (Sauer et al. 2017), making it a species of conservation concern in the United States, threatened in Canada, and a priority 1 species on the West Virginia State Wildlife Action Plan (U.S. Fish and Wildlife Service 2008, West Virginia Division of Natural Resources 2015). Canada Warblers have historically benefitted from gap dynamics in old-age forests that have high vertical structure and well-developed understories (Lambert and Faccio 2005, Zlonis and Niemi 2014). Population declines are thought to be a result of forests reaching mid-successional stages that have little structure and understory (Franzreb and Rosenberg 1997, Oswalt and Smith 2014). Understanding Canada Warbler space use in the central Appalachians is important for determining which factors may promote the species to guide conservation and management plans and ensure long-term population viability.

For this project, I evaluated central Appalachian songbirds at the community level and species level. At the community level I assessed spatial and temporal dynamics of 16 species along an elevation gradient to determine the potential movements in their elevational distributions and shed light on what factors drive long-term changes in occupancy. At the species level I evaluated the factors associated with Canada Warbler occupancy in the southern extent of their range, to better understand their space use and guide future conservation actions. These two 
topics involving forest birds in the central Appalachian Mountains seek to improve our understanding of the dynamics and space use of montane bird species to maintain diversity and improve conservation efforts. 
CHAPTER 1: Spatial and temporal avian occupancy dynamics on a Central Appalachian Elevation Gradient

\author{
ABSTRACT \\ Mountains are important areas for avian diversity and conservation since they have steep \\ elevational and environmental gradients. In the central Appalachian Mountains, several songbird \\ species have trailing edge populations that are restricted to high elevations. Climate change and \\ other factors can cause species distributions to shift along an elevation gradient, which is of \\ particular concern for montane birds in restricted trailing edge populations. For this chapter I \\ evaluated the long-term dynamics of several breeding songbirds in the central Appalachian \\ Mountains using a 26-year (1993-2018) historic dataset of 5922 point counts surveys from the \\ Monongahela National Forest, West Virginia. I modeled colonization and persistence rates for 16 \\ songbird species in a Bayesian framework. Colonization and persistence rates were modeled as a \\ function of year, elevation, and harvest. I then derived equilibrium occupancy for each species to \\ evaluate the change in occupancy over the 26-year period and across the elevation gradient. Five \\ species expanded upwards, 3 species expanded downwards, 1 species contracted downwards, 1 \\ species shifted downwards, and 6 species had no directional change in equilibrium occupancy. \\ None of the 16 species contracted upwards and there was little evidence of climate-induced \\ elevational movement. Varying responses along the elevational gradient are likely due to a \\ combination of several factors, including changing forest conditions and regional population trends. \\ Spruce restoration and regeneration of northern hardwood and spruce forests are likely driving the \\ upward and downward expansions observed in 5 species, suggesting that climate-induced \\ movements may be alleviated by more direct changes to forest conditions.
}




\section{INTRODUCTION}

Montane areas typically harbor high avian biodiversity where environmental gradients restrict species distributions and allow many species to exist over a small spatial extent (Able and Noon 1976). As a result, mountainous regions are of particular conservation value since they may be more vulnerable to environmental change and loss of biodiversity (Myers et al. 2000, Dirnböck et al. 2010). Steep environmental gradients in mountainous areas often lead to a high number of species at the edge of their range, where local colonization and extinction events allow distributions to shift, expand, and contract through time (Thomas and Lennon 1999). Assessing the long-term dynamics of bird communities is fundamental to determining how avian distributions change through time and which mechanisms facilitate these changes. While longterm studies have provided valuable insight into avian population dynamics (Franzreb and Rosenberg 1997, Sauer et al. 2017), less is understood of how avian distributions change spatially through time (Brown et al. 1995). Understanding the spatial dynamics of birds is essential for determining how species and communities will respond to environmental change (Tylianakis et al. 2008) and is important for improving the success of conservation plans (De Wan et al. 2009). A wide-range of biotic and abiotic factors can affect avian distributions and dynamics, including climatic conditions, ecological succession, anthropogenic forces, and species interactions (Mehlman 1997, Hobson and Bayne 2000, Martin 2001, Archaux and Bakkaus 2007, Tingley and Beissinger 2013). Of these potential impacts, there is great interest in understanding the role that climate change may play, especially in montane areas where species' distributions are often more restricted (Shoo et al. 2006, Tingley et al. 2012).

Climate change can affect bird phenology and distributions (Crick et al. 1997, Thomas and Lennon 1999, Van Buskirk et al. 2009). For example, earlier spring green-up and insect 
hatch dates have forced some songbirds to migrate earlier or nest earlier to track phenological changes (Crick et al. 1997, Mayor et al. 2017). Birds may also alter their distributions to mitigate the effects of climate change (Thomas and Lennon 1999). In general, species are expected to shift poleward in latitude and upward in elevation to track temperature changes, a pattern that has been observed in many instances (Hitch and Leberg 2007, Forero-Medina et al. 2011, Tingley et al. 2012, Freeman and Class Freeman 2014).

In mountainous areas, changes in avian distributions may be more pronounced over a small area given restricted species distributions and steep environmental gradients (Shoo et al. 2006). Birds may respond directly to climatic conditions or may indirectly respond to changes in biotic conditions which can lead to a variety of elevational responses. Direct responses can occur when changing climatic conditions cause a species' upper or lower physiological limit to move along an elevation gradient (Root 1988, Martin 2001, Canterbury 2002, McCain and Grytnes 2010). In many cases, however, birds are expected to exhibit indirect responses to climate change, since species distributions are more strongly linked to biotic conditions (Terborgh 1985, Auer and King 2014). Thus, changes to forest conditions resulting from climate change are expected to drive range shifts in many species (Beckage et al. 2008, Foster and D'Amato 2015).

In general, high elevation montane species are expected to contract their lower elevational range upwards, restricting them to smaller mountaintop habitats (Dirnböck et al. 2010, Freeman and Class Freeman 2014). Species distributed lower on the elevation gradient may respond by shifting their entire range upwards (Forero-Medina et al. 2011, Kirchman and Van Keuren 2017) or by expanding at the upper extent of their range (Freeman and Class Freeman 2014, DeLuca and King 2017). Upward movements have been observed in Peru (Forero-Medina et al. 2011), New Guinea (Freeman and Class Freeman 2014), California 
(Tingley et al. 2012), New York (Kirchman and Van Keuren 2017), and New Hampshire (DeLuca and King 2017), but responses vary considerably across taxa and geographic area (Tingley et al. 2012, Auer and King 2014). In California and New Hampshire, Tingley et al. (2012) and DeLuca and King (2017) observed a substantial downward expansion of high elevation species, while Archaux (2004) observed minimal altitudinal movement of birds in the French Alps. This variation is likely because of unique life-history traits that constrain bird distributions in different ways (Tingley et al. 2012, Auer and King 2014). Given the diversity of avian life-histories, species will vary in the magnitude and direction of their responses to environmental change (Auer and King 2014). Furthermore, geographic variation in avian movement may be a result of differences in the species studied, varying time scales, or regional differences in the rate of change in environmental conditions (Archaux 2004, Tingley et al. 2012, DeLuca and King 2017).

For many species, the slow pace of climate-induced movements may be overshadowed by other dynamic changes in forest conditions and biotic interactions. These factors are often difficult to disentangle from long-term changes in climate, and may limit expected avian responses (Clavero et al. 2011). For example, several studies have observed downslope expansions of boreal forest ecotones as spruce and fir forests recover following human disturbance (Vogelmann et al. 2012, Foster and D’Amato 2015). This has allowed some coniferadapted birds to remain stable or shift downslope (Wilson et al. 2013, DeLuca and King 2017). The strong relationship between birds and forest conditions may limit or obscure climate-induced movement (Jankowski et al. 2013). Given the lack of support for a clear pattern of climateinduced movement across species or location, further studies are necessary to better understand the processes that may be occurring in montane avian distributions. Finally, birds that adapt their 
behavior or phenology may alleviate climate change effects without the need to shift their range (Socolar et al. 2017). These behavioral and phenological changes may also be better able to track year-to-year fluctuations in spring green-up, bud-burst, and insect hatches (Crick et al. 1997, Van Dongen et al. 1997, Socolar et al. 2017).

The rate at which species may respond to warming is dependent on the pace of climatic change. Global average temperatures have increased over the past century by $0.7-0.9^{\circ} \mathrm{C}$, and the rate of warming has doubled since 1975 (Lindsey and Dahlman 2018). Regionally within the central Appalachians of West Virginia, the average daily high temperature during the breeding season (May-July) shows a significantly increasing trend of $0.06{ }^{\circ} \mathrm{C}$ per year between 1993 and 2018 (NOAA 2018; Figure 1.1 A), amounting to an increase of $1.4^{\circ} \mathrm{C}$ in average summer temperature over the 26-year period. Breeding season (May-July) precipitation totals fluctuated from year-to-year but show a stable long-term average trend between 2000 and 2018 (NOAA 2018; Figure 1.1 B). Increases in summer temperature throughout the central Appalachian Mountains has the potential to directly and indirectly affect the diverse community of birds found along the steep elevation gradient in this region (Buckelew and Hall 1994, Freeman and Class Freeman 2014, DeLuca and King 2017).

Assessing the spatial and temporal dynamics of montane avian species is essential for understanding how birds respond to climate change and for guiding landscape-level conservation plans to maintain biodiversity in these unique areas. The central Appalachians host many trailing-edge populations of northern breeding bird species which makes it an ideal landscape to assess the long-term dynamics of montane avian distributions (Buckelew and Hall 1994). In conjunction with researchers at West Virginia University, the U.S. Forest Service has been conducting avian point count surveys in the central Appalachians of West Virginia since 1993, 
providing a rich dataset to investigate avian occupancy dynamics. My objective is to assess the spatial and temporal occupancy dynamics for a suite of avian species distributed along the elevation gradient by estimating local colonization, persistence, and occupancy probabilities over the 26-year period while controlling for changing forest conditions. Since past studies have reported widely varying results, this project will contribute to our understanding of the complex changes that may be occurring in montane avian communities as a result of climate change and other factors. Additionally, no other published study has assessed long-term temporal dynamics of birds in the south/central Appalachians. I predict that occupancy of low elevation species will increase through time in high elevations and remain constant at low elevations, representing an upward expansion of their elevational distribution. I also predict that occupancy of high elevation species will decrease in low elevations and remain constant in high elevations, representing an upward contraction. Lastly, I predict that occupancy of generalist species will not respond directionally along the elevation gradient.

\section{STUDY AREA}

Sampling occurred throughout public lands within the Monongahela National Forest (MNF), West Virginia (Figure 1.2). This area has been federally protected since 1920 and encompasses 688,000 hectares, 371,000 of which are federally owned (Monongahela National Forest 2018a). Eight federally designated wilderness areas are located in the national forest, the largest being the Cranberry Wilderness (19,350 hectares), and the smallest being the Big Draft Wilderness (2,081 hectares). The MNF contains a large section of the central Appalachian Mountain range and has a steep elevation gradient ranging from 300 meters to West Virginia's highest point, Spruce Knob, at 1482 meters. (Monongahela National Forest 2018a). The mountainous terrain in the MNF affects local climate, with average temperatures 2-4 degrees 
Celsius lower than other parts of West Virginia, and the highest annual rainfall in the state (Buckelew and Hall 1994). Conditions in the MNF also vary longitudinally due to the orographic effect. While the western part of the MNF receives over 150 centimeters of annual rainfall that produces moist forest conditions, the eastern portion of the MNF receives half as much rainfall, leading to a greater proportion of dry oak-pine forests (Monongahela National Forest 2011).

A majority of MNF land is composed of 70-100-year-old stands with a high regional tree diversity (Monongahela National Forest 2011). Forests in the MNF can be categorized into four major types that are distributed along the elevation gradient: mixed mesophytic, oak/pine, northern hardwood, and spruce/hemlock (DeMeo 1999). In low elevations, typically below 850 meters, oak/pine and mixed mesophytic forests are dominant, making up 39\% and 33\% of public land, respectively (Monongahela National Forest 2011). Mixed mesophytic forests are characterized by species that prefer moderately moist soils, including Tulip Poplar (Liriodendron tulipifera), Basswood (Tilia americana), and Hickory (Carya spp.). As elevations increase, forests transition into northern hardwood forests, characterized by Yellow Birch (Betula alleghaniensis), Beech (Fagus grandifolia), and Sugar Maple (Acer saccharum), which make up 18\% of public land (Monongahela National Forest 2011). Remnant boreal forests occupy many high elevation summits, often above 1150 meters and are characterized by thick Red Spruce (Picea rubens) stands that make up 6\% of public land (Cogbill and White 1991, Monongahela National Forest 2011). The Monongahela Forest Management Plan sets aside 31\% of land specifically for wildlife habitat, $22 \%$ for forest age class management, $17 \%$ for spruce restoration, and 22\% for backcountry areas (Monongahela National Forest 2011). Of the 371,000 hectares of public land, the MNF manages 600-800 hectares per year through commercial timber harvest and thins approximately 1600 hectares per year (Monongahela National Forest 2011). 


\section{METHODS}

\section{Point count protocols}

U.S. Forest Service staff and researchers from West Virginia University conducted point count surveys throughout public land in the MNF from 1993 to 2018 (DeMeo 1999, Johnson and Wood 2017; Figure 1.3). Surveys were 10-minute unlimited radius stationary point counts where observers recorded all individuals seen or heard during the count period (Ralph et al. 1995). Point counts began as early as May 18 and continued to as late as July 15. Each 10-minute point count was further divided into three time intervals: 0-3 $\mathrm{min}, \geq 3-5 \mathrm{~min}, \geq 5-10 \mathrm{~min}$ (Ralph et al. 1995). Each individual was only recorded the first time they were observed during the 10-minute survey. With this removal sampling method, detection probability can be estimated from a single visit per year (Farnsworth et al. 2002, Rota et al. 2009). Detection type (song, call, visual), age/sex, and distance to point count center $(\leq 50 \mathrm{~m}$ or $>50 \mathrm{~m})$ were recorded for all individuals, but all detections were used in statistical analysis. Surveys began within 15 minutes of sunrise and continued until no later than 10:30 AM. Surveys were not conducted on days with rain, heavy fog, or high wind, following the general guidelines outlined by Ralph et al. (1995). Each point was sampled once per year (DeMeo 1999, Johnson and Wood 2017), and date was recorded for each point count survey. Information on time of day, wind speed, and sky condition were not available for all point counts.

\section{Selection of sites}

Locations of long-term point counts were initially established by stratifying by the four major forest types (dry oaks, mixed mesophytic, northern hardwoods, red spruce) and then randomly selecting sites in each stratum. Historic transects started along gravel roads and consisted of 10-15 points separated by 250 meters (DeMeo 1999; Figure 1.4). Over the study 
period, other transects were established by the U.S. Forest Service using similar protocols (Johnson and Wood 2017), and researchers from West Virginia University established several points in harvested areas in 1993 and 2005 (Duguay et al. 2001, McDermott et al. 2011).

I also established 136 new points in 2017 to ensure an approximately equal number of points among three elevation strata: less than $853 \mathrm{~m}, 853 \mathrm{~m}-1158 \mathrm{~m}$, and above $1158 \mathrm{~m}$ (Chapter 2). To select points in 2017, roads and trails were combined into a single linear shapefile (Monongahela National Forest 2005, U.S. Census Bureau 2007), and random points were generated along this feature in ArcMap 10.3 (ESRI 2018). Only roads classified as S14000 or greater by the U.S. Census Bureau (typically gravel roads) were used in the random point generation (U.S. Census Bureau 2018). These randomly generated points indicated the starting point of each transect. Transects created from road points began 100 meters off road in a random direction (e.g. left, right), and subsequent points were placed perpendicular to the road (Figure 1.4 A). Points generated along trails began 100 meters from the nearest trailhead and continued along the trail (Figure 1.4 B). Each transect contained 10-12 points separated by a minimum of 250 meters. Randomly generated transect locations were omitted from surveys if the transect could not be completely contained in public land. The general order in which sites were surveyed was determined by random number assignment to transects, while being flexible to logistics and travel constraints.

\section{Environmental variables}

I obtained spatial layers for elevation, forest type, and forest age to use as predictor variables (Table 1.1). Elevation for each point count location was obtained from a 7.5 minute $30-$ meter DEM (U.S. Geological Survey 1979). To determine the general forest type, a GIS layer of forest stands within the MNF was obtained that designated stands into five classes: mixed 
mesophytic, oak/pine, northern hardwoods, spruce, and open (Monongahela National Forest 2018b). To determine which points were within harvested stands, I identified harvest sale areas (Monongahela National Forest 2017) and digitized the extent of each harvest using historic aerial orthophotos from 1996, 2002 , 2007, 2009, 2011, 2014, and 2016 (U.S. Geological Survey 1996, The WV Statewide Addressing and Mapping Board 2004, USDA-FSA-APFO Aerial Photography Field Office 2007-2016). In some harvested areas, harvest sale area information only indicated the year of sale and not the exact year of harvest, since timbering could occur up to 3 years following the sale year. In these harvest areas, I assumed harvest occurred 3 years following the sale year unless aerial imagery indicated that harvest occurred earlier. Harvested sites were then categorized into young harvest (0-19 years post-harvest) and old harvest (20-40 years post-harvest). All other point count locations were considered non-harvest (> 40 years post-harvest). Since point counts were conducted over a 26-year period, variables of more finescale environmental changes were not available for this study.

\section{Statistical Analysis}

I used a dynamic multi-species occupancy model in a Bayesian framework to evaluate avian temporal dynamics throughout the MNF, which estimates initial occupancy, local colonization, and persistence rates for selected species over the study period (Table 1.2; Royle and Kéry 2007, Zipkin et al. 2010). This hierarchical modeling framework allows us to gain inference in how occupancy changes through time and space for each species. First, I modeled the initial occupancy state $\left(\mathrm{z}_{s, i, 1}\right)$ of species $s$ at site $i$ during time step 1 as a Bernoulli random variable:

$$
\mathrm{Z}_{s, i, 1} \sim \operatorname{Bern}\left(\psi_{s, i, 1}\right)
$$


The latent occupancy state in subsequent years was also modeled as a Bernoulli random variable, with the probability of occurrence modeled as a function of presence in the previous time step $\left(\mathrm{Z}_{s, i, t-1}\right)$, persistence $\left(\phi_{s, i, t}\right)$, and colonization $\left(\gamma_{s, i, t}\right)$ rates between years $t-1$ and $t$ :

$$
\mathrm{Z}_{s, i, t} \sim \operatorname{Bern}\left(\mathrm{z}_{s, i, t-1} * \phi_{s, i, t}+\left(1-\mathrm{Z}_{s, i, t-1}\right) * \gamma_{s, i, t}\right)
$$

Initial occupancy $(\psi)$, colonization $(\gamma)$, and persistence $(\phi)$, and conditional detection (p) probabilities were modeled as a function of covariates,

$$
\begin{gathered}
\operatorname{logit}\left(\psi_{s, i, 1}\right)=\boldsymbol{x}_{i, 1} * \beta_{\mathrm{s}}, \\
\operatorname{logit}\left(\gamma_{s, i, t}\right)=\boldsymbol{w}_{i, t} * \alpha_{\mathrm{s}}, \\
\operatorname{logit}\left(\phi_{s, i, t}\right)=\boldsymbol{w}_{i, t} * \varepsilon_{\mathrm{s}} \\
\operatorname{logit}\left(\mathrm{p}_{s}\right)=\boldsymbol{h}_{i, t} * \eta_{\mathrm{s}}
\end{gathered}
$$

where $\boldsymbol{x}, \boldsymbol{w}$, and $\boldsymbol{h}$ represent covariates and $\beta_{\mathrm{s}}, \alpha_{\mathrm{s}}, \varepsilon_{\mathrm{s}}$, and $\eta_{\mathrm{s}}$ represent a vector of regression coefficients for each species (Royle and Kéry 2007, Green et al. 2019). I modeled initial occupancy probability as a quadratic function of elevation and a linear function of forest type (i.e., mixed mesophytic). I modeled colonization and persistence probabilities as a linear function of year and harvest type, and a quadratic function of elevation. I also included interactive effects between year and elevation to allow elevational gradients in colonization and persistence rates to vary across time. While I controlled for major anthropogenic changes to forest conditions with harvest type, other consistent site-level data on vegetation conditions were not available, so I was unable to directly model subtle changes in forest structure or composition. Finally, I modeled detection probability as a linear and quadratic function of ordinal day (other detection covariates were not available for all point count surveys) (Table 1.1).

I assumed a random coefficients model, where species-specific slope coefficients were drawn from a higher-level distribution for each species $s$ and coefficient $j$ : 


$$
\begin{aligned}
& \beta_{\mathrm{s}, \mathrm{j}} \sim \operatorname{Normal}\left(\mu_{\mathrm{j}}, \tau_{\mathrm{j}}\right) \\
& \alpha_{\mathrm{s}, \mathrm{j}} \sim \operatorname{Normal}\left(\theta_{\mathrm{j}}, \omega_{\mathrm{j}}\right) \\
& \varepsilon_{\mathrm{s}, \mathrm{j}} \sim \operatorname{Normal}\left(\rho_{\mathrm{j}}, \zeta_{\mathrm{j}}\right)
\end{aligned}
$$

where $\mu, \theta$, and $\rho$ represent a community-level mean and $\tau, \omega$, and $\zeta$ represent a community-level standard deviation of regression coefficient $j$. I assumed the following prior distributions for hierarchical hyperparameters:

$$
\begin{gathered}
\mu_{\mathrm{j}}, \theta_{\mathrm{j}}, \rho_{\mathrm{j}} \sim \operatorname{Normal}(0,1) \\
\tau_{\mathrm{j}}, \omega_{\mathrm{j}}, \zeta_{\mathrm{j}} \sim \operatorname{Gamma}(1,1) .
\end{gathered}
$$

I used a logistic prior distribution for detection probability slope coefficients:

$$
\eta_{\mathrm{s}} \sim \operatorname{Logistic}(0,1)
$$

I derived estimates of equilibrium occupancy from posterior parameter estimates of the fitted model. Equilibrium occupancy is deterministically related to colonization $(\gamma)$ and persistence $(\phi)$ rates (Royle and Kéry 2007):

$$
\psi_{s, t}^{(e q)}=\frac{\gamma_{s, t}}{1-\phi_{s, t}+\gamma_{s, t}}
$$

I used the equation above to determine how equilibrium occupancy varied across the entire elevation gradient. Finally, I evaluated the temporal change in equilibrium occupancy:

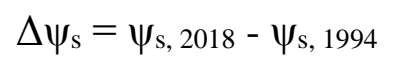

between 1994 and 2018 at low $(700 \mathrm{~m})$ and high $(1250 \mathrm{~m})$ elevations. These elevations represented the $10^{\text {th }}$ and $90^{\text {th }}$ percentiles of the sampled elevation gradient. A change in equilibrium occupancy was assumed if the $95 \%$ credible intervals of $\Delta \psi_{s}$ did not overlap zero. I then categorized the changes for each species at low and high elevations into six trend responses: increasing, decreasing, expanding, contracting, shifting, and no trend; and three directional responses: up, down, none (Table 1.3). For an increasing species, equilibrium occupancy 
increases uniformly at low and high elevations and for a decreasing species, equilibrium occupancy decreases uniformly at low and high elevations (Table 1.3). An expanding species is one where occupancy increases at one elevation extreme and does not change at the other. A contracting species is one where occupancy decreases at one elevation and does not change at the other. A species that exhibits a shift is one where occupancy increases at one elevation extreme and decreases at the other extreme (Table 1.3).

The dynamic multi-species occupancy model was fit using JAGS version 4.3.0 (Plummer 2003) with the jagsUI package (Kellner 2017) in R version 3.4.3 (R Core Team 2018). I ran two Markov chains for 20,000 iterations and eliminated the first 15,000 iterations as burn-in. To check model convergence, I ensured that $\hat{R}$ was approximately equal to 1.00 for all posterior distributions.

To select which species to include in the model, I chose all forest bird species that were detected at $>15 \%$ of all point count surveys (George and Zack 2008; Table 1.2). Species detected at $<15 \%$ of all surveys had difficulty converging in models and were omitted from analysis. I separated species into three elevation groups: low, high, and generalist (Table 1.2). Low elevation species were those that were negatively associated with elevation, high elevation species were those that were positively associated with elevation, and generalists were those that were not associated with elevation. I used the breeding distributions outlined in the West Virginia Breeding Bird Atlas to verify each grouping (Buckelew and Hall 1994).

\section{RESULTS}

Of the 139 species detected at least once, I assessed the dynamics of 16 forest bird species that were detected at $>15 \%$ of all point count surveys (Table 1.1). Over the 26-year period, 5922 point count surveys were conducted at 1651 unique locations. Of the 1651 
locations, 1225 locations were surveyed at least twice, and 134 locations were surveyed 10 or more times (Table 1.4). Yearly effort was variable, ranging from 0 points surveyed in 2016, to 654 points in 1996, with an average of 227 points surveyed per year (Figure 1.5). Elevations ranged from 359 meters to 1420 meters with a mean of 996 meters (Table 1.1). Surveys occurred in mixed mesophytic forests (35\%), oak-pine forests (27\%), northern hardwood forests (20\%), spruce forests (9\%) and natural openings (9\%), with each forest type sampled approximately equal to its availability in the MNF (Monongahela National Forest 2011; Table 1.1). Of the 5922 point count surveys conducted, 306 surveys were conducted in young harvest and 263 surveys were conducted in old harvest (Table 1.1).

\section{Initial occupancy}

Initial occupancy was positively associated with elevation for American Robin (Turdus migratorius), Dark-eyed Junco (Junco hyemalis), and Magnolia Warbler (Setophaga magnolia) (posterior log odds ratios in Table 1.5). Initial occupancy was highest at $983 \mathrm{~m}$ for Blackthroated Blue Warbler (Setophaga caerulescens) and at $1032 \mathrm{~m}$ for Veery (Catharus fuscescens) (Table 1.5). No other relationships with initial occupancy were found (95\% CI of initial occupancy coefficients overlapped 0 ).

\section{Colonization probability}

The effect of elevation on colonization probability remained constant over time for 8 species (95\% CI for interaction coefficients between time and elevation overlapped 0; Table 1.6). Of these, colonization was positively associated with elevation for 6 species: Black-capped Chickadee (Poecile atricapillus), Blackburnian Warbler (Setophaga fusca), Dark-eyed Junco, Hermit Thrush (Catharus guttatus), Magnolia Warbler, and Winter Wren (Troglodytes hiemalis); and was maximized at $692 \mathrm{~m}$ for Blue Jay (Cyanocitta cristata) and at $709 \mathrm{~m}$ for Red-eyed Vireo 
(Vireo olivaceus) (posterior mean log odds ratios in Table 1.6). Colonization probability decreased over time for Magnolia Warbler and Red-eyed Vireo, and increased over time for Blue Jay (Table 1.6).

The effect of elevation on colonization probability changed over time for 8 species ( $95 \%$ CI for interaction terms between time and elevation or elevation ${ }^{2}$ did not overlap 0; Table 1.6). Five species were more likely to colonize high elevations later in the study: American Robin, Blue-headed Vireo (Vireo solitarius), Black-throated Green Warbler (Setophaga virens), Blackthroated Blue Warbler, and Ovenbird (Seiurus aurocapilla). Wood Thrush (Hylocichla mustelina) and Scarlet Tanager (Piranga olivacea) were less likely to colonize high elevations later in the study, and Veery was less likely to colonize low elevations later in the study (Table 1.6).

Colonization was higher in young harvest (0-19 years) compared to non-harvest (> 40 years) for 5 species: American Robin, Black-capped Chickadee, Red-eyed Vireo, Scarlet Tanager, and Wood Thrush; and was lower in young harvest compared to non-harvest for 7 species: Blue-headed Vireo, Black-throated Blue Warbler, Black-throated Green Warbler, Darkeyed Junco, Hermit Thrush, Magnolia Warbler, and Winter Wren (Table 1.6). Colonization did not differ between old harvest (20-40 years) and non-harvest for any species (Table 1.6).

\section{Persistence probability}

The effect of elevation on persistence probability remained constant over time for 8 species (95\% CI for interaction terms between time and elevation overlapped 0; Table 1.7). Of these species, persistence increased with elevation for Hermit Thrush, Magnolia Warbler, and Winter Wren, decreased with elevation for American Robin and Wood Thrush, and did not change across elevation for Blue Jay (posterior mean log odds ratios in Table 1.7). Persistence 
was highest at $855 \mathrm{~m}$ for Black-capped Chickadee, $1066 \mathrm{~m}$ for Blackburnian Warbler, and 1041 $\mathrm{m}$ for Ovenbird (Table 1.7). Persistence probability increased over time for Blackburnian Warbler, Blue Jay, Hermit Thrush, and Magnolia Warbler (Table 1.7).

The effect of elevation on persistence changed over time for 8 species (95\% CI for interaction terms between time and elevation or elevation ${ }^{2}$ did not overlap 0). American Robin and Blue-headed Vireo were more likely to persist in high elevations later in the study (Table 1.7). Black-throated Blue Warbler, Dark-eyed Junco, Scarlet Tanager, and Veery were more likely to persist in low elevations later in the study (Table 1.7); and Black-throated Green Warbler and Red-eyed Vireo were less likely to persist in low elevations later in the study (Table 1.7).

Persistence was lower in young harvest compared to non-harvest for Blue-headed Vireo, and was higher in young harvest compared to non-harvest for Black-throated Green Warbler and Red-eyed Vireo (Table 1.7). Persistence was higher in old harvest compared to non-harvest for American Robin and Black-throated Green Warbler (Table 1.7).

\section{Equilibrium occupancy dynamics}

I combined colonization and persistence rates to derive spatial and temporal changes in species equilibrium occupancy (Royle and Kéry 2007; Figure 1.6). Five species expanded up in elevation: American Robin, Blue-headed Vireo, Black-throated Green Warbler, Magnolia Warbler, and Ovenbird; with occupancy at 1250 m tripling for American Robin, and increasing by 50-60\% for Blue-headed Vireo and Magnolia Warbler (Figure 1.7, Table 1.8). Three species expanded down in elevation: Black-capped Chickadee, Blackburnian Warbler, Dark-eyed Junco (Figure 1.8, Table 1.8); with occupancy at $700 \mathrm{~m}$ doubling for Dark-eyed Junco and Blackburnian Warbler, and increasing by $60 \%$ for Black-capped Chickadee. 
Winter Wren contracted down, with occupancy at $1250 \mathrm{~m}$ decreasing by approximately 40\% (Figure 1.8 G, Table 1.8); and Scarlet Tanager shifted down, with occupancy increasing at $700 \mathrm{~m}$ by $20 \%$ and decreasing at $1250 \mathrm{~m}$ by $30 \%$ (Figure $1.8 \mathrm{E}$, Table 1.8 ). The remaining six species showed no directional change in occupancy (Figure 1.7 and 1.8, Table 1.8). Of these species, 2 showed no trend (Black-throated Blue Warbler and Veery; Figure 1.8), 2 species

decreased uniformly, with occupancy declining by approximately 35\% for Red-eyed Vireo and $50 \%$ for Wood Thrush (Figure 1.8D, H), and 2 species increased uniformly, with occupancy increasing by approximately 50\% for Hermit Thrush and doubling for Blue Jay (Figure 1.7F-G).

Equilibrium occupancy was higher in young harvest (0-19 years) compared to old harvest and non-harvest (> 20 years) for 4 species: Black-capped Chickadee, Ovenbird, Red-eyed Vireo, and Wood Thrush (Figure 1.9). Occupancy was higher in young harvest compared to non-harvest (> 40 years) for American Robin and Scarlet Tanager (Figure 1.9). Five species had lower occupancy in young harvest compared to old harvest and non-harvest: Blue-headed Vireo, Black-throated Blue Warbler, Dark-eyed Junco, Magnolia Warbler, and Winter Wren (Figure 1.9).

\section{DISCUSSION}

Consistent with a majority of prior studies (Archaux 2004, Tingley et al. 2012, DeLuca and King 2017), I found heterospecific variation in occupancy changes along an elevation gradient. Five species modeled exhibited an upward expansion of occupancy. This is consistent with increasing temperatures that may be driving these dynamics in instances where a species is physiologically constrained by temperature at high elevations (McCain and Grytnes 2010). However, only 1 of the 4 low elevation species expanded upwards: Ovenbird (Figure 1.7 E). Increasing temperatures could be particularly driving this species since it may be physiologically 
limited by cooler temperatures in high elevations (Root 1988, Canterbury 2002). For other species expanding upwards, changes in forest conditions is likely a more direct driver (Able and Noon 1976, Jankowski et al. 2013, DeLuca and King 2017). Of the 5 species that expanded upwards, 3 are associated with spruce forests in this region: Black-throated Green Warbler, Magnolia Warbler, and Blue-headed Vireo (Buckelew and Hall 1994). These species may be responding to the increase of spruce forests in high elevations, from both active and passive Red Spruce restoration efforts throughout the MNF (Figure 1.10 A; Mayfield III and Hicks Jr. 2009, Nowacki et al. 2009, Monongahela National Forest 2011). Many Red Spruce in the MNF have also matured from saplings to small understory trees (Figure 1.10 A; USDA Forest Service: Northern Research Station 2018), contributing more to forest structure and composition which may improve the suitability for these species (DeLuca and King 2017).

Downward expansions occurred in 3 high elevation species: Black-capped Chickadee, Blackburnian Warbler, and Dark-eyed Junco (Figure 1.8); contrary to expectations of climateinduced upward contractions (Sekercioglu et al. 2008, Dirnböck et al. 2010). Low elevation expansions may be a result of the downward expansions of northern hardwood and spruce forests that are occurring in the Appalachians due to restoration efforts (Figure 1.10; Monongahela National Forest 2011, Vogelmann et al. 2012, Foster and D'Amato 2015, USDA Forest Service: Northern Research Station 2018). Similar downward movements of Black-capped Chickadee, Dark-eyed Junco, and Blackburnian Warbler were observed in the northern Appalachians by DeLuca and King (2017). Additionally, the spread of spruce and northern hardwood forests into lower elevations may be driving the downward shift observed in Scarlet Tanager (Figure 1.8 E), a species that typically occupies deciduous mesophytic forests (Buckelew and Hall 1994). 
Changes in occupancy may also be reflecting regional population trends. Population increases would likely cause species distributions to expand as densities increase, while population declines would likely cause species distributions to contract towards their core where habitat quality likely is higher (Fretwell and Lucas 1970, Thomas and Lennon 1999). Of the 10 species that expanded up or down or increased uniformly (Table 1.8), 9 species have increasing population trends in West Virginia, and 1 shows stable populations (Sauer et al. 2017). For example, the upward expansion in Ovenbird could be a result of observed population increases in West Virginia (Sauer et al. 2017) allowing birds to colonize at high elevation margins of their distribution. Furthermore, of the 3 species that declined or contracted down (Figure 1.8, Table 1.8), Red-eyed Vireo and Winter Wren have remained stable and Wood Thrush declined in West Virginia (Sauer et al. 2017). The decrease in equilibrium occupancy of Wood Thrush, especially from high elevations (Figure 1.8 H), suggests that the species may be abandoning areas at its range edge and withdrawing to its core range where conditions may be more suitable (Buckelew and Hall 1994, Thomas and Lennon 1999). Observed occupancy changes of the two generalist species is likely a reflection of regional population increases as well (Sauer et al. 2017), where Blue Jay increased uniformly across elevation (Figure 1.7 F) and American Robin occupancy increased above $750 \mathrm{~m}$ (Figure $1.7 \mathrm{~A}$ ).

While occupancy changed unevenly across the elevation gradient for 10 of the 16 species, no species contracted upwards (Table 1.8). This provides evidence that climate-induced range retractions are not occurring for the species studied, contrary to predictions for many montane avian species (Sekercioglu et al. 2008, Sorte and Jetz 2010). Furthermore, the lack of contraction supports the idea that expansion and regeneration of northern hardwood and spruce forests may counteract short-term climate change effects, which has been observed in other areas (Clavero et 
al. 2011, DeLuca and King 2017). While the risk of climate-induced extinction in the region does not seem to have increased for the species studied, more restricted high elevation species like Yellow-rumped Warbler, Red Crossbill, and Swainson's Thrush may still be vulnerable to climate-induced range contraction in the central Appalachians (Buckelew and Hall 1994, Sekercioglu et al. 2008).

The dynamic occupancy model also provided insight into the effects of harvest on colonization, persistence, and occupancy. Six species showed positive responses to young harvest (Figure 1.9): Black-capped Chickadee, Ovenbird, Red-eyed Vireo, and Scarlet Tanager, American Robin, and Wood Thrush, suggesting that these species benefit from the change in forest conditions following harvest. Five species showed negative responses to young harvest (Figure 1.9): Blue-headed Vireo, Black-throated Blue Warbler, Dark-eyed Junco, Magnolia Warbler, and Winter Wren, suggesting that these species tend to prefer less-disturbed forest conditions. While most of these associations are consistent with past findings (Buckelew and Hall 1994, King and Degraaf 2000, Vanderwel et al. 2007, McDermott and Wood 2009), some studies have suggested that species such as Ovenbird, Scarlet Tanager, Red-eyed Vireo, and Wood Thrush typically respond negatively to forest fragmentation resulting from timber management (Campbell et al. 2007, Vanderwel et al. 2007), contrary to what I observed. The use of unlimited radius point count surveys may have allowed these species to be detected outside of the harvested stand itself. Nonetheless, these results suggest that these species are using sites close to young harvest stands more frequently than old harvest and mature forest stands. Although these adult breeding forest birds may avoid harvested areas, many studies have found that fledglings and post-breeding individuals often move to harvested areas with dense understories, which is thought to be important for fledgling survival (Anders et al. 1998, Vega 
Rivera et al. 1998, 2003, Marshall et al. 2003, McDermott and Wood 2010). This suggests that some mature forest species, such as Ovenbird and Wood Thrush, may benefit from selecting sites close to harvested areas, especially small-scale harvests like those typically found in the MNF (Monongahela National Forest 2011), and may explain the higher occupancy in or near young harvests for several species in this study.

Although no clear pattern was observed in the 16 birds species analyzed, it is apparent that habitat use by birds is dynamic across space and time throughout the central Appalachians. Multiple factors likely drive avian occupancy dynamics, including direct climate-induced movement (Tingley et al. 2012), change in forest structure and composition (Campbell et al. 2007, DeLuca and King 2017), and density dependent effects that reflect regional population trends (Thomas and Lennon 1999). Given multiple competing factors, I found little evidence of purely climate driven changes in species' elevational distributions. Contrary to predictions, of the 16 species monitored, only 1 of 4 low elevation species expanded upwards, and none of the high elevation species exhibited upward contractions, suggesting that climate-induced movements may be alleviated by more direct changes to forest conditions. This analysis provides some of the first evaluations of the temporal dynamics of Central Appalachian forest birds on an elevation gradient. Montane bird communities are very diverse and have high conservation value, so monitoring the spatial and temporal occupancy dynamics will continue to be an essential tool for informing landscape-scale conservation plans. 


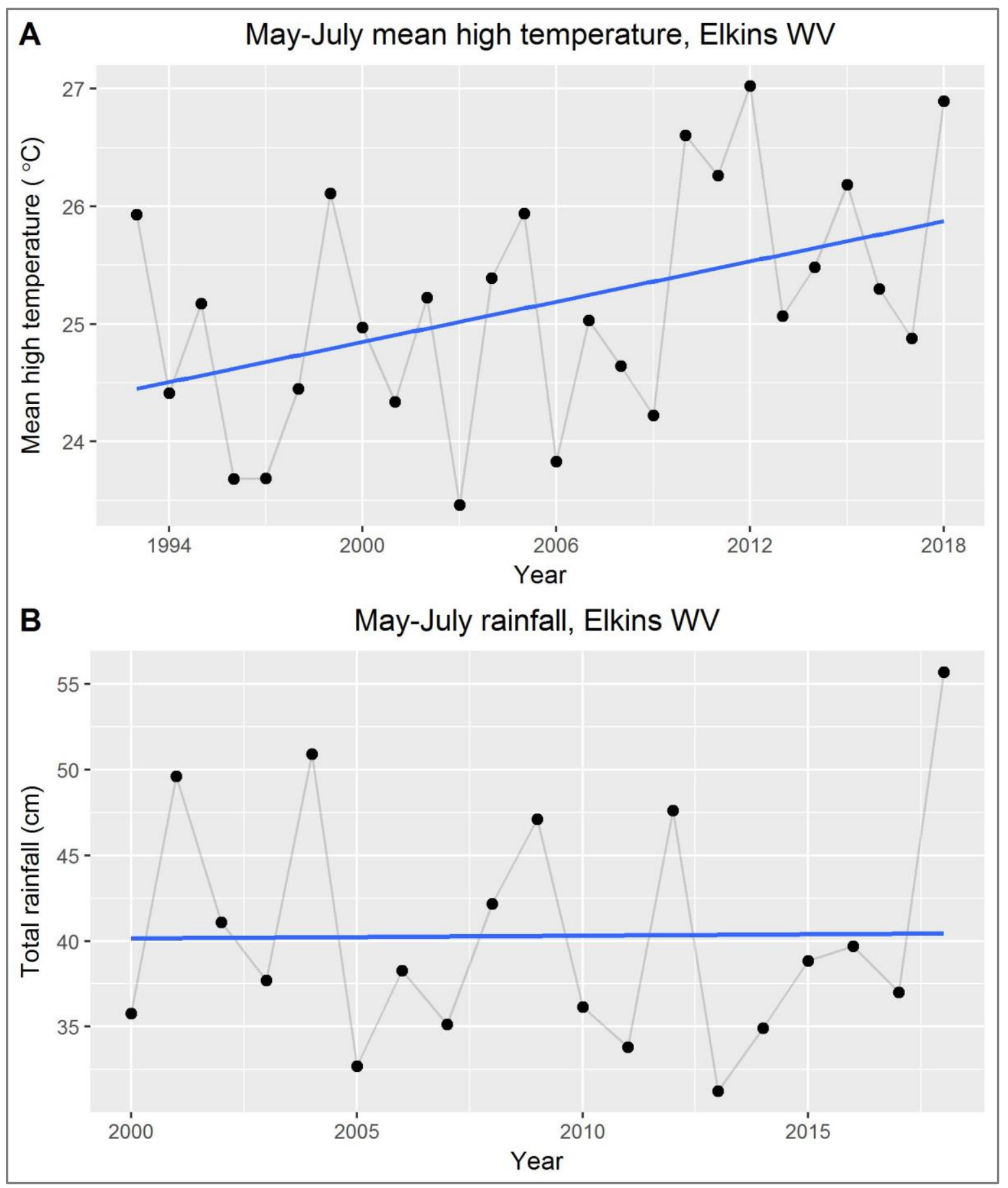

Figure 1.1 Average daily high temperature (A) and total rainfall in centimeters (B) for May through July in Elkins, West Virginia, USA (NOAA 2018). The blue line is the best fit linear regression, where mean expected temperature is significantly increasing (0.06 degrees $\mathrm{C} /$ year) and total May-July rainfall has no significant change over time. 


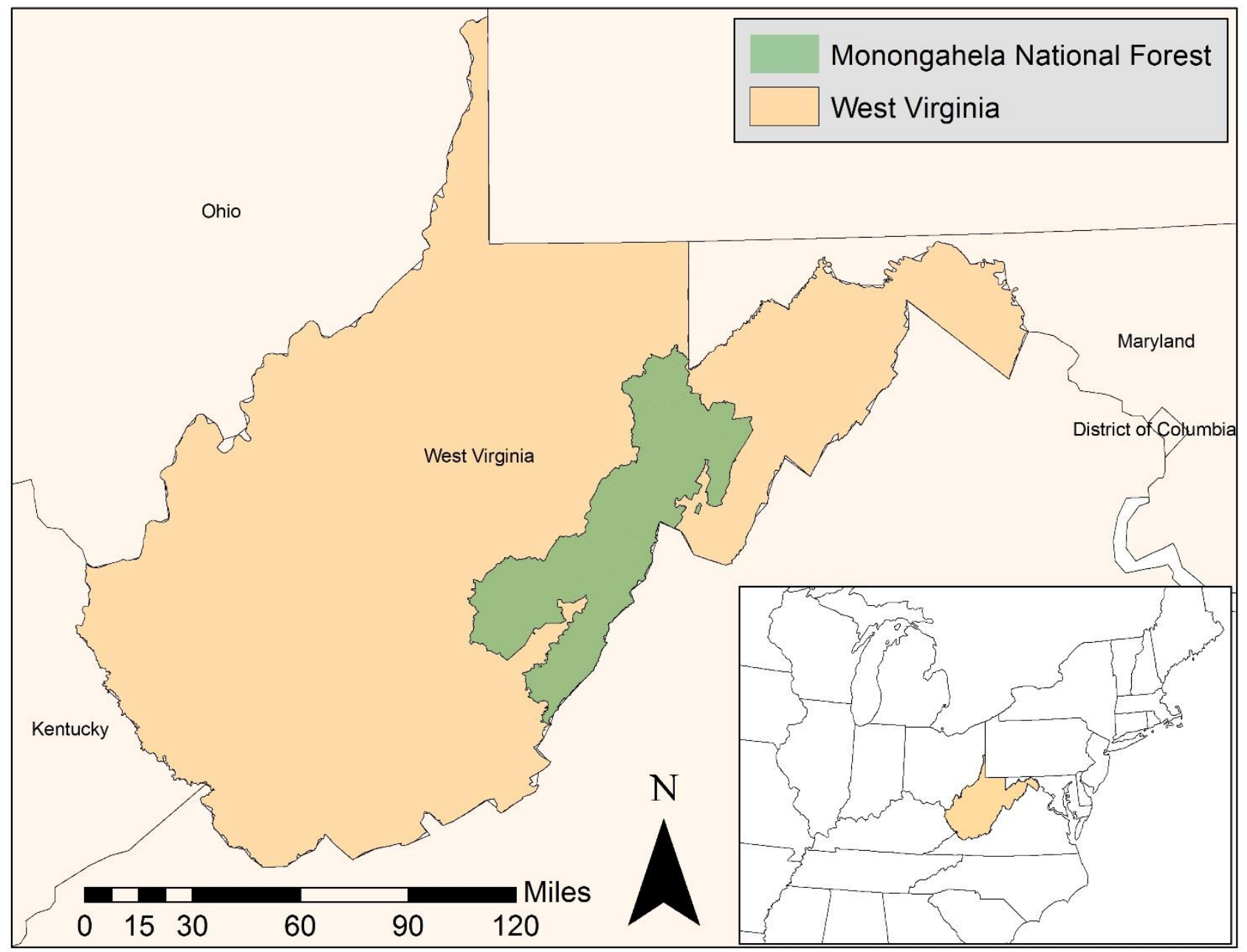

Figure 1.2. The Monongahela National Forest study site in West Virginia, USA where 5922 avian point count surveys were conducted in public land between 1993 and 2018. The forest is 688,000 hectares in size with about half publicly owned. 


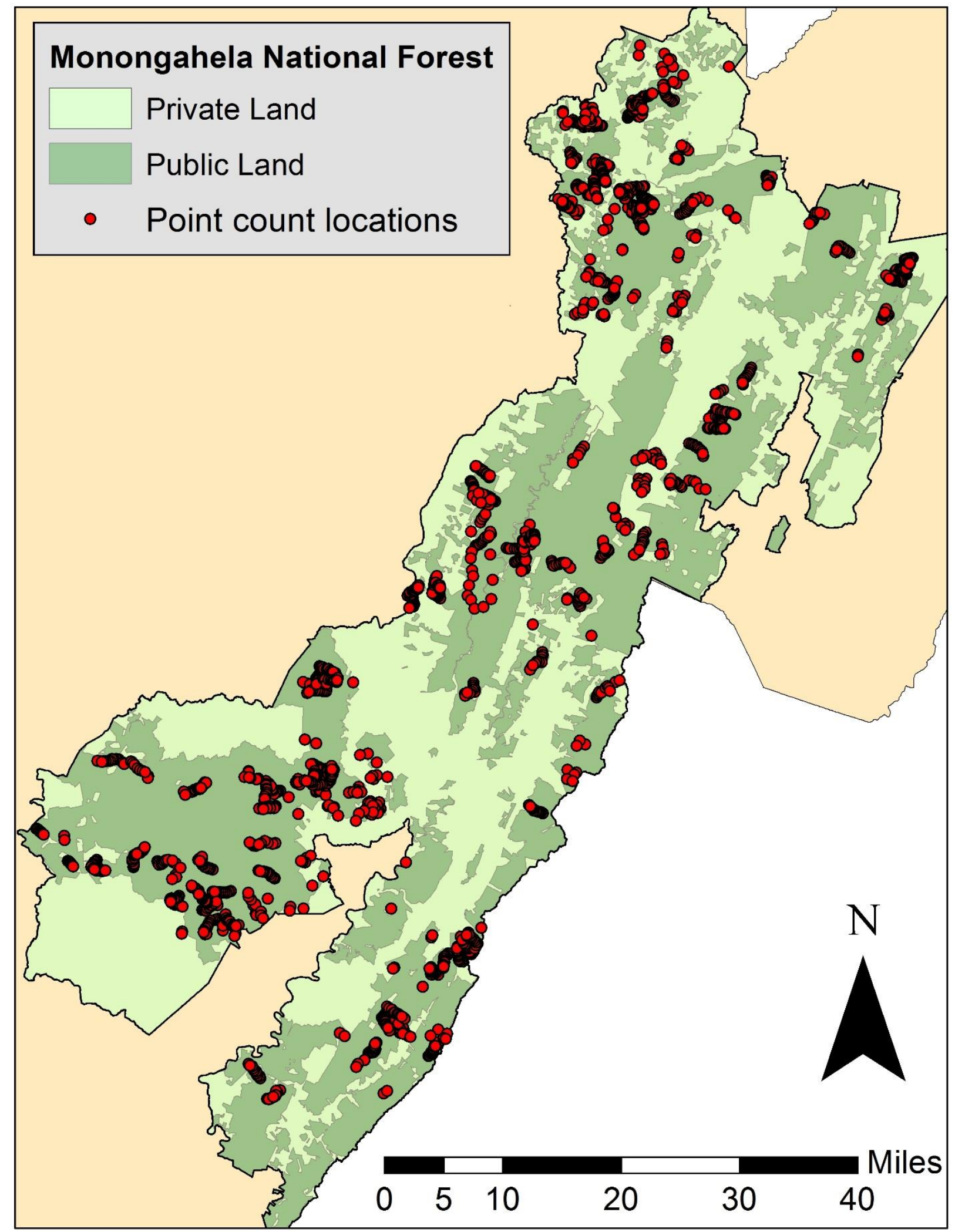

Figure 1.3. The locations of all avian point count surveys conducted on public land in the Monongahela National Forest, West Virginia, USA, 1993-2018. A total of 5922 point count surveys were conducted at 1651 locations. Detection/non-detection data for 16 bird species was used to model occupancy dynamics over the 26-year study period. 


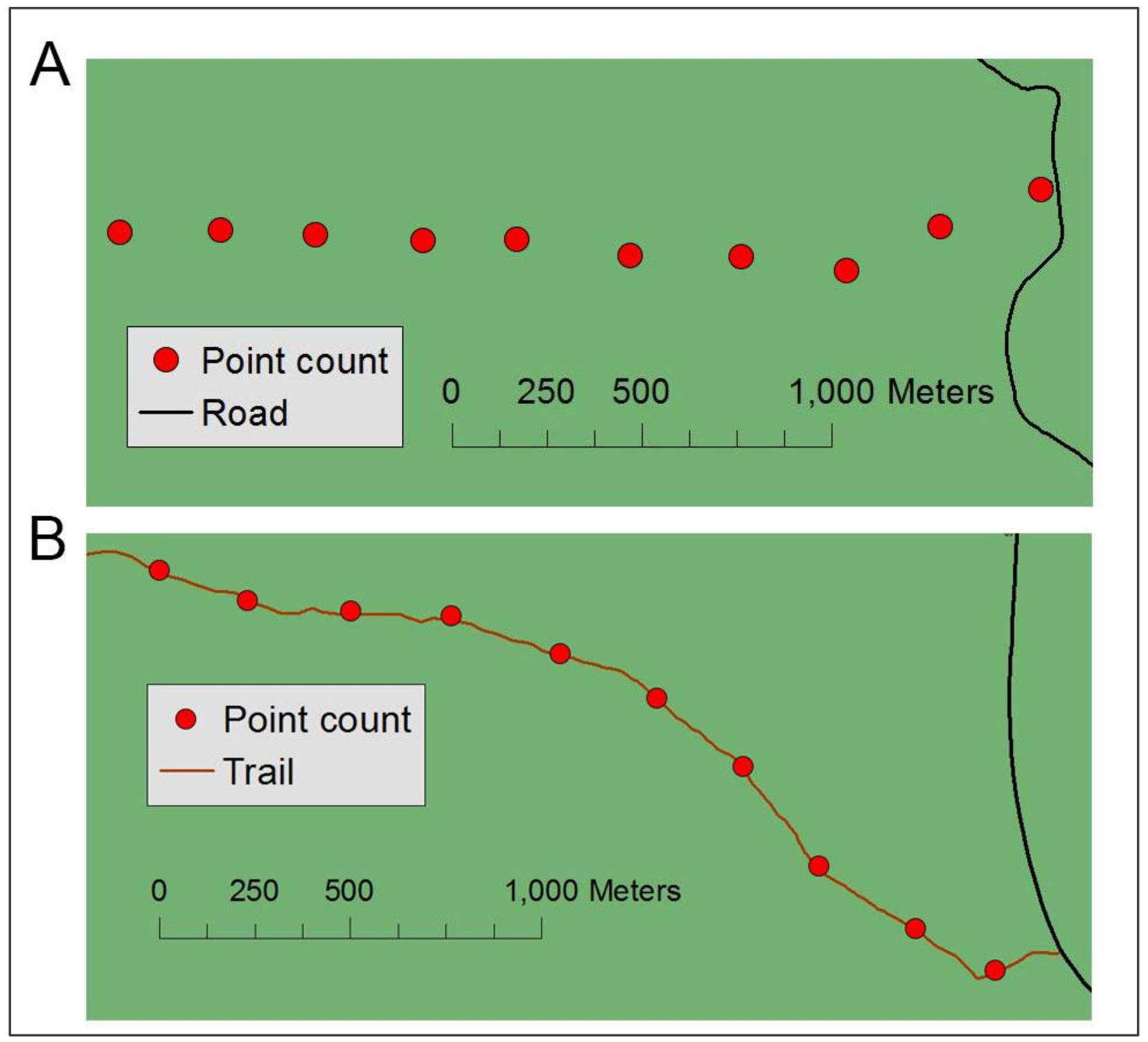

Figure 1.4. Point count transects were established along gravel roads and trails on public land in the Monongahela National Forest, West Virginia between 1993 and 2018. Points randomly generated along roads (A) started 100 meters from the road and subsequent points were placed perpendicular to the road spaced at least 250 meters apart. Points randomly generated along trails (B) began 100 meters from the trailhead and subsequent points were placed along the trail spaced 300 meters apart. A total of 5922 ten-minute unlimited radius point count surveys were conducted at 1651 locations. 


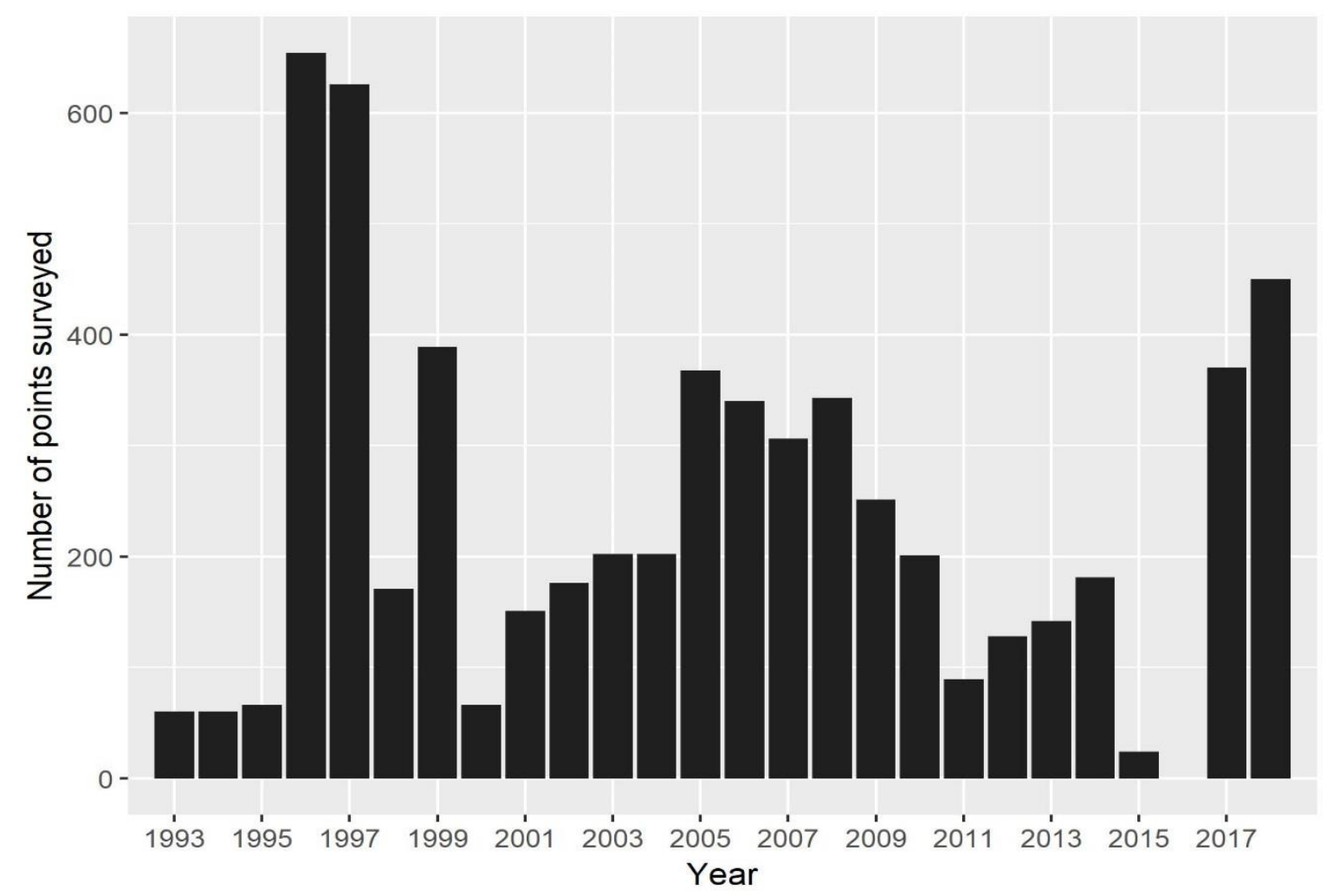

Figure 1.5. The yearly point count survey effort throughout public land in the Monongahela National Forest, West Virginia between 1993 and 2018. Over the 26-year period, a total of 5922 unlimited radius point count surveys were conducted. Detection/non-detection data for 16 songbird species was used to model spatial and temporal avian occupancy dynamics. 
A Change in high elevation (1250 m) equilibrium occupancy between 1994 and 2018

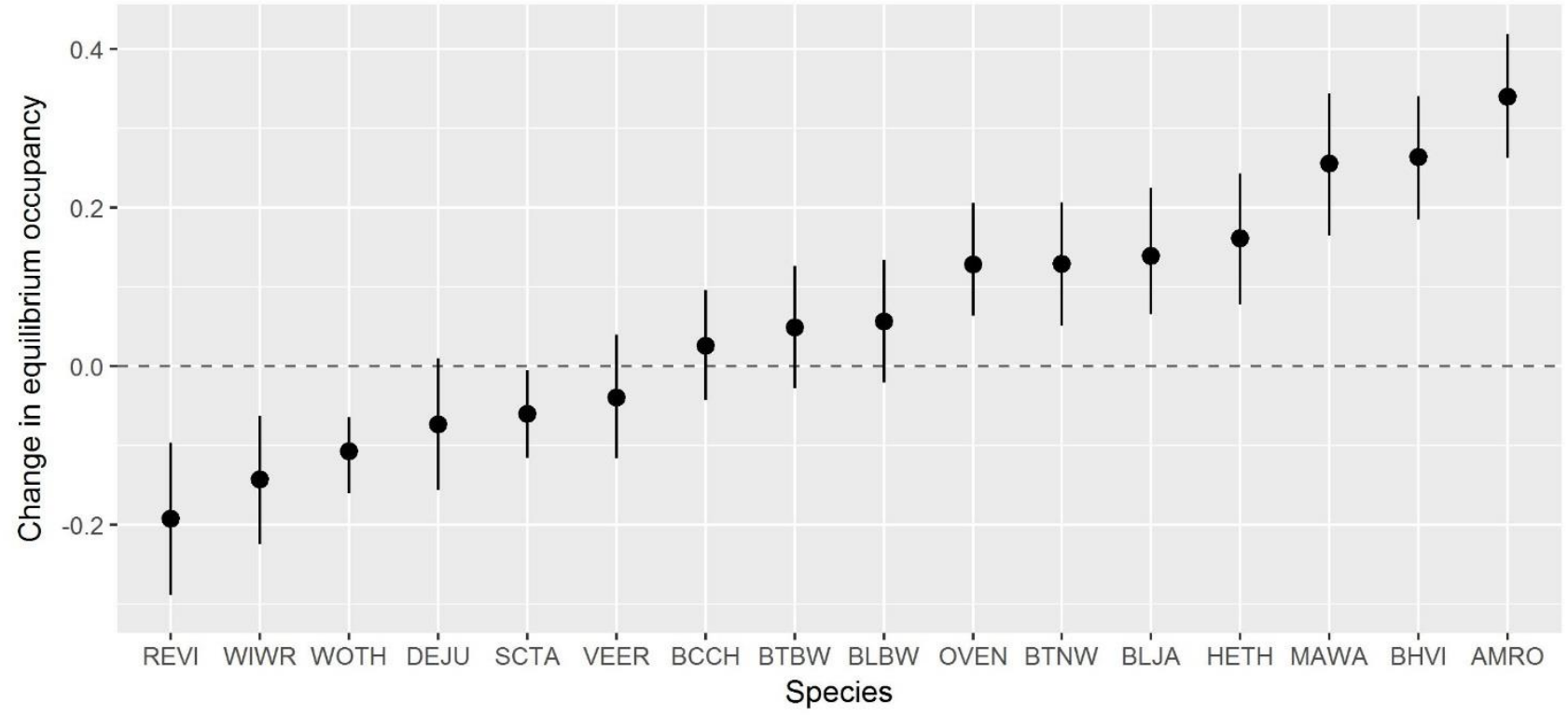

B Change in low elevation (700 m) equilibrium occupancy between 1994 and 2018

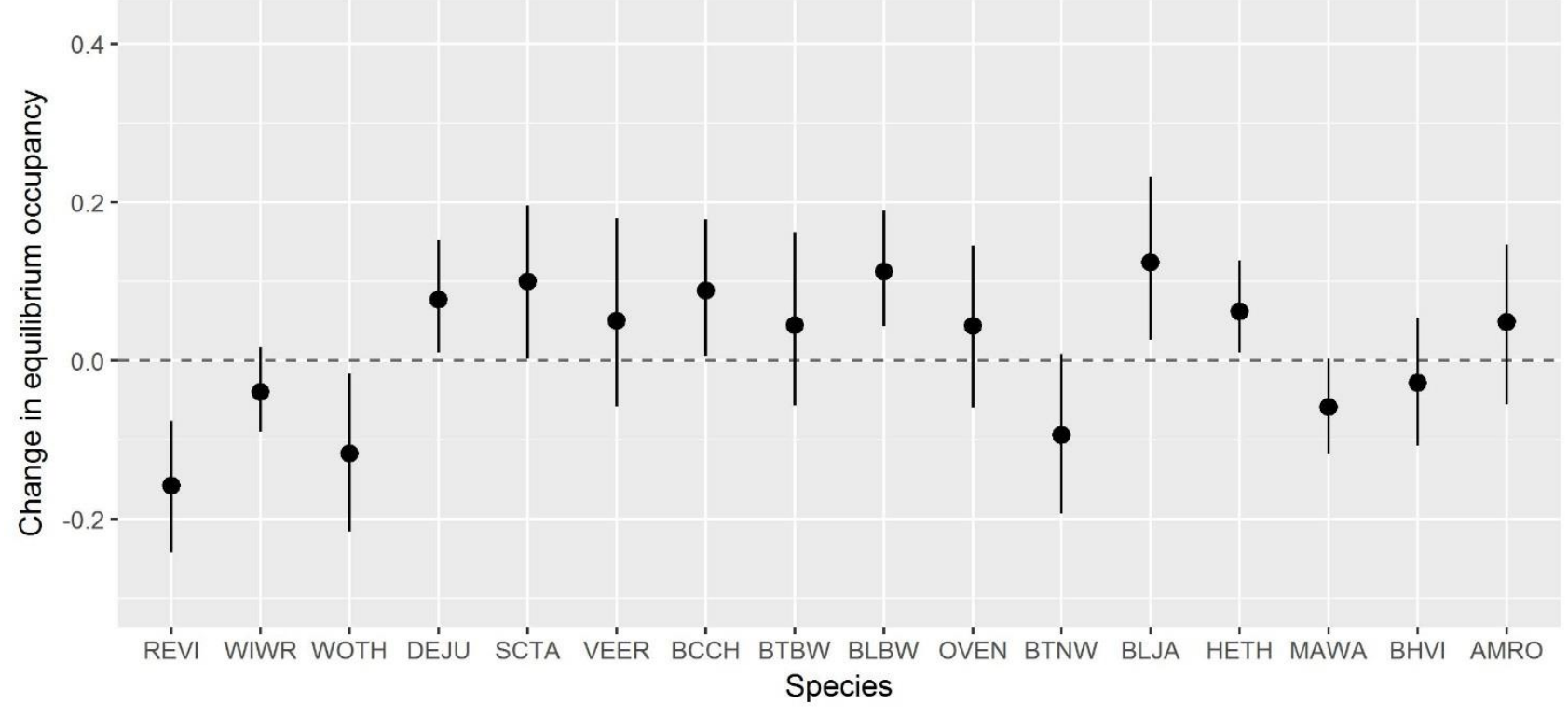

Figure 1.6. The change in equilibrium occupancy between 1994 and 2018 at high elevation (A) and low elevation (B) for 16 avian species in the Monongahela National Forest, West Virginia, 1994-2018. The $90^{\text {th }}$ percentile of the surveyed elevational distribution was used for high elevations $(1250 \mathrm{~m})$ and the $10^{\text {th }}$ percentile of the surveyed elevational distribution was used for low elevations $(700 \mathrm{~m})$. Dots indicate the point estimate and vertical bars indicate $95 \%$ credible intervals. Detection/non-detection data was obtained from 5922 unlimited radius point count surveys was used to model equilibrium occupancy, colonization, and persistence of species that were detected at $>15 \%$ of all point count surveys. Refer to Table 1.1 for a species code key. 

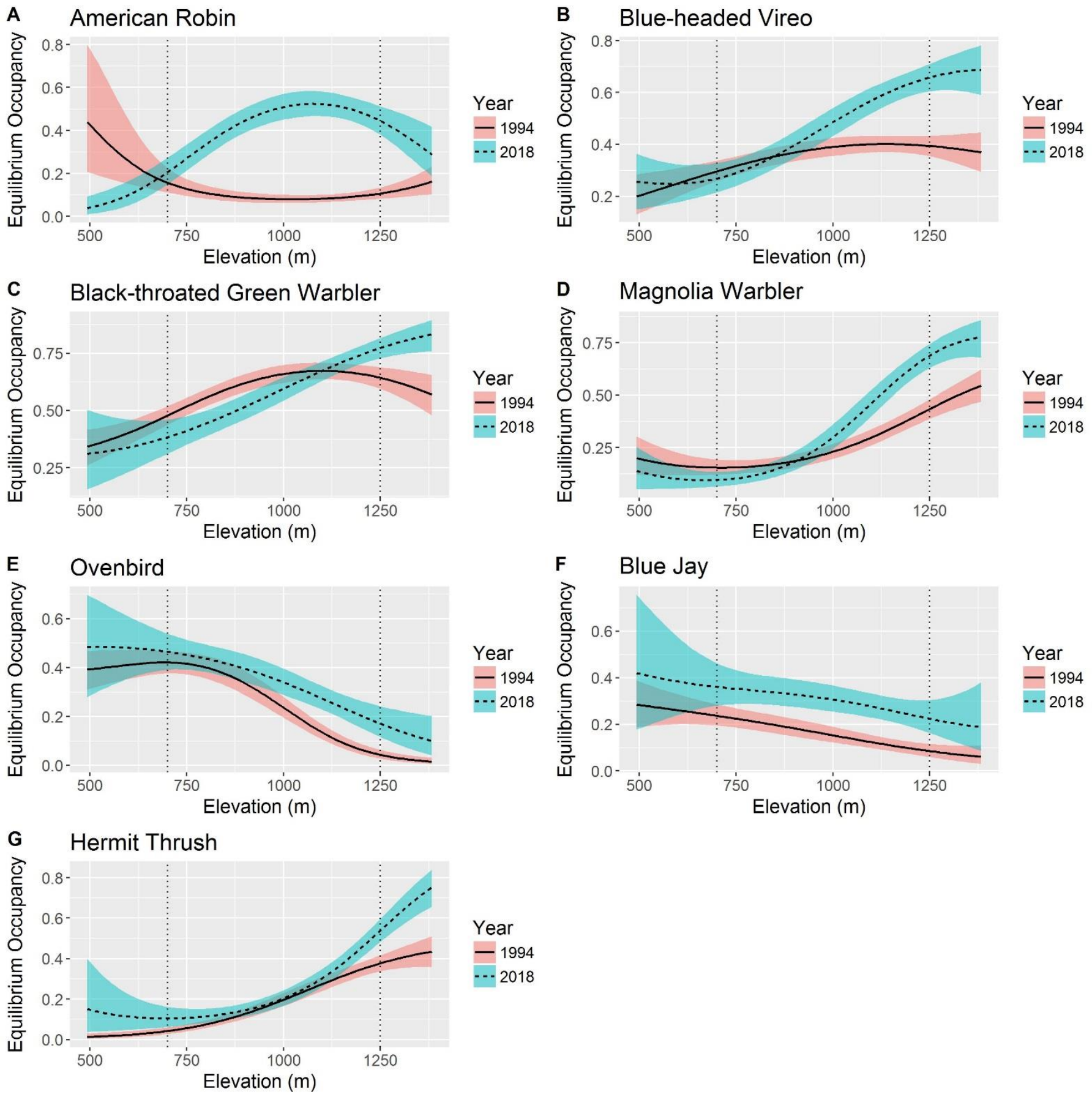

Figure 1.7. Equilibrium occupancy for the 8 species that expanded upwards or increased uniformly between 1994 and 2018 in the Monongahela National Forest, West Virginia, USA. Plots show how average occupancy varies by elevation in 1994 (solid line) and 2018 (dashed line). Red and blue areas indicate $95 \%$ credible intervals. Vertical dotted lines are the $10^{\text {th }}$ and $90^{\text {th }}$ percentiles of the surveyed elevational distribution that were used to represent low (700 m) and high elevations (1250 $\mathrm{m})$. I calculated equilibrium occupancy from species-specific colonization and persistence rates that were evaluated in a dynamic multi-species occupancy model. Detection/non-detection data was obtained from 5922 unlimited radius point count surveys conducted at 1651 locations. 

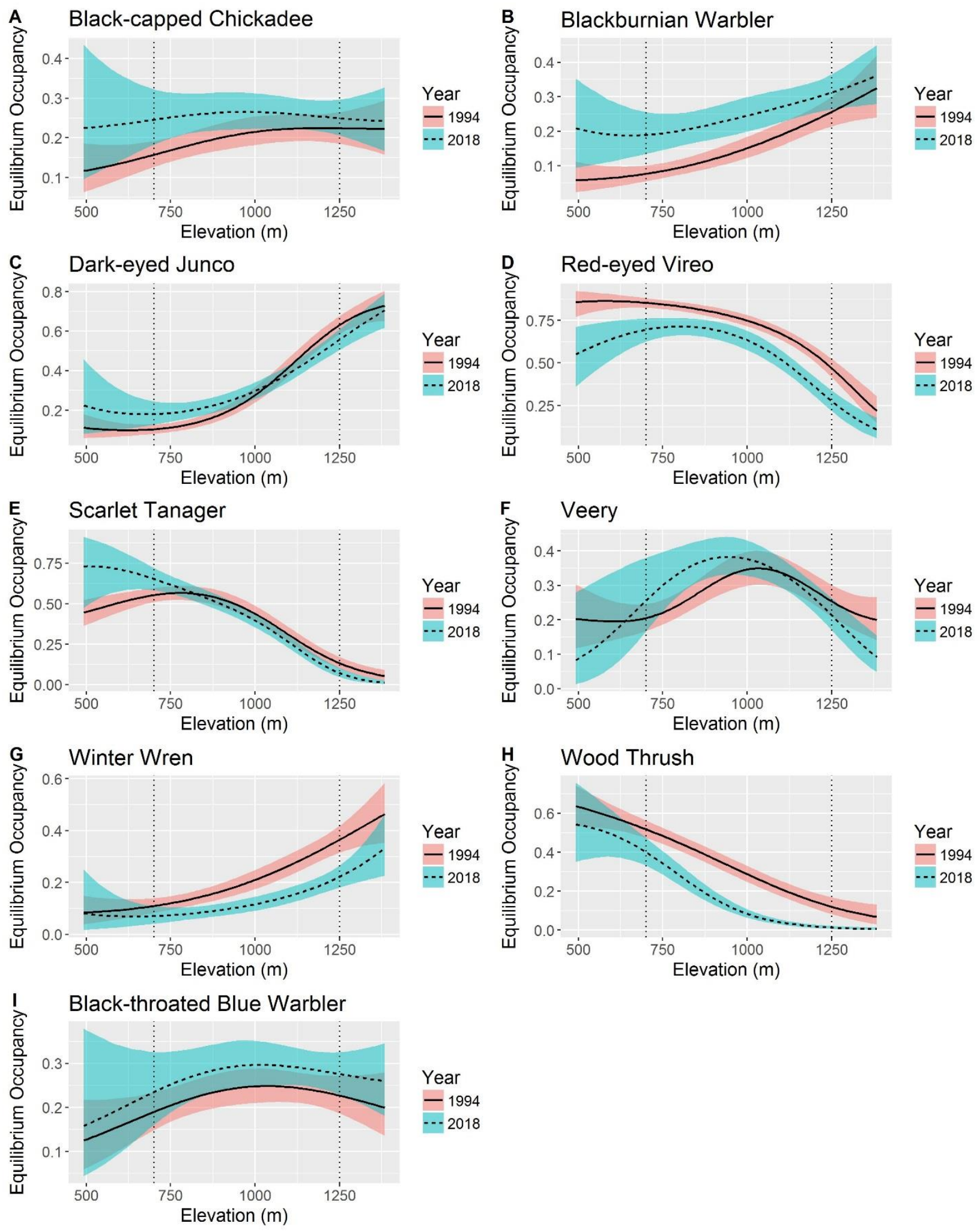

Figure 1.8. Equilibrium occupancy for the 9 species that expanded downwards, contracted downwards, decreased uniformly (Red-eyed Vireo), or remained constant between 1994 and 2018 in the Monongahela National Forest, West Virginia, USA. Plots show how average occupancy varies by elevation in 1994 (solid line) and 2018 (dashed line). Red and blue areas indicate $95 \%$ credible intervals. Vertical dotted lines are the $10^{\text {th }}$ and $90^{\text {th }}$ percentiles of the surveyed elevational distribution that were used to represent low $(700 \mathrm{~m})$ and high elevations $(1250 \mathrm{~m})$. I calculated equilibrium occupancy from species-specific colonization and persistence rates that were evaluated in a dynamic multi-species occupancy model. Detection/non-detection data was obtained from 5922 unlimited radius point count surveys conducted at 1651 locations. 


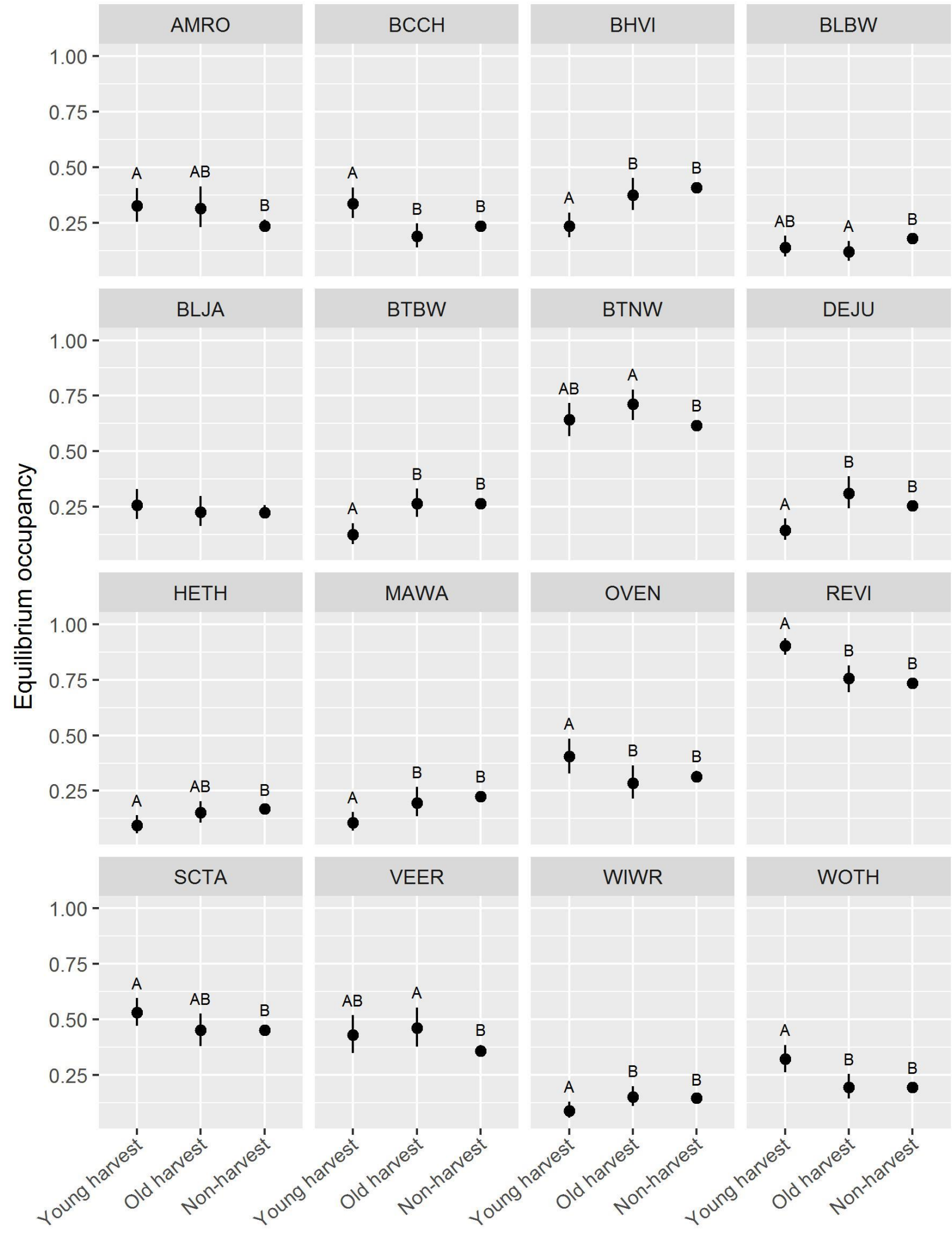

Figure 1.9. Equilibrium occupancy probability in young harvest (0-19 years), old harvest (20-40 years), and nonharvest stands (> 40 years) for the 16 species analyzed (Table 1) throughout the Monongahela National Forest, West Virginia, USA, 1994-2018. Dots indicate the point estimate and vertical lines indicate $95 \%$ credible intervals. Letters indicate levels whose $95 \%$ credible interval for $\Delta \Psi_{\mathrm{s}}$ does not overlap 0 . All other covariates were held at their mean. Equilibrium occupancy was derived from colonization and persistence rates calculated in a dynamic multi-species occupancy model (Royle and Kery 2007) using avian detection/non-detection data from 5922 point count surveys conducted at 1651 locations. 

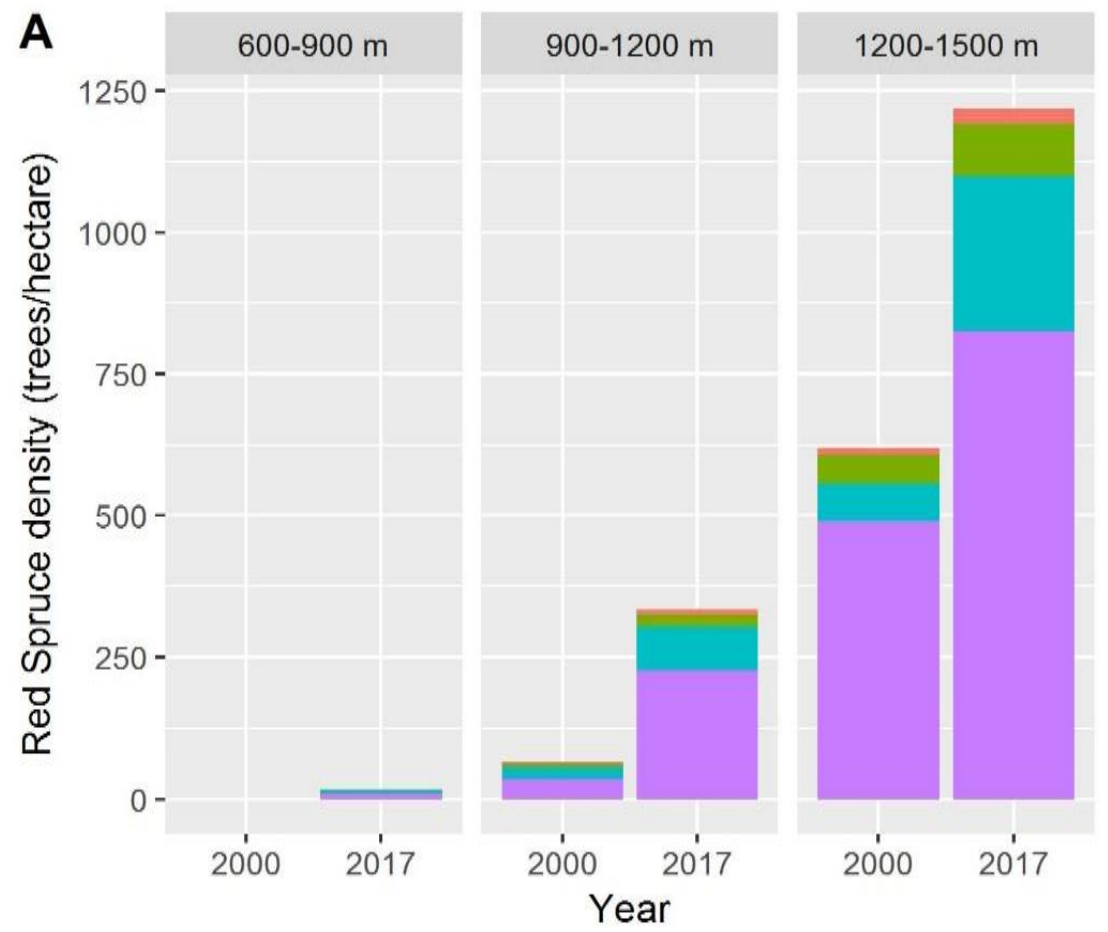

\section{Tree size}
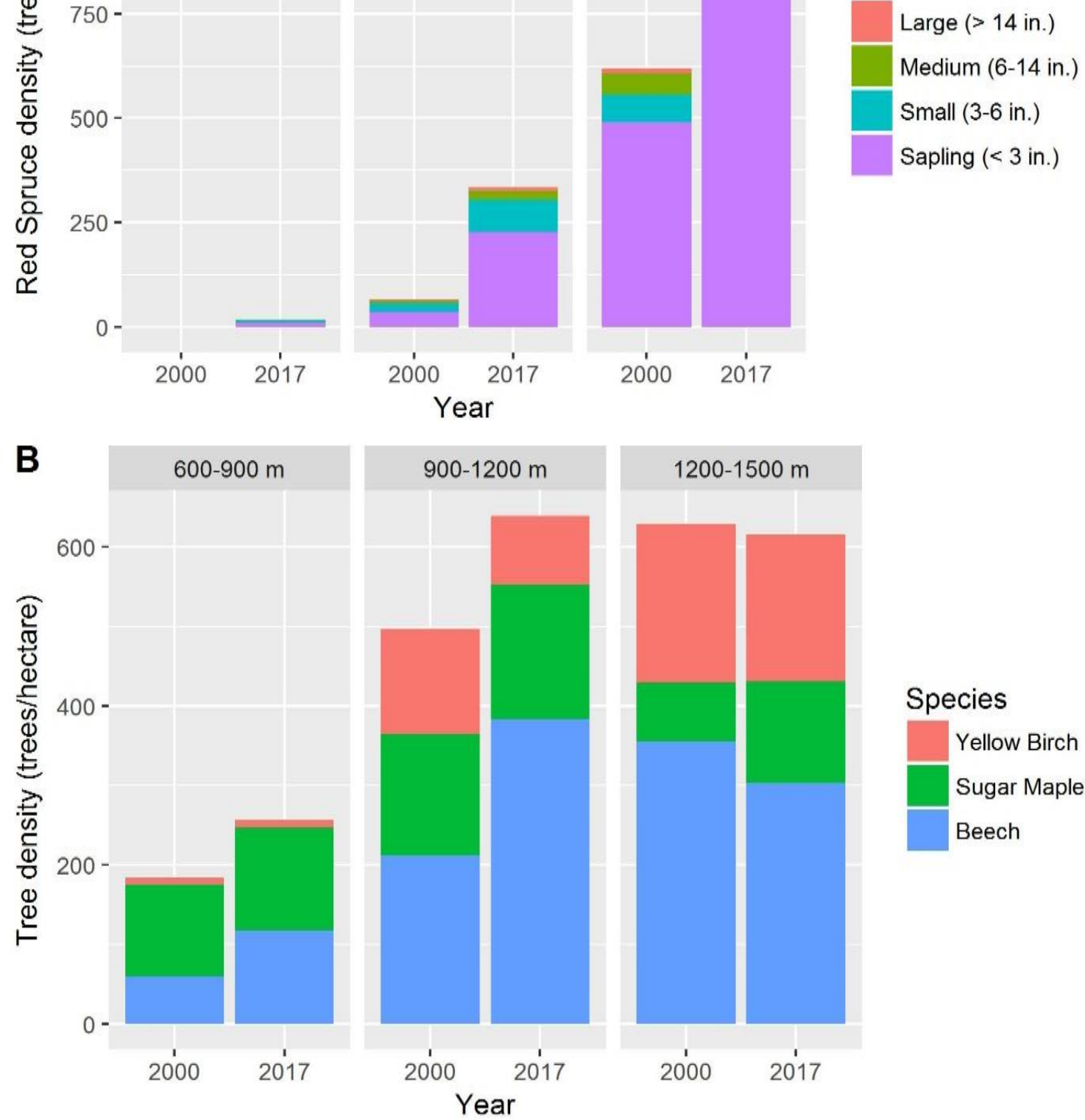

\section{Species}

Yellow Birch
Sugar Maple Beech

Figure 1.10. Estimated density of Red Spruce trees (A) and three northern hardwood species (B) in three elevation classes throughout the Monongahela National Forest, West Virginia in 2000 and 2017. Density estimates were obtained from Forest Inventory Analysis (FIA) data (USDA Forest Service: Northern Research Station 2018). 
Table 1.1. Detection and occupancy covariates used in the dynamic multi-species occupancy model of 16 forest songbirds. Detection/non-detection data was obtained from 5922 unlimited radius point count surveys at 1651 locations in the Monongahela National Forest, West Virginia, 1993-2018. Levels describe the categories for categorical variables and the units for continuous variables. For continuous variables, I report the mean and range, and for categorical variables I report the proportion of point count surveys that fell in each level.

\begin{tabular}{lllr}
\hline Covariate & Model & Levels & Mean (Range) \\
\hline Date & Detection & Continuous & June 12 (May 18-July 15) \\
Elevation & Initial occupancy, colonization, & Continuous (meters) & 996 (359-1420) \\
& and persistence & & \\
Forest type & Initial occupancy & Categorical: & 0.35 \\
& & Mixed mesophytic & 0.27 \\
& & Oak/pine & 0.20 \\
& & Northern hardwood & 0.09 \\
& & Spruce & 0.09 \\
Year & Colonization and persistence & Open & Continuous \\
Harvest & Colonization and persistence & Categorical: & $005(1993-2018)$ \\
& & Young harvest $(0-19 \mathrm{yr})$ & 0.06 \\
& & Old harvest $(20-40 \mathrm{yr})$ & 0.05 \\
& & Non-harvest $(>40 \mathrm{yr})$ & 0.89 \\
\hline
\end{tabular}


Table 1.2. Summary of the 16 species included in the dynamic multi-species occupancy model to evaluate the changes in occupancy through time along an elevation gradient in the Monongahela National Forest, West Virginia, 1993-2018. Detection/non-detection data was obtained from 5922 unlimited radius avian point count surveys conducted at 1651 locations. Mean elevation and $10^{\text {th }}$ and $90^{\text {th }}$ percentiles (p10, p90) are shown for each species. Detections is the number of point count surveys that each species was detected with the percent of total in parentheses.

\begin{tabular}{lrrrr}
\hline Species & Alpha & $\begin{array}{r}\text { Elevation }(\mathbf{m}) \\
\text { Code }\end{array}$ & $\begin{array}{r}\text { Detections } \\
(\mathbf{p 1 0}, \mathbf{p 9 0})\end{array}$ & $\begin{array}{r}\text { Elevation } \\
\text { group }\end{array}$ \\
\hline American Robin (Turdus migratorius) & AMRO & $1000(703,1243)$ & $1238(20)$ & Generalist \\
Blackburnian Warbler (Setophaga fusca) & BLBW & $1037(730,1292)$ & $1088(18)$ & $\begin{array}{r}\text { High } \\
\text { Black-capped Chickadee (Poecile atricapillus) }\end{array}$ \\
Black-throated Blue Warbler (Setophaga caerulescens) & BCCH & $989(699,1247)$ & $1190(19)$ & High \\
Black-throated Green Warbler (Setophaga virens) & BTNW & $1016(704,1248)$ & $1411(23)$ & High \\
Blue Jay (Cyanocitta cristata) & BLJA & $936(703,1257)$ & $3645(60)$ & High \\
Blue-headed Vireo (Vireo solitarius) & BHVI & $1000(701,1268)$ & $2449(40)$ & High \\
Dark-eyed Junco (Junco hyemalis) & DEJU & $1054(717,1290)$ & $1955(32)$ & High \\
Hermit Thrush (Catharus guttatus) & HETH & $1085(753,1304)$ & $1382(22)$ & High \\
Magnolia Warbler (Setophaga magnolia) & MAWA & $1048(690,1294)$ & $1826(30)$ & High \\
Ovenbird (Seiurus aurocapilla) & OVEN & $898(659,1176)$ & $1542(25)$ & Low \\
Red-eyed Vireo (Vireo olivaceus) & REVI & $941(681,1216)$ & $3840(63)$ & Low \\
Scarlet Tanager (Piranga olivacea) & SCTA & $906(661,1165)$ & $2137(35)$ & Low \\
Veery (Catharus fuscescens) & VEER & $998(704,1236)$ & $1610(26)$ & High \\
Winter Wren (Troglodytes hiemalis) & WIWR & $1053(698,1299)$ & $1059(17)$ & High \\
Wood Thrush (Hylocichla mustelina) & WOTH & $866(633,1142)$ & $1313(21)$ & Low \\
\hline
\end{tabular}


Table 1.3. Criteria for categorizing occupancy dynamics given changes in equilibrium occupancy between 1994 and 2018 at low $(700 \mathrm{~m})$ and high $(1250 \mathrm{~m})$ elevations. Zero indicates no change in occupancy, - indicates a decrease in occupancy over the study period, and + indicates an increase in occupancy over the study period. Direction and trends are categorized for each of the 16 species included in the dynamic occupancy model that used avian point count surveys in the Monongahela National Forest, West Virginia, 1993-2018.

\begin{tabular}{cclr}
\hline Change in equilibrium occupancy & & \\
\hline $\mathbf{7 0 0} \mathbf{~ m}$ & $\mathbf{1 2 5 0} \mathbf{~ m}$ & Trend & Direction \\
\hline 0 & 0 & None & None \\
0 & + & Expanding & Up \\
0 & - & Contracting & Down \\
- & - & Decreasing & None \\
- & 0 & Contracting & Up \\
- & + & Shifting & Up \\
+ & + & Increasing & None \\
+ & 0 & Expanding & Down \\
+ & - & Shifting & Down \\
\hline
\end{tabular}


Table 1.4. A total of 5922 avian point count surveys were conducted at 1651 locations on public land in the Monongahela National Forest, West Virginia between 1993 and 2018. Point count sites received varying levels of effort, and 1651 locations were surveyed between 1 and 16 times over the 26-year study period.

\begin{tabular}{lr}
\hline $\begin{array}{l}\text { Number of } \\
\text { point count sites }\end{array}$ & $\begin{array}{r}\text { Number of years } \\
\text { surveyed }\end{array}$ \\
\hline 426 & 1 \\
533 & 2 \\
178 & 3 \\
125 & 4 \\
84 & 5 \\
100 & 5 \\
43 & 6 \\
25 & 7 \\
3 & 8 \\
16 & 9 \\
2 & 10 \\
9 & 11 \\
19 & 12 \\
32 & 13 \\
33 & 14 \\
23 & 15 \\
\hline
\end{tabular}


Table 1.5. Posterior log odds ratios of initial occupancy parameters for the 16 species included in the dynamic multi-species occupancy model. Initial occupancy was modeled using avian detection/non-detection data from 60 point count surveys conducted in 1993 throughout the Monongahela National Forest, West Virginia. Initial occupancy in 1993 was modeled as a function of elevation (linear and quadratic) and categorical forest type. Estimates for the four forest types (mixed mesophytic, northern hardwood, spruce, open) are relative to oak/pine forest. Values in bold have $95 \%$ credible intervals that do not overlap zero.

\begin{tabular}{lcrrrrr}
\hline \multicolumn{7}{c}{ Initial occupancy parameters } \\
\hline Species & Elev & Elev ^2 & Meso & N Hard & Spruce & Open \\
\hline American Robin & $\mathbf{1 . 8 1}$ & -0.11 & 0.45 & -0.03 & -0.27 & -0.39 \\
Black-capped Chickadee & 1.11 & -0.03 & -0.27 & 1.27 & 0.01 & -0.29 \\
Blue-headed Vireo & 0.56 & -0.99 & 0.94 & 1.09 & 0.15 & -0.34 \\
Blackburnian Warbler & 1.57 & -0.48 & 0.32 & 0.36 & 0.52 & -0.45 \\
Blue Jay & -0.16 & -1.08 & 0.56 & -0.26 & -0.21 & -0.30 \\
Black-throated Blue Warbler & 0.14 & $\mathbf{- 0 . 9 2}$ & 1.09 & 0.14 & 0.95 & -0.57 \\
Black-throated Green Warbler & 1.12 & -0.81 & 1.12 & 0.84 & -0.15 & -0.35 \\
Dark-eyed Junco & $\mathbf{1 . 8 0}$ & -0.73 & 0.24 & 1.39 & -0.72 & -0.34 \\
Hermit Thrush & 2.01 & 0.30 & 0.41 & 0.60 & -1.01 & -0.40 \\
Magnolia Warbler & $\mathbf{2 . 2 8}$ & -0.77 & -0.26 & 1.32 & 0.75 & -0.27 \\
Ovenbird & -1.71 & -1.12 & 0.13 & -0.96 & -0.26 & -0.32 \\
Red-eyed Vireo & -0.54 & -0.94 & 0.10 & 0.01 & -0.12 & -0.35 \\
Scarlet Tanager & -1.79 & -0.68 & 0.44 & -0.11 & -0.13 & -0.32 \\
Veery & 0.60 & $\mathbf{- 0 . 9 9}$ & 1.03 & 0.71 & 0.07 & -0.39 \\
Winter Wren & 0.12 & -0.48 & 0.81 & 1.48 & 1.85 & -0.74 \\
Wood Thrush & -1.63 & -1.06 & 1.18 & -0.51 & -0.11 & -0.32 \\
\hline
\end{tabular}


Table 1.6. Posterior log odds ratios of colonization parameters for the 16 species included in the dynamic multispecies occupancy model. Local colonization probability was modeled as a function of elevation (linear and quadratic), year, and harvest type. The model also included interactions between elevation and year and elevation^2 and year. Log odds ratios for young harvest (0-19 years) and old harvest (20-40 years) are relative to non-harvest (> 40 years). Values in bold have $95 \%$ credible intervals that do not overlap zero. Colonization was modeled using avian detection/non-detection data from 5922 unlimited radius point count surveys conducted at 1651 locations in the Monongahela National Forest, West Virginia, 1993-2018.

\begin{tabular}{|c|c|c|c|c|c|c|c|}
\hline \multirow[b]{2}{*}{ Species } & \multicolumn{7}{|c|}{ Colonization parameter estimates } \\
\hline & Elev & $\operatorname{Elev}^{\wedge} 2$ & Year & Elev * time & $\operatorname{Elev}^{\wedge} 2 *$ time & $\begin{array}{r}\text { Young } \\
\text { harvest }\end{array}$ & $\begin{array}{r}\text { Old } \\
\text { harvest }\end{array}$ \\
\hline American Robin & 0.25 & -0.11 & 0.71 & 0.09 & -0.22 & 0.54 & -0.01 \\
\hline Black-capped Chickadee & 0.20 & -0.02 & 0.03 & -0.02 & 0.00 & 0.55 & -0.14 \\
\hline Blue-headed Vireo & 0.28 & 0.05 & -0.20 & 0.05 & 0.10 & -0.61 & -0.16 \\
\hline Blackburnian Warbler & 0.44 & 0.15 & 0.09 & -0.08 & 0.05 & -0.05 & -0.41 \\
\hline Blue Jay & -0.41 & -0.16 & 0.20 & 0.08 & -0.07 & 0.17 & -0.26 \\
\hline Black-throated Blue Warbler & 0.39 & -0.10 & -0.09 & 0.13 & 0.00 & -0.77 & 0.31 \\
\hline Black-throated Green Warbler & 0.38 & 0.06 & -0.29 & 0.19 & 0.04 & -0.45 & 0.14 \\
\hline Dark-eyed Junco & 0.91 & 0.27 & 0.03 & -0.05 & -0.05 & -0.63 & 0.11 \\
\hline Hermit Thrush & 1.00 & 0.07 & -0.12 & -0.07 & 0.10 & -0.86 & -0.12 \\
\hline Magnolia Warbler & 0.64 & 0.37 & -0.17 & 0.05 & 0.04 & -0.75 & -0.14 \\
\hline Ovenbird & -0.85 & -0.16 & 0.05 & 0.15 & -0.02 & 0.18 & -0.16 \\
\hline Red-eyed Vireo & -0.65 & -0.27 & -0.55 & -0.03 & 0.07 & 0.94 & 0.42 \\
\hline Scarlet Tanager & -0.95 & -0.46 & 0.07 & -0.06 & -0.16 & 0.68 & -0.11 \\
\hline Veery & 0.25 & -0.33 & 0.05 & 0.18 & -0.23 & -0.01 & 0.21 \\
\hline Winter Wren & 0.58 & -0.19 & -0.11 & 0.10 & -0.10 & -0.70 & 0.20 \\
\hline Wood Thrush & -1.11 & -0.09 & -0.48 & -0.14 & -0.01 & 1.04 & -0.17 \\
\hline
\end{tabular}


Table 1.7. Posterior log odds ratios of persistence parameters for the 16 species included in the dynamic multispecies occupancy model. Local persistence probability was modeled as a function of elevation (linear and quadratic), year, and harvest type. The model also included interactions between elevation and year and elevation^2 and year. Log odds ratios for young harvest (0-19 years) and old harvest (20-40 years) are relative to non-harvest (> 40 years). Values in bold have $95 \%$ credible intervals that do not overlap zero. Persistence was modeled using avian detection/non-detection data from 5922 unlimited radius point count surveys conducted at 1651 locations in the Monongahela National Forest, West Virginia, 1993-2018.

\begin{tabular}{|c|c|c|c|c|c|c|c|}
\hline \multicolumn{8}{|c|}{ Persistence parameter estimates } \\
\hline Species & Elev & Elev $^{\wedge} 2$ & Year & Elev * time & $\operatorname{Elev}^{\wedge} 2 *$ time & $\begin{array}{r}\text { Young } \\
\text { Harvest } \\
\end{array}$ & $\begin{array}{r}\text { Old } \\
\text { harvest }\end{array}$ \\
\hline American Robin & -0.15 & -0.07 & 0.30 & 0.30 & -0.11 & 0.01 & 0.67 \\
\hline Black-capped Chickadee & -0.16 & -0.20 & 0.17 & -0.07 & 0.03 & 0.17 & -0.53 \\
\hline Blue-headed Vireo & 0.45 & -0.22 & 0.42 & 0.18 & -0.07 & -0.88 & -0.07 \\
\hline Blackburnian Warbler & 0.11 & -0.22 & 0.26 & -0.05 & -0.07 & -0.76 & -0.37 \\
\hline Blue Jay & -0.06 & 0.10 & 0.35 & 0.00 & 0.12 & 0.11 & 0.56 \\
\hline Black-throated Blue Warbler & -0.39 & -0.11 & 0.25 & -0.17 & 0.00 & -0.50 & -0.50 \\
\hline Black-throated Green Warbler & $\mathbf{0 . 3 3}$ & -0.18 & 0.10 & -0.04 & 0.11 & 0.53 & 0.45 \\
\hline Dark-eyed Junco & 0.57 & -0.02 & 0.07 & -0.28 & 0.13 & -0.53 & 0.37 \\
\hline Hermit Thrush & 0.45 & -0.01 & $\mathbf{0 . 3 3}$ & -0.10 & 0.14 & 0.13 & -0.12 \\
\hline Magnolia Warbler & 0.70 & -0.29 & 0.36 & 0.23 & -0.09 & -0.46 & -0.12 \\
\hline Ovenbird & -0.19 & -0.24 & 0.12 & 0.08 & 0.16 & 0.36 & -0.01 \\
\hline Red-eyed Vireo & -0.38 & -0.20 & 0.14 & 0.12 & -0.09 & 1.00 & -0.09 \\
\hline Scarlet Tanager & -0.62 & -0.12 & -0.18 & -0.05 & 0.25 & -0.06 & 0.13 \\
\hline Veery & -0.10 & -0.40 & 0.03 & -0.43 & 0.34 & 0.46 & 0.39 \\
\hline Winter Wren & 0.36 & 0.30 & 0.05 & -0.24 & 0.06 & -0.39 & -0.32 \\
\hline Wood Thrush & -0.89 & -0.19 & -0.05 & -0.25 & -0.12 & -0.36 & 0.33 \\
\hline
\end{tabular}


Table 1.8. Change in equilibrium occupancy between 1994 and 2018 at high and low elevations for the 16 species (Table 1.1) included in the dynamic multi-species occupancy model. Criteria for trend and direction are outlined in Table 1.2. The 10th and 90th percentiles of the surveyed elevational distribution were used to represent low (700 m) and high elevations $(1250 \mathrm{~m}$ ). Yearly occupancy was calculated using colonization and persistence rates (Royle and Kery 2007) that were modeled using avian detection/non-detection data from 5922 unlimited radius point count surveys conducted at 1651 locations in the Monongahela National Forest, West Virginia, 1993-2018. Values in bold have $95 \%$ credible intervals that do not overlap zero. Direction indicates the general elevational movement of occupancy outlined in Table 1.2.

\begin{tabular}{|c|c|c|c|c|}
\hline \multicolumn{5}{|c|}{ Change in occupancy } \\
\hline Species & $\begin{array}{r}\text { Low } \\
\text { elevation }\end{array}$ & $\begin{array}{r}\text { High } \\
\text { elevation }\end{array}$ & Trend & Direction \\
\hline American Robin & 0.05 & $\mathbf{0 . 3 4}$ & Expanding & Up \\
\hline Black-capped Chickadee & 0.09 & 0.03 & Expanding & Down \\
\hline Blue-headed Vireo & -0.03 & 0.26 & Expanding & $\mathrm{Up}$ \\
\hline Blackburnian Warbler & 0.11 & 0.06 & Expanding & Down \\
\hline Blue Jay & 0.12 & 0.14 & Increasing & None \\
\hline Black-throated Blue Warbler & 0.04 & 0.05 & No trend & None \\
\hline Black-throated Green Warbler & -0.09 & 0.13 & Expanding & Up \\
\hline Dark-eyed Junco & 0.08 & -0.07 & Expanding & Down \\
\hline Hermit Thrush & 0.06 & 0.16 & Increasing & None \\
\hline Magnolia Warbler & -0.06 & 0.25 & Expanding & Up \\
\hline Ovenbird & 0.04 & 0.13 & Expanding & Up \\
\hline Red-eyed Vireo & -0.16 & -0.19 & Decreasing & None \\
\hline Scarlet Tanager & $\mathbf{0 . 1 0}$ & -0.06 & Shifting & Down \\
\hline Veery & 0.05 & -0.04 & No trend & None \\
\hline Winter Wren & -0.04 & -0.14 & Contracting & Down \\
\hline Wood Thrush & -0.12 & -0.11 & Decreasing & None \\
\hline
\end{tabular}


CHAPTER 2: Evaluating Canada Warbler Environmental Correlates on a Central Appalachian Elevation Gradient in its Southern Breeding Distribution

\section{ABSTRACT}

Several songbird species have trailing edge populations throughout the central Appalachian Mountains, including the Canada Warbler (Cardellina canadensis), a species of conservation concern due to continual population declines. I assessed the environmental factors associated with the Canada Warbler in its southern breeding distribution to understand their space use and inform conservation efforts. Using detection/non-detection data from 840 point count surveys in the Monongahela National Forest, West Virginia in 2017 and 2018, I evaluated occupancy of Canada Warblers in a multi-species occupancy modelling framework that accounted for potential interactions between Black-throated Blue Warbler (Setophaga caerulescens) and Hermit Thrush (Catharus guttatus). I found that Canada Warblers were more likely to occur in mid-elevations, in areas with high Rhododendron (Rhododendron maximum) density, closer to riparian areas, and in northern hardwood forests. Canada Warblers were also positively associated with Black-throated Blue Warblers. Conservation actions for Canada Warblers in its southern breeding distribution should span across a range of elevations in northern hardwood forests. Additionally, protection of riparian areas, especially those with dense Rhododendron thickets, will likely benefit Canada Warblers in their Appalachian distribution. 


\section{INTRODUCTION}

Forests of the central Appalachian Mountains have high avian diversity and host several species of conservation concern, many of which are understory specialists associated with gapdynamics (Buckelew and Hall 1994, West Virginia Division of Natural Resources 2015). The Canada Warbler (Cardellina canadensis) is one forest gap specialist that has experienced rangewide declines of $2 \%$ annually on average since 1966 , amounting to a $63 \%$ total decline over the 50-year period (Sauer et al. 2017). As a result, it is listed as a species of conservation concern by Partners in Flight (Species Conservation Profiles n.d.), a species of management concern by the U.S Fish and Wildlife Service (U.S. Fish and Wildlife Service 2008), threatened in Canada (COSEWIC 2008), and is a "priority 1 species" in the West Virginia State Wildlife Action Plan (West Virginia Division of Natural Resources 2015). Forest maturation is thought to be a major driver of population declines, since many forests are reaching mid-successional stages that often have limited structure and open understories (Monongahela National Forest 2011, Oswalt and Smith 2014).

While the Canada Warbler has experienced declines in most its breeding range, the southern extent of its distribution has observed different trends. Populations in Pennsylvania have remained relatively stable since 1966, and West Virginia is the only state in all of the BBS regions that has observed a significant increase in Canada Warblers, of $2.81 \%$ annually on average (Sauer et al. 2017). This exception to range-wide declines may be indicative of unique forest characteristics in the southern Appalachians that provide optimal habitat. Understanding the biotic and abiotic factors that affect avian habitat selection and space use is essential for improving the success of management and conservation plans to ensure long-term population viability. 
As an understory specialist, Canada Warblers consistently occupy environments with high densities of shrubs and small stems (Sodhi and Paszkowski 1995, Chace et al. 2009, Ball et al. 2016). Canada Warblers nest on the forest floor, where high stem densities conceal nests and improve reproductive success (Goodnow and Reitsma 2011), while supporting higher Canada Warbler abundances (Hobson and Bayne 2000). Additionally, Canada Warblers that arrive earlier on their breeding grounds choose sites with greater understory stem density (Hallworth et al. 2008b), and territory size decreases with increasing shrub density (Flockhart et al. 2016). Smaller territories may either be a result of greater resource abundance within an area (Smith and Shugart 1987), or higher densities of Canada Warblers occupying the area (Both and Visser 2000).

A well-developed understory layer often forms in response to canopy openings that allow sunlight to reach the forest floor and promote regeneration. While Canada Warblers have historically benefited from understory development created by gap-dynamics in old-growth forests (Zlonis and Niemi 2014), they have also been observed in several other types of canopy openings, including wooded swamps and stream edges that limit canopy growth and create dense thickets (Swift et al. 1984, Hallworth et al. 2008a, Reitsma et al. 2008, Gross 2009, Ball et al. 2016). These riparian areas often form relatively large corridors with a complex understory and moist forest floor that Canada Warblers exploit for breeding (Hallworth et al. 2008b, Ball et al. 2016). In the Appalachian extent of their range, Canada Warblers are anecdotally known to prefer cool forest valleys with dense Rhododendron (Rhododendron maximum) thickets (Gross 2009). Wind and ice-throw in high elevation areas can also create canopy openings that Canada Warblers use in the northern Appalachian Mountains (Faccio 2003, Chace et al. 2009). Canada Warblers are opportunistic in this regard, historically occupying thickets resulting from the death 
of American Chestnut (Castanea dentata) (Brooks 1940), and may show similar responses to small openings formed by insect-induced mortality of Eastern Hemlock (Tsuga canadensis) and Ash (Fraxinus spp.) (Tingley et al. 2002).

Forest composition and successional stage also play a role in affecting Canada Warbler space use. The Canada Warbler occupies a variety of forest types during breeding, including deciduous forests (Machtans and Latour 2003, Ball et al. 2016, Hunt et al. 2017) and conifer stands (Grinde and Niemi 2016), but seems to prefer mixed conifer and deciduous stands (Sodhi and Paszkowski 1995, Hagan and Meehan 2002, Grinde and Niemi 2016). While Canada Warblers use many forest types, forest age may have a greater effect on occupancy. Canada Warblers frequently use young regenerating forests with dense understories (Weakland et al. 2002, Lambert and Faccio 2005, Becker et al. 2012), but as forests mature to mid-successional stages the canopy closes and the understory layer thins, causing local extinctions of Canada Warblers (Clebsch and Busing 1989, Lambert and Faccio 2005). However, as mid-successional forests continue to age, gap-dynamic processes begin to occur, where tree-falls create greater structural diversity in the understory (Clebsch and Busing 1989, Hart et al. 2015), thus improving habitat suitability for Canada Warblers (Zlonis and Niemi 2014). As a result, secondary succession causes forests to continually change in their suitability for Canada Warblers and other understory specialists even when forests are minimally disturbed (Holmes and Sherry 2001).

Since a majority of forests in eastern North America are in mid-successional mature stages, old-growth forests with gap dynamics are limited (Monongahela National Forest 2011, Oswalt and Smith 2014). One method to create greater structure and understory is through timber harvest, which can artificially mimic gap-dynamics by opening the canopy (Sheehan et al. 2014). 
Canada Warblers use harvested areas throughout their range to varying degrees. Several studies in New Hampshire, Maine, and West Virginia found higher abundances in recently harvested stands compared to less disturbed stands (Hagan et al. 1997, King and Degraaf 2000, Weakland et al. 2002, Hallworth et al. 2008a), where individuals colonized harvested areas 5 years after clearcutting and became common 15 years following the disturbance (DeGraaf and Yamasaki 2003). Canada Warblers begin to experience local extinctions from harvested areas approximately 20 years following management as forests mature (Lambert and Faccio 2005).

Although Canada Warblers occupy many harvest types, Becker et al. (2012) observed the highest abundances in light partial harvests (compared to clear-cuts and heavy partial harvests), which often mimic smaller natural openings such as tree-fall gaps and riparian areas where much of the canopy is retained. Higher abundances of Canada Warblers in these silvicultural treatments suggests that the species may prefer more intact areas with small scale disturbance and the retention of large canopy trees (Becker et al. 2012).

While Canada Warblers prefer harvested sites in some instances, other studies have found conflicting results. Grinde and Niemi (2016) found that the probability of local extinction was higher in recently harvested stands compared to mature forests (> 75 years old) with a welldeveloped understory, while several other studies found higher abundances in federally designated wilderness compared to post-harvest stands (Drapeau et al. 2000, Zlonis and Niemi 2014, Ball et al. 2016, Hunt et al. 2017). Conflicting results on the use of harvested areas indicates that timber management may be context specific, where the use of harvested stands is dependent upon the harvest intensity and the availability of old-age forests with gap-dynamics.

In the southern extent of its range, it is evident that Canada Warblers occupy relatively high elevations due to their restricted distribution, but no studies have directly evaluated their 
elevational distribution. In West Virginia, the Canada Warbler regularly nests throughout the Monongahela National Forest in areas above 640 meters, forming a somewhat isolated breeding range in this region (Buckelew and Hall 1994). Recent management guidelines suggest that Canada Warblers typically occupy areas above 850 meters in the Appalachian region (Harding et al. 2017), while some have also suggested that Canada Warblers may be limited at their high elevation extent where forests are dominated by spruce and lack deciduous vegetation (Sabo 1980, Ball et al. 2016). Additionally, the narrow range of Canada Warblers in their southern extent is of concern given expected upward shifts in avian distributions as a result of climate change, which may further restrict their breeding range in montane areas (Sekercioglu et al. 2008, Dirnböck et al. 2010).

While understory structure influences Canada Warbler space use, the availability of perch trees in the mid-story may also affect occupancy. These perching sites are important for singing males in attracting females and for flycatching and hawking insects in flight, a foraging behavior that is used frequently by the species (Sodhi and Paszkowski 1995). Hallworth et al. (2008a) observed higher occupancy and male pairing success in forests with more perch trees. Canopy openings often clear mid-story vegetation and create perch trees with greater visibility and where songs can be heard at greater distances, thus aiding in attracting a female (Hallworth et al. $2008 b)$.

In addition to environmental factors, the role of heterospecific interactions should also be considered as a factor shaping the spatial distribution of Canada Warblers (Gotelli et al. 2010, Ricklefs 2013). Interactions can affect bird occurrence both positively (Forsman et al. 2002) and negatively through direct encounters and indirect competition for resources (Gotelli et al. 2010). In Minnesota, Grinde and Niemi (2016) found that Canada Warbler occupancy was negatively 
associated with the presence of the Black-and-White Warbler (Mniotilta varia) and Hermit Thrush (Catharus guttatus), presumably due to competition for nest sites. Within the mountains of West Virginia, some songbird species share similar preferences for a dense shrub layer: Black-throated Blue Warbler (Setophaga caerulescens) in lower elevation deciduous forests (Holway 1991), and the Hermit Thrush in high elevation mixed and conifer forests (Martin and Roper 1988). Canada Warblers on breeding grounds often exhibit aggression and territoriality towards other birds, and these encounters may limit their use of otherwise suitable habitat (Cody 1981, Grinde and Niemi 2016). Although it is difficult to directly attribute heterospecific associations to mechanisms of competition or mutualism, previous findings warrant further investigation into the limiting factors of Canada Warbler occupancy.

Only two studies have examined Canada Warblers in the southern portion of its range, and both investigated their habitat use in harvested areas (Weakland et al. 2002, Becker et al. 2012). Little is known about specific environmental correlates of the Canada Warbler in less disturbed forest settings throughout the central Appalachians. Gaining a better understanding of the environmental factors associated with Canada Warblers will help guide management and conservation actions for this species, and potentially for other declining understory specialists. Assessing Canada Warbler occupancy in the Central Appalachian Mountains may also shed light on the factors that are driving regional population growth amidst range-wide declines. My objective is to determine the environmental correlates associated with Canada Warbler occupancy across an elevation gradient on its breeding grounds in the Monongahela National Forest, West Virginia. I predict that Canada Warbler occupancy will be positively related to shrub and Rhododendron stem density, proximity to riparian areas, and suppressed tree density (to act as perch sites). I also predict that Canada Warbler occupancy will be negatively related to 
the density of overstory trees since Canada Warblers are dependent on canopy gaps and openings. I hypothesize that Canada Warblers will occur most frequently at mid and high elevations (> 850 meters) where conditions are most similar to the core of their breeding range. Furthermore, I predict that Canada Warbler occupancy will be higher in young harvest stands (019 years post-harvest) compared to old harvest stands (20 to 40 years post-harvest) and mature and old-age forests. Finally, I predict that Canada Warbler occupancy will be negatively associated with the occupancy of Black-throated Blue Warblers and Hermit Thrush due to competition for nest sites and resources

\section{STUDY AREA}

Sampling occurred throughout public lands within the Monongahela National Forest (MNF), West Virginia (Figure 1.2). This area has been federally protected since 1920 and encompasses 688,000 hectares, 371,000 of which are federally owned (Monongahela National Forest 2018a). Eight federally designated wilderness areas are located in the national forest, the largest being the Cranberry Wilderness (19,350 hectares), and the smallest being the Big Draft

Wilderness (2,081 hectares). The MNF contains a large section of the central Appalachian Mountain range and has a steep elevation gradient ranging from 300 meters to West Virginia's highest point, Spruce Knob, at 1482 meters. (Monongahela National Forest 2018a). The mountainous terrain in the MNF affects local climate with average temperatures 2-4 degrees Celsius lower than other parts of West Virginia and the highest annual rainfall in the state, creating an altitudinal gradient in forest conditions (Buckelew and Hall 1994, Nowacki et al. 2009). Vegetative conditions also vary longitudinally due to the orographic effect. While the western part of the MNF receives over 150 centimeters of annual rainfall that produces moist 
forest conditions, the eastern portion of the MNF receives half as much rainfall, leading to a greater proportion of dry oak-pine forests (Monongahela National Forest 2011).

A majority of MNF land is composed of 70-100-year-old stands with a high regional tree diversity (Monongahela National Forest 2011). Forests in the MNF can be categorized into four major types that are distributed along the elevation gradient: mixed mesophytic, oak/pine, northern hardwood, and spruce/hemlock (DeMeo 1999). In low elevations, typically below 850 meters, oak-pine and mixed mesophytic forests are dominant, making up 39\% and 33\% of public land, respectively (Monongahela National Forest 2011). Mixed mesophytic forests are characterized by species that prefer moderately moist soils, including Tulip Poplar (Liriodendron tulipifera), Basswood (Tilia americana), and Hickory (Carya spp.). As elevation increases, forests transition into northern hardwood forests, characterized by Yellow Birch (Betula alleghaniensis), Beech (Fagus grandifolia), and Sugar Maple (Acer saccharum), which make up 18\% of public land (Monongahela National Forest 2011). Remnant boreal forests occupy many high elevation summits, often above 1150 meters and are characterized by thick Red Spruce (Picea rubens) stands that make up 6\% of public land (Cogbill and White 1991, Monongahela National Forest 2011). Eastern Hemlock contributes about 10\% of the basal area within MNF (Morin et al. 2011) and Rhododendron is common in the understory where it often forms dense thickets (Anderson 2008). The Monongahela Forest Management Plan sets aside 31\% of land specifically for wildlife habitat, $22 \%$ for forest age class management, $17 \%$ for spruce restoration, and 22\% for backcountry areas (Monongahela National Forest 2011). Of the 371,000 hectares of public land, the MNF manages 600-800 hectares per year through commercial timber harvest and thins approximately 1600 hectares per year (Monongahela National Forest 2011). 


\section{METHODS}

\section{Point count protocols}

I conducted 10-minute unlimited radius stationary point count surveys to evaluate Canada Warbler space use throughout the MNF in 2017 and 2018. Survey protocols were originally devised by DeMeo (1999), which have consistently been used to sample birds within the MNF for over two decades (Johnson and Wood 2017). I continued using historic protocols so data would be compatible with previous data collected within the MNF (Chapter 1). Point counts began May 18 and continued to July 15 in both years. I recorded all individuals seen or heard during the 10-minute period. Each 10-minute point count was further divided into three time intervals: 0-3 $\min , \geq 3-5 \mathrm{~min}, \geq 5-10 \mathrm{~min}$ (Ralph et al. 1995). Individuals were only recorded the first time they were observed during the 10-minute survey. With this removal sampling method, detection probability can be estimated from a single visit per year (Farnsworth et al. 2002, Rota et al. 2009). For each individual detected, I recorded the detection distance ( $<50 \mathrm{~m}$ or $\geq 50 \mathrm{~m})$, time interval, detection type (song, call, visual, flyover, drumming), and age/sex (male, female, adult, juvenile, unknown). Surveys began within 15 minutes of sunrise and continued until no later than 10:30 AM. Surveys were not conducted on days with rain, heavy fog, or high wind, following the general guidelines outlined by Ralph et al. (1995). Each point was sampled once per year, consistent with historic protocols (DeMeo 1999, Johnson and Wood 2017).

\section{Selection of point count sites}

To sample across the entire elevation gradient, I stratified points into three classes: less than $853 \mathrm{~m}$, between $853 \mathrm{~m}$ and $1158 \mathrm{~m}$, and above $1158 \mathrm{~m}$ (Figure 2.1). I chose the $853 \mathrm{~m}$ break point for the strata because this is the suggested lower limit for Canada Warblers in the Appalachians (Harding et al. 2017). The $1158 \mathrm{~m}$ break point was chosen because it represents 
the general ecotone shift from northern hardwoods to conifers and creates approximately equal elevation ranges for each strata (Cogbill and White 1991). In 2018, I also included 90 points ( $23 \%$ of all point counts) within harvested stands that had some residual trees to ensure that managed areas were properly represented in sampling.

Within each stratum, point counts were conducted at a mix of historic locations and newly established sites. I selected 130 historic points originally created by Demeo (1999) and the U.S. Forest Service (Johnson and Wood 2017) that had been surveyed for 10 or more years. Locations of long-term point counts were established by stratifying by the four major forest types (dry oaks, mixed mesophytic, northern hardwoods, red spruce) and then randomly selecting sites in each strata (more details in DeMeo 1999). Historic points were placed on transects of 10-15 points and separated by 250 meters (DeMeo 1999).

I also established new point count transects in 2017 to ensure equal sampling among the three elevation strata. Roads and trails were combined into a single linear shapefile, and random points were generated along this feature in ArcMap 10.3 (ESRI 2018). Only roads classified as S14000 or greater by the U.S. Census Bureau (typically gravel roads) were used in the random point generation (U.S. Census Bureau 2018). These randomly generated points indicated the starting point of each transect. Transects created from road points began 100 meters off road in a random direction (e.g. left, right), and subsequent points were placed perpendicular to the road (Figure 1.4 A). Points generated along trails began 100 meters from the nearest trailhead and continued along the trail (Figure 1.4 B). Each transect contained 10-12 points separated by a minimum of 250 meters. Randomly generated transect locations were omitted from surveys if the transect could not be completely contained in public land. The general order in which sites were 
surveyed was determined by random number assignment to transects, while being flexible to logistics and travel constraints.

To select harvest sites, I stratified harvest sale areas by elevation $(\leq 853 \mathrm{~m}, 853-1158 \mathrm{~m}$, and $>1158 \mathrm{~m})$ and harvest age $(\leq 10$ years, $11-20$ years, and $>20$ years). Of the 90 additional harvest points sampled in 2018, I revisited 22 historic points established in 1993-1996 that were harvested in the 1980's (Duguay et al. 2001). To supplement these historic sites and ensure sampling across elevation and harvest age strata, I also established several new harvest points. In each elevation and harvest age strata, I randomly selected harvested stands (Monongahela National Forest 2017). I then digitized the extent of each harvest using historic aerial orthophotos from 1996, 2002, 2007, 2009, 2011, 2014, and 2016 (U.S. Geological Survey 1996, The WV Statewide Addressing and Mapping Board 2004, USDA-FSA-APFO Aerial Photography Field Office 2007-2016). Surveyed stands were mostly in even-aged silvicultural treatments that had some seed-tree or reserve trees retained, with an average stand size of 11 hectares. Even-aged cutting is the predominant silvicultural method used in the MNF, making up approximately $75 \%$ of all managed area (Monongahela National Forest 2011). Additionally, uneven-aged stands were difficult to detect using aerial imagery and harvest sale information was limited. Within each digitized stand, I placed points 250 meters apart and oriented them to maximize the number of points that could be placed in each harvest area, with no constraints on distance to harvest edge (Figure 2.2).

\section{Occupancy covariates}

At each point count site, I measured several biotic and abiotic variables thought to affect Canada Warbler occupancy (Table 2.1). I measured trees with a variable-radius plot centered on the point count, using an angle gauge to determine which trees were in the plot. All trees $>2.5$ 
$\mathrm{cm}$ in diameter were included in the plot. For each tree within the variable radius plot, I recorded the species, DBH, and canopy position. Canopy position is a categorical classification that separates trees into six classes (suppressed, intermediate, codominant, dominant, legacy and open growth), and is used to estimate vertical forest structure (Jennings et al. 1999; Figure 2.3).

I surveyed shrubs using a five-meter radius plot consistent with DeMeo (1999) protocols. Within each plot, I counted all stems taller than 0.5 meters for each species present. All strictly shrub species (e.g. Rhododendron) were counted regardless of stem diameter, while saplings were only counted if they had a diameter less than $2.5 \mathrm{~cm}$ (DeMeo 1999). Vegetation was surveyed within three days of completing the avian point count. For all sites with no major change, I surveyed vegetation only once in 2017 or 2018 (McDermott et al. 2011).

I obtained several abiotic variables from remotely sensed spatial layers in ArcMap 10.3 (ESRI 2018). To determine the general forest type for each location, I used a spatial layer of forest stands within the MNF that designates stands into four forest classes: mixed mesophytic, oak/pine, northern hardwoods, and spruce (Monongahela National Forest 2018b). I determined elevation for each location using a 7.5 minute 30-meter DEM (U.S. Geological Survey 1979). To determine the minimum distance from each point count to a wetland feature, I combined streams from the National Hydrography Dataset (USGS 2018) with areas classified as woody wetland and emergent herbaceous wetland from the National Land Cover Database (NLCD) of 2011 (Homer et al. 2015). I also categorized points into 4 forest age classes: young harvest (0-19 years), old harvest (20-40 years), mature forest (40-120 years), and old-age forest (> 120 years) (Monongahela National Forest 2018b). I split harvest at 20 years because past studies suggest that Canada Warblers begin to go locally extinct approximately 20 years following harvest (Lambert and Faccio 2005). Before including covariates in occupancy models I calculated 
correlation coefficients for all variable pairs to eliminate highly correlated predictor variables. Since the absolute value of the correlation coefficient for all variable pairs was $<0.5 \mathrm{I}$ did not eliminate any variables from modelling (Lewis et al. 2019).

\section{Detection covariates}

I measured several factors thought to influence detection probability at each point count site (Table 2.1). I recorded the date and hours since sunrise at the start of each survey. During the 10-minute count, I measured the maximum wind speed (mph) with a Kestrel 1000 anemometer, and I recorded sky condition, adapted from the U.S. Weather Bureau and BBS protocols (U.S. Geological Survey 1998). Surveys were not conducted during heavy rain, fog, or wind (sky code $>3)$.

\section{Statistical analyses}

I incorporated Canada Warbler detection/non-detection data from unlimited radius point count surveys into a multi-species occupancy modelling framework developed by Rota et al. (2016). This framework allows us to model the factors that influence occupancy of multiple species while simultaneously accounting for imperfect detection. Here I jointly modeled Canada Warbler, Black-throated Blue Warbler, and Hermit Thrush. To model detection, I separated detection/non-detection data into the three point count time intervals to act as replicate surveys. I modified the detection model in Rota et al. (2016) to account for unequal interval lengths using techniques similar to logistic exposure models (Shaffer 2004). Multi-species occupancy models can include up to $2^{S}-1$ linear models (where $S$ is the number of species) that account for increasingly higher-order species interactions (Rota et al. 2016). First-order linear models affect the probability of each species occurring when all others are absent, second-order linear models affect the probability of two species occurring together, and third-order linear models affect the 
probability of all three species occurring together. Third-order linear models were fixed at zero for this analysis.

To model multi-species occupancy, I fit five models, each increasing in complexity. I first fit a detection-only model with all detection covariates while assuming constant occupancy and independence between species. I modeled detection probability for each species as a function of ordinal day, hours after sunrise, wind speed, and sky code (Appendix A). I included linear and quadratic effects of ordinal day and hours after sunrise. To create a more parsimonious detection model, I then removed covariates with slope coefficients that were close to zero, defined as a slope coefficient with $90 \%$ confidence intervals that overlapped 0 . I compared the two models using AIC, carrying the detection covariates from the most parsimonious model to the next step (Burnham and Anderson 2004; Table 2.2, Appendix A).

Next, using the most parsimonious detection model, I modeled $1^{\text {st }}$ order occupancy as a function of all covariates while assuming pairwise independence between all species $\left(2^{\text {nd }}-\right.$ order linear models were fixed at 0 ). I selected 12 covariates thought to influence occupancy (Table 2.1) to create a global model (Appendix B). I modeled elevation as a quadratic effect for Canada Warbler and Black-throated Blue Warbler and a linear effect for Hermit Thrush. I log transformed distance to riparian and rhododendron density covariates to represent a non-linear pseudo-threshold effect. I then removed $1^{\text {st }}$-order occupancy covariates with slope coefficients that had $90 \%$ confidence intervals that overlapped 0 (Table 2.2, Appendix B) and compared models using AIC. Finally, using the most parsimonious occupancy model, I then fit a model assuming constant pairwise dependence between all species by fixing second-order models at 1 (Table 2.2). For categorical covariates (i.e. forest type, forest age), contrasts were performed to assess differences in occupancy between each level. 


\section{RESULTS}

I conducted a total of 840 point count surveys throughout the MNF. In 2017, I completed 380 point counts. In 2018, I surveyed all 2017 points again (omitting 10 points in pipeline construction), along with the 90 additional timber harvest points for a total of 460 points. I detected Canada Warblers at $7 \%$ of all surveys, Black-throated Blue Warblers at $37 \%$ of all surveys, and Hermit Thrush at 36\% of all surveys (Table 2.3). Canada Warblers were detected between $592 \mathrm{~m}$ and $1282 \mathrm{~m}$ in elevation, a range of 690 meters along the 894 meter sampling gradient. The best fit model included detection covariates, $1^{\text {st }}$-order occupancy covariates, and constant $2^{\text {nd }}$-order covariates (Table 2.2; Appendix C). Since there is little model selection uncertainty between the two top models (Top model weight $=0.95, \Delta \mathrm{AIC}>2$ ), I report results from the top model only (Table 2.2; Appendix C).

\section{First-order occupancy effects}

Canada Warbler occupancy exhibited a quadratic relationship with elevation, with greatest occupancy probability at an elevation 897 meters (Figure 2.4 A; Log odds ratios in Appendix C). They were more likely to occur closer to riparian areas and in areas with high Rhododendron stem density (Figure 2.4 B-C; Appendix C). Canada Warbler occupancy was significantly lower in oak/pine forests compared to the other three forest types, and occupancy was higher in northern hardwood forests compared to mixed mesophytic forests (Figure 2.4 D; Appendix C). Occupancy did not differ between forest age classes. Overstory and suppressed tree density, percent deciduous trees, and shrub stem density were not strong predictors of occupancy and were eliminated in the model selection procedure (Appendix B).

Black-throated Blue Warbler occupancy was higher in 2018 compared to 2017 (Figure 2.5 A; Log odds ratios in Appendix C). There was a quadratic relationship with elevation, with 
greatest occupancy at an elevation of 989 meters (Figure 2.5 B; Appendix C). Black-throated Blue Warblers were more likely to occur closer to streams and in areas with high shrub stem density, Rhododendron stem density, and suppressed tree density, and were less likely to occur in areas with high overstory tree density (Figure 2.5 C-G; Appendix C).Their occupancy was significantly higher in northern hardwood, mixed mesophytic, and spruce forests compared to oak/pine forests (Figure $2.5 \mathrm{H}$; Appendix C).

Hermit Thrush occupancy was positively associated with elevation, percent conifer trees, and overstory tree density (Figure 2.6 A-C; log odds ratios in Appendix C). Hermit Thrush were most likely to occur in old-age forests (> 120 years) and least likely to occur in young harvests (0-19 years) (Figure 2.6 D; Appendix C). Occupancy did not differ between mature forest (40120 years) and old harvests (20-40 years) (Figure 2.6 D; Appendix C). Occupancy was significantly higher in mixed mesophytic, northern hardwood, and oak/pine forests compared to spruce forests (Figure 2.6 E; Appendix C).

Second-order occupancy effects

After accounting for $1^{\text {st-}}$-order effects, Canada Warblers and Black-throated Blue Warblers were positively related to one another, with Canada Warbler occupancy higher when Black-throated Blue Warblers were also present at a location (Figure 2.7; Appendix C). Hermit Thrush were not associated with Canada Warblers or Black-throated Blue Warblers (Appendix C).

\section{Detection probability}

Canada Warbler detection probability exhibited a quadratic effect with day of year, with greatest detection probability at approximately June 13 (Figure 2.8 A; Appendix C). Canada Warblers were more likely to be detected later in the morning (Figure $2.8 \mathrm{~B}$; Appendix C). Wind 
speed and sky condition were not strongly associated with Canada Warbler detection (Appendix C). Black-throated Blue Warblers were more likely to be detected earlier in the morning and when wind speed was low (Figure 2.8 C-D; Appendix C). Hermit Thrush detection was not strongly associated with any covariates (Appendix C).

\section{DISCUSSION}

This is the first study to evaluate multi-species occupancy of the Canada Warbler in the southern extent of their breeding range where several novel relationships were observed.

Evaluating space use along an elevation gradient offers new insight into how elevation may limit Canada Warblers in the central Appalachian Mountains. Although Canada Warblers were detected along most of the sampled elevation gradient, there was a quadratic relationship between Canada Warbler occupancy and elevation. Previous management guidelines for Canada Warblers suggest managing for this species above 850 meters in the Appalachians (Harding et al. 2017). However, we found Canada Warblers had the highest occupancy probability at $897 \mathrm{~m}$ with occupancy declining upslope and downslope from this mid-point (Figure 2.4). This shows that the elevational distribution of Canada Warblers is more complex than a low elevation cutoff that is frequently suggested for Appalachian birds (Buckelew and Hall 1994, Graves 1997, Harding et al. 2017), and managing solely above this cutoff would ignore a substantial portion of the Canada Warbler population in the MNF. The Canada Warbler likely occupies these midelevations most frequently in West Virginia because the environmental conditions are most similar to conditions in the core of its range, with a mix of conifer and deciduous vegetation (Sodhi and Paszkowski 1995, Grinde and Niemi 2016). Low Canada Warbler occupancy in high elevation areas suggests that they may be avoiding mountaintop patches which typically have limited vegetative structure and diversity (Sabo 1980). Additionally, while climate change 
projections predict local extinctions of montane species (Sekercioglu et al. 2008), our findings suggest that Canada Warblers are not currently limited by elevation and there is low short-term risk of climate-induced local extinction.

Varying intensities of timber management have been demonstrated to both increase (Hagan et al. 1997, King and Degraaf 2000, Weakland et al. 2002, Hallworth et al. 2008a, Becker et al. 2012) and decrease (Drapeau et al. 2000, Zlonis and Niemi 2014, Ball et al. 2016, Hunt et al. 2017) Canada Warbler occupancy. Our results show that Canada Warblers occurred in harvested and unharvested stands at a similar frequency. Past studies found that Canada Warbler use of managed areas is lower in intense even-aged cuts (Becker et al. 2012), which is the primary silvicultural treatment used in the MNF (Monongahela National Forest 2011). Canada Warblers would likely benefit more from uneven-aged partial harvest treatments that retain greater canopy cover (Becker et al. 2012, Grinde and Niemi 2016). Despite a relatively small sample size for young harvest (56 point counts) and old harvest (59 point counts) that may have limited inference, harvested stands were over-sampled relative to their availability in the MNF (Monongahela National Forest 2011).

The multi-species occupancy model made it possible to account for potential interactions between species, which can affect bird distributions and occupancy. After accounting for other environmental factors, Canada Warblers exhibited a positive association with Black-throated Blue Warblers. This positive effect is contrary to what was expected, given overlapping habitat preferences that may result in competition for resources (Sabo 1980). A possible explanation may be that the two species are using different niches at a fine scale and avoiding direct competition (Morrison 1982, Cody 1985, Marini and Cavalcanti 1993). Alternatively, the positive relationship between these species may be acting as a proxy for other un-modeled 
environmental variables, or could indicate a mutualistic interaction occurring. Heterospecific attraction has been observed between several bird species, where one species uses the presence of another species as a mechanism to locate high quality habitat and reduce search effort (Forsman et al. 2002, 2007, Mönkkönen and Forsman 2002). This behavior has been observed between migrant birds, where later arriving species use cues from a species that arrives earlier (Szymkowiak et al. 2017). In this case, Canada Warblers may be utilizing a similar mechanism with Black-throated Blue Warblers, by using social cues as an indicator of suitable habitat. Since Canada Warblers arrive on the breeding grounds later than most migrants and have a short breeding season (Francis and Cooke 1986, Wilson et al. 2000), the use of heterospecific attraction could reduce the costs of finding a high quality breeding site which may improve reproductive success (Mönkkönen and Forsman 2002). While there are no previous observations of heterospecific attraction in Canada Warblers, Hunt et al. (2017) observed a similar process of conspecific attraction. Canada Warblers tend to cluster together, likely using conspecific social cues to locate suitable habitat (Hunt et al. 2017). The positive relationship between these two species highlights the potential for species interactions to impact space use of Canada Warbler and warrants further investigation into the possible mechanisms that are driving this relationship. Canada Warbler occupancy was positively associated with Rhododendron stem density (Figure 2.4 B), which has been anecdotally reported as a favored shrub (Gross 2009, Wilson et al. 2013), but this is the first study to quantitatively support this relationship. Rhododendron is likely selected by Canada Warblers in the central Appalachians because of the thick tangles it often forms, which may provide an abundance of sites that conceal nests and reduce predation on eggs and young (Gates and Giffen 1991, Gates and McKearnan 2003). Canada Warblers may also occupy these areas because Rhododendron thickets help maintain an open mid-story layer 
by limiting sapling growth (Clinton et al. 1994, Rivers et al. 1999), which is thought to be important for singing males in attracting mates (Hagan and Meehan 2002, Hallworth et al. 2008b). Finally, Canada Warblers may occupy areas with Rhododendron because these shrubs provide an adequate understory layer for a longer time compared to saplings that undergo rapid forest succession. Rhododendron is a relatively long-lived shrub that can persist in shaded understories, thus providing suitable habitat even as forests mature and canopies close (Anderson 2008). These unique characteristics of Rhododendron may be a contributor to the increasing populations observed in West Virginia (Sauer et al. 2017).

While Canada Warblers were positively associated with Rhododendron density, I found no association with overall shrub stem density, a feature that Canada Warblers are typically associated with (Sodhi and Paszkowski 1995, Chace et al. 2009, Ball et al. 2016). Throughout the Appalachians, selection of Rhododendron may limit the Canada Warbler's reliance on other shrubs (Rivers et al. 1999), or may be a consequence of the difficulty in measuring spatial variation of the understory.

Canada Warblers were more likely to occur close to streams and wetlands, which is consistent with several other studies (Swift et al. 1984, Hallworth et al. 2008a, Reitsma et al. 2008, Gross 2009, Ball et al. 2016). Streams and wetlands provide canopy openings that promote the development of understory shrubs and saplings while creating a moist forest floor required for nesting. In addition to riparian areas directly improving environmental conditions for Canada Warblers, this association may also be acting as a proxy for high understory density which was difficult to directly measure.

Canada Warbler occupancy also varied between forest types, with a general avoidance of oak/pine forests presumably because these sites tended to be dry with a rocky substrate. 
Consistent with past studies (Reitsma, L. et al. 2009, Grinde and Niemi 2016, Harding et al. 2017), I found that Canada Warblers use a variety of forest types if the necessary micro-habitat features are available, with highest occupancy in northern hardwood forest.

Gaining a better understanding of the environmental factors that affect space use of birds can improve our success of conservation and management plans for species of concern. My findings provide new insight into the factors that affect habitat selection of Canada Warblers in their trailing edge distribution of the central Appalachians. I found that Canada Warblers tended to occur lower on the elevation gradient than previously described, so conservation actions should span across the entire elevation gradient in northern hardwood forests to effectively manage for the species. Continued protection of riparian corridors (Naiman et al. 1993, Monongahela National Forest 2011) will likely benefit Canada Warblers as forests mature, especially those with well-established Rhododendron thickets. I discovered several unique relationships of an understory specialist species of conservation concern, which will aid in the conservation of this species guild for trailing edge populations throughout the Appalachian Mountains. 


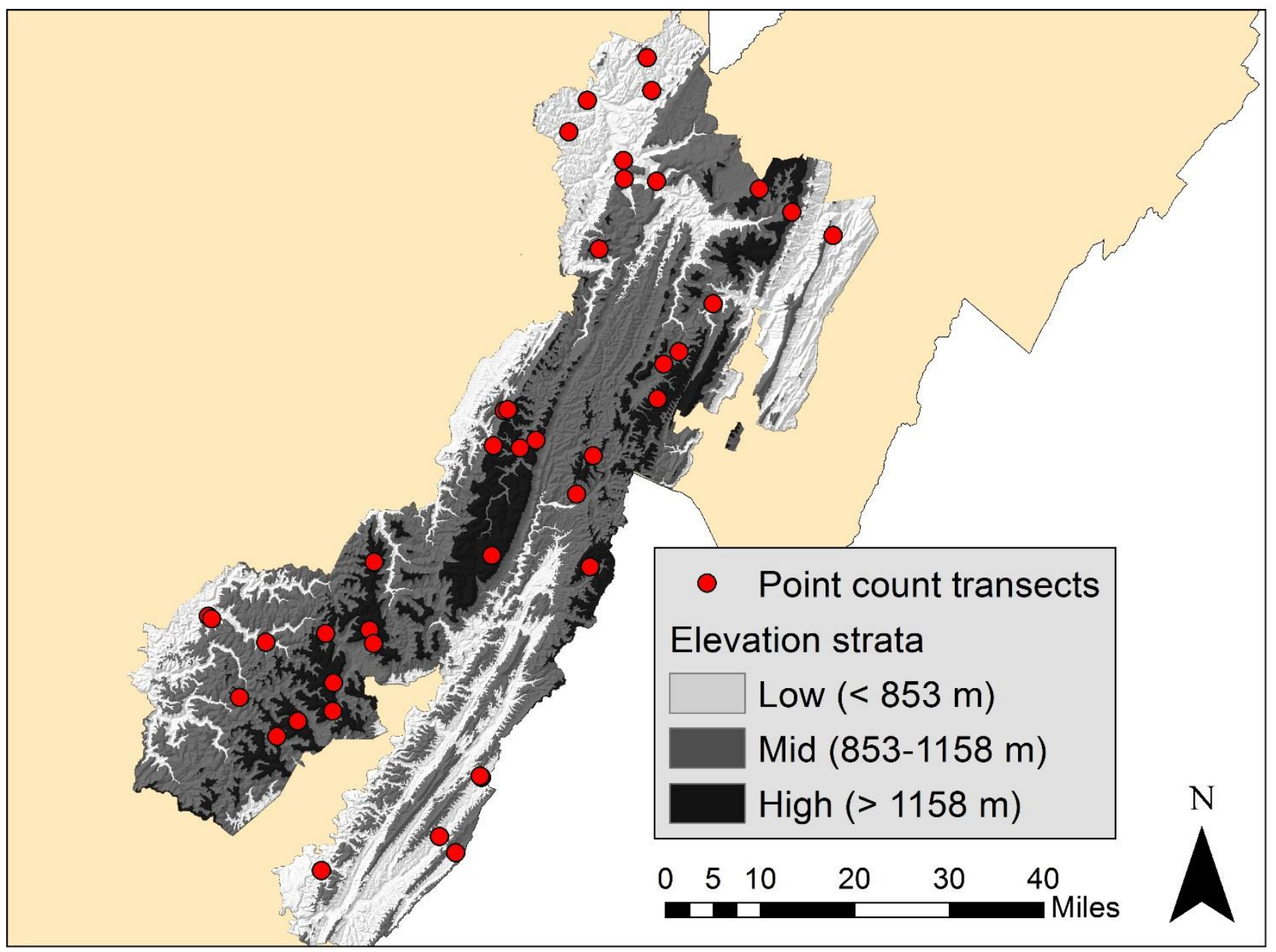

Figure 2.1. Locations of point count transects in the Monongahela National Forest, West Virginia, 2017-2018. I stratified points across the three elevation zones. Each transect consists of 10-15 point count sites where detection/non-detection sampling occurred for Canada Warbler (Cardellina canadensis), Black-throated Blue Warbler (Setophaga caerulescens), and Hermit Thrush (Catharus guttatus). 


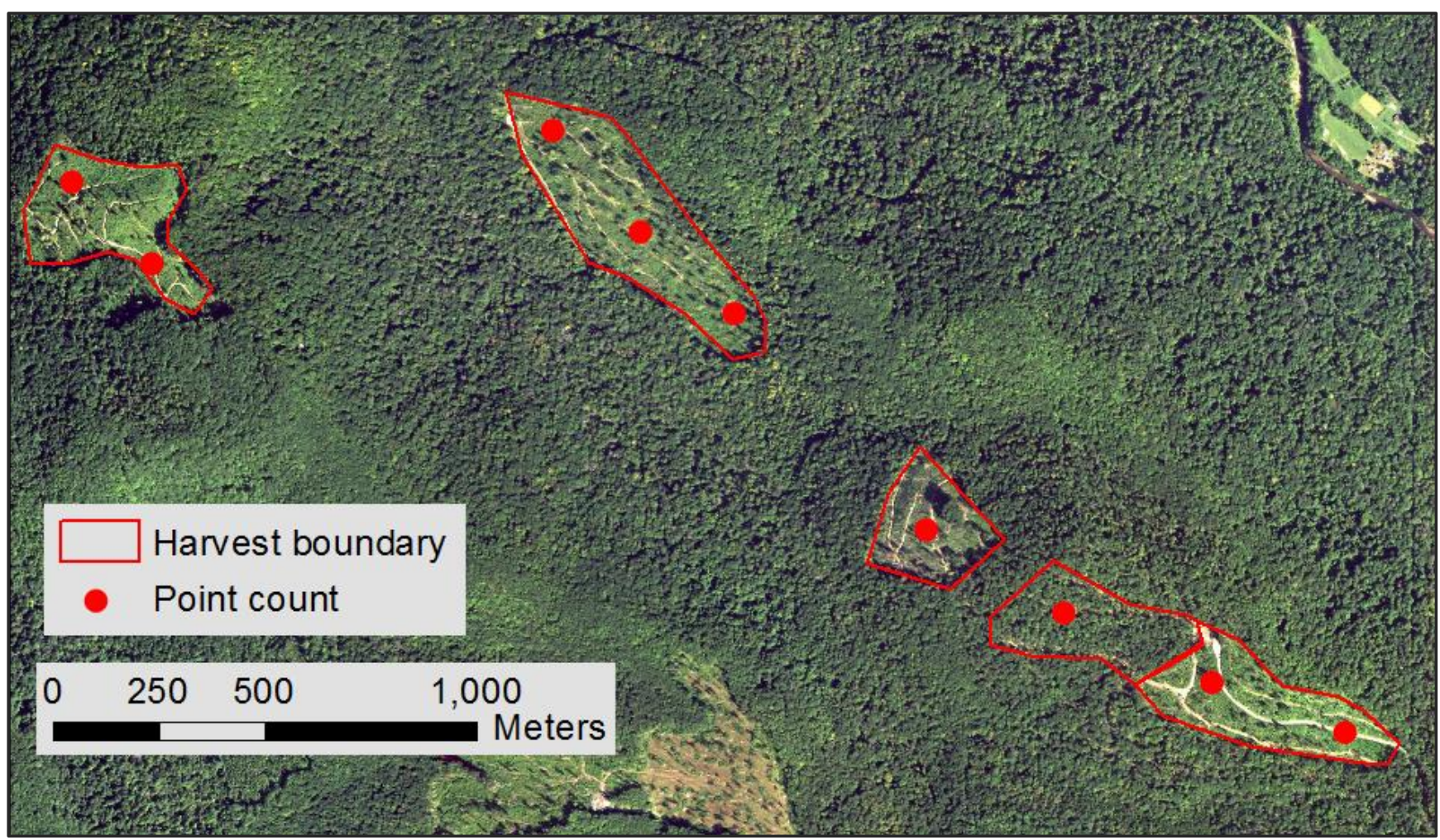

Figure 2.2. Placement of point count sites in harvested stands in the Monongahela National Forest, West Virginia, to assess occupancy of Canada Warbler (Cardellina canadensis), Black-throated Blue Warbler (Setophaga caerulescens), and Hermit Thrush (Catharus guttatus). Harvest sale areas were randomly selected among 3 elevation strata $(<850 \mathrm{~m}, 850$ $1150 \mathrm{~m},>1150 \mathrm{~m})$ and 3 age classes $(<10 \mathrm{yr}, 10-20 \mathrm{yr},>20 \mathrm{yr})$, and stands that retained some residual trees were delineated using historic aerial imagery. Points were spaced at least $250 \mathrm{~m}$ apart. In the summer of 2018, 90 point count sites were surveyed in harvested stands. 


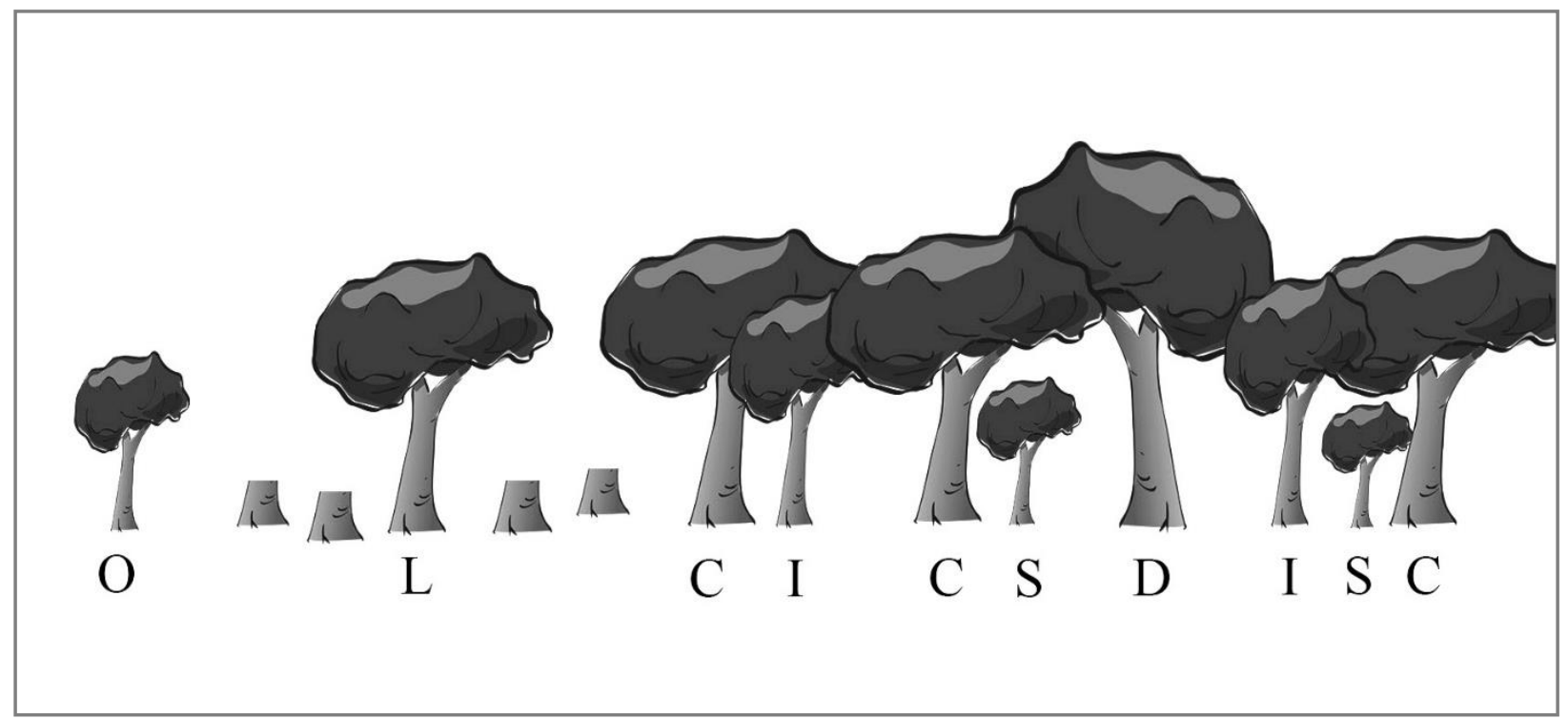

Figure 2.3. The canopy position classification system adapted from Jennings et al. (1999) used to sample vertical diversity of trees at each point count site in the Monongahela National Forest, West Virginia, 2017-2018.

Codominant trees (C) form the main forest canopy. Dominant trees (D) have their crown above the main canopy formed by codominant trees. Intermediate trees (I) are shorter than codominant trees but still receive some direct sunlight. Suppressed trees (S) are well-below the canopy and receive little or no direct sunlight. Open growth trees $(\mathrm{O})$ are found in unforested areas that have broken canopy. Legacy trees $(\mathrm{L})$ are uncut dominant/codominant trees in timber harvests where the canopy layer is broken. 
A

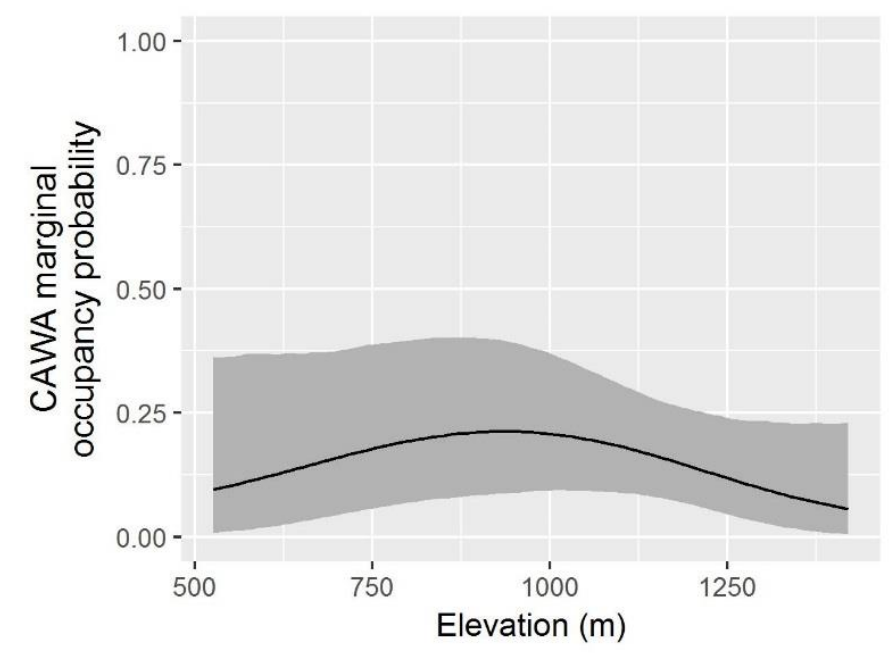

C

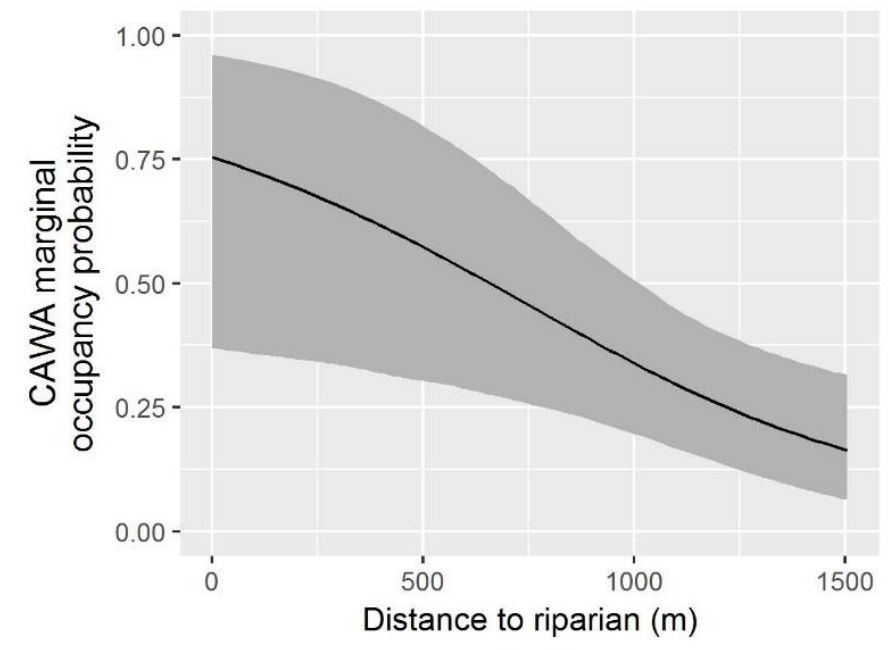

B

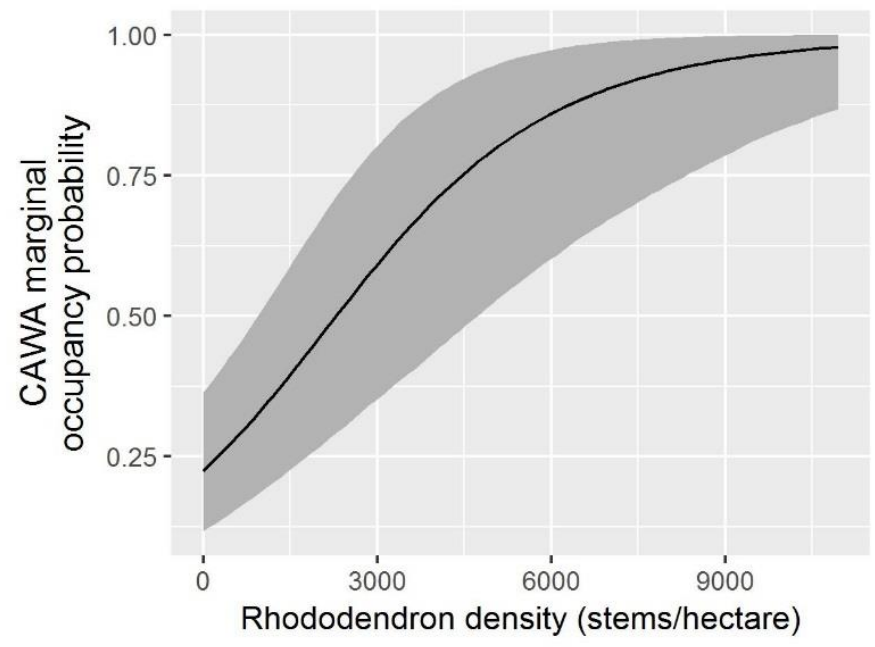

D

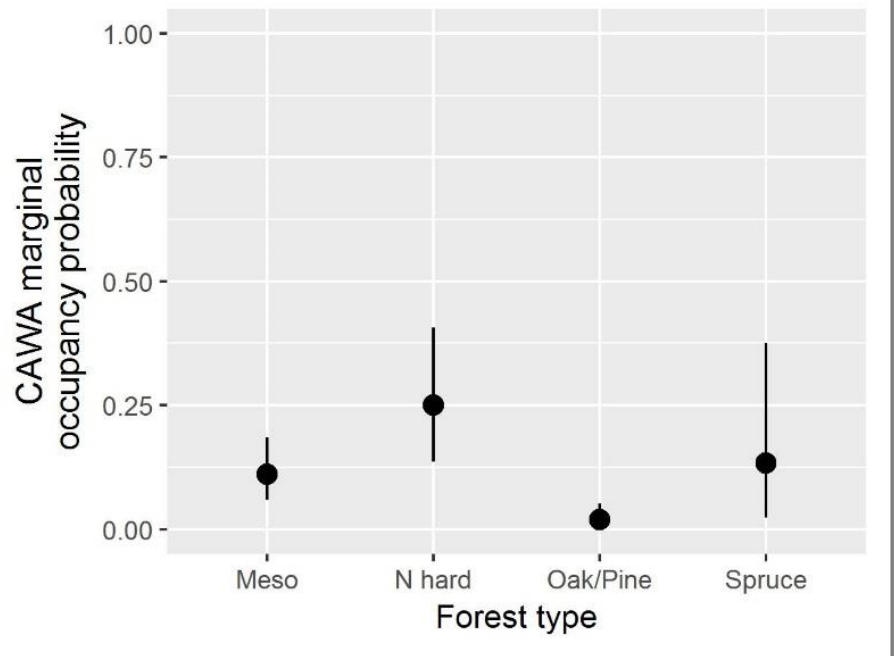

Figure 2.4. Marginal occupancy probability of Canada Warbler (Cardellina canadensis) in the Monongahela National Forest, West Virginia, $2017-2018$ obtained from detection/non-detection data at 840 unlimited radius point count surveys. Black lines/dots represent the point estimate, and gray areas/error bars represent the $95 \%$ confidence interval. Elevation was modeled with a quadratic effect, and Rhododendron density and distance to riparian were modeled with pseudo-threshold effects. Forest types are mixed mesophytic, northern hardwood, oak/pine, and spruce. For each covariate of interest, all other continuous covariates were held at their mean, and forest type was held at northern hardwood. 


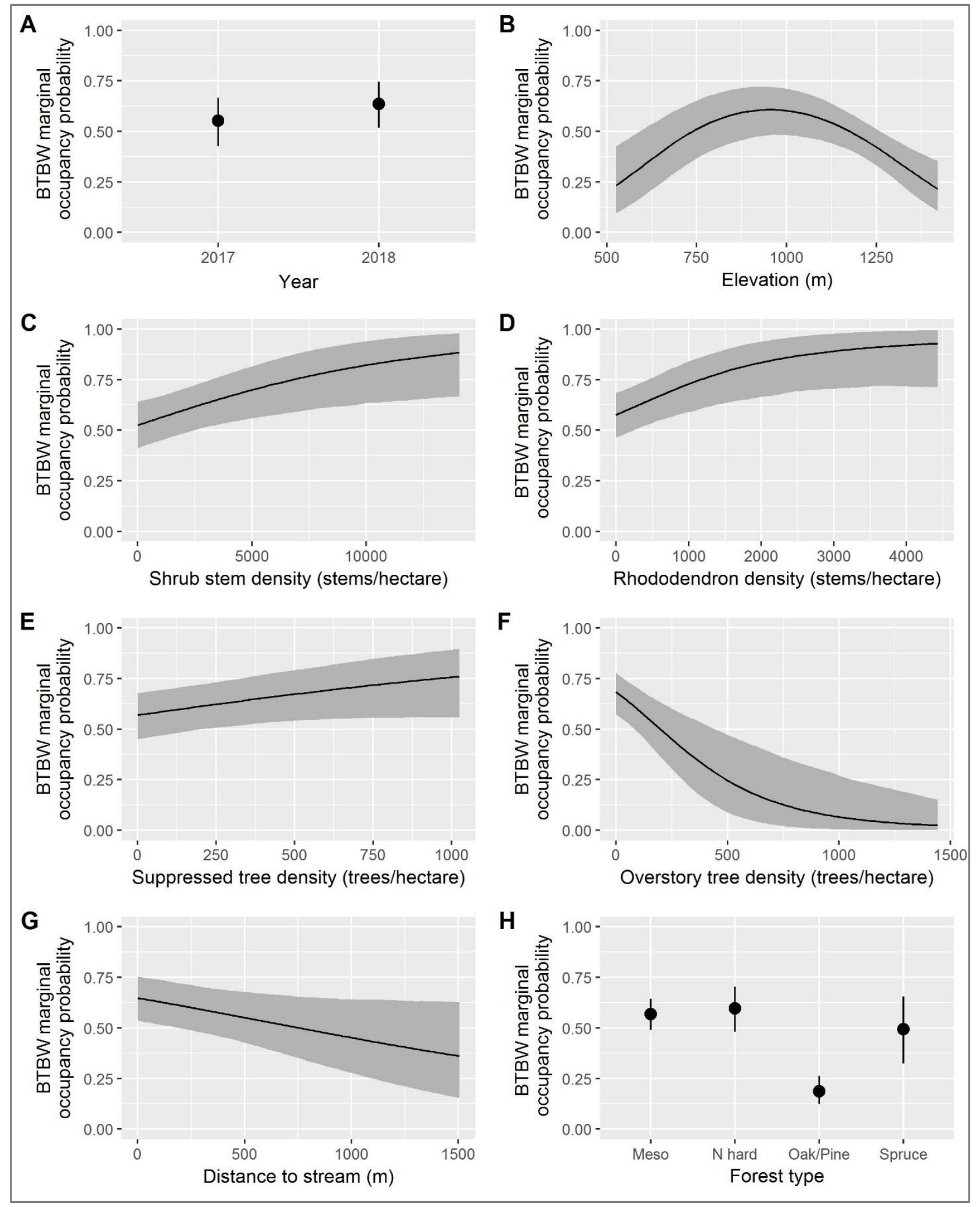

Figure 2.5. Marginal occupancy probability of Black-throated Blue Warbler (Setophaga caerulescens) in the Monongahela National Forest, West Virginia, 2017 - 2018 obtained from detection/non-detection data at 840 unlimited radius point count surveys. Black lines/dots represent the point estimate, and gray areas/error bars represent the $95 \%$ confidence interval. Elevation was modeled with a quadratic effect. Distance to stream was modeled with a pseudo-threshold effect. Forest types are mixed mesophytic, northern hardwood, oak/pine, and spruce. For each covariate of interest, all other continuous covariates were held at their mean, forest type was set to northern hardwood, and year was held at 2017. 

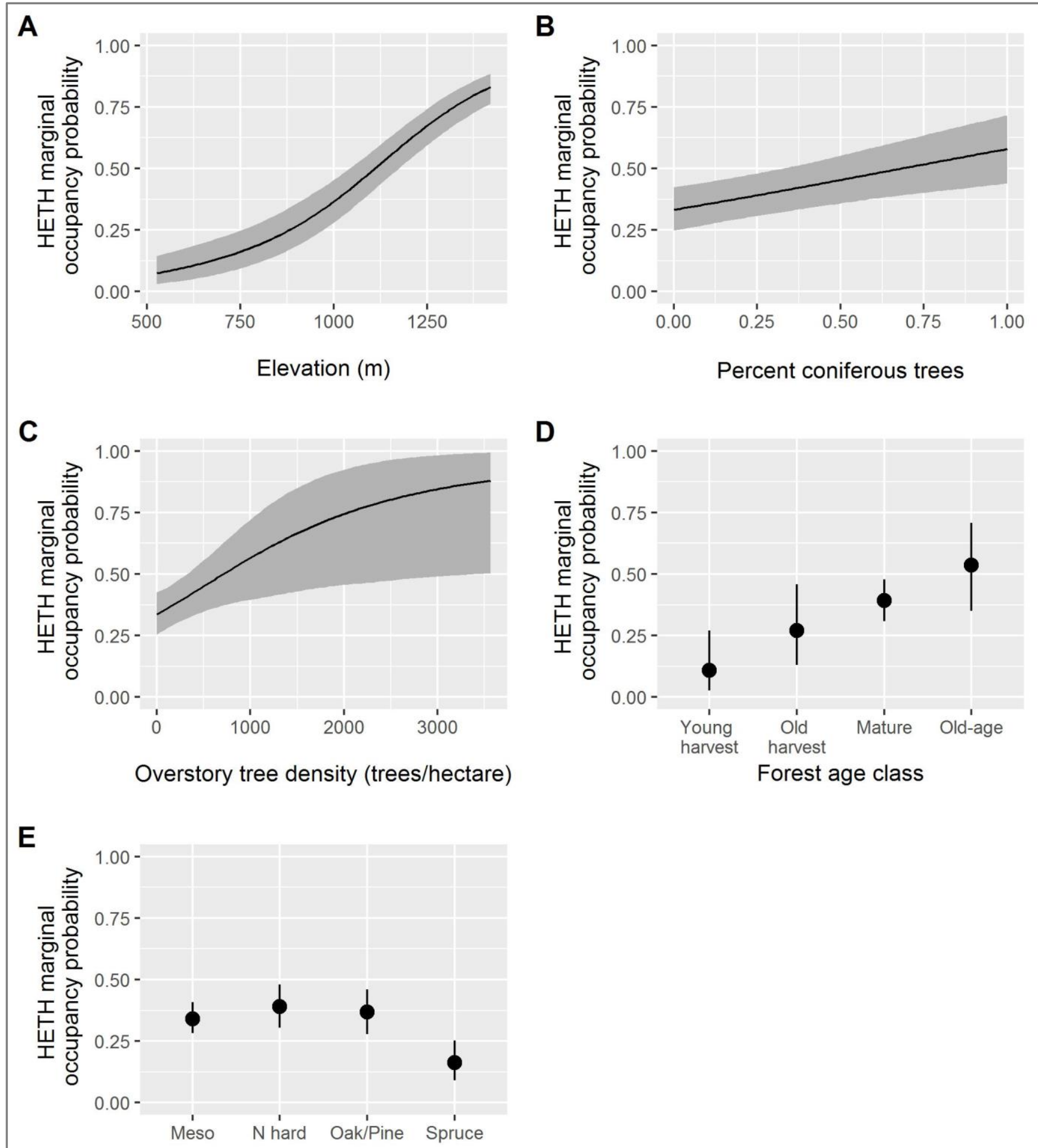

Forest type

Figure 2.6. Marginal occupancy probability of Hermit Thrush (Catharus guttatus) in the Monongahela National Forest, West Virginia, 2017 - 2018 obtained from detection/non-detection data at 840 unlimited radius point count surveys. Black lines/dots represent the point estimate, and gray areas/error bars represent $95 \%$ confidence intervals. Forest types are mixed mesophytic, northern hardwood, oak/pine, and spruce. Forest age classes are young harvest (0-19 yr), old harvest (20-40 yr), mature forest (40-120 yr) and old-age forest (> $120 \mathrm{yr}$ ). For each covariate of interest, all other continuous covariates were held at their mean, forest type was held at northern hardwood, and forest age was held at mature. 


\section{A Conditional on BTBW presence}

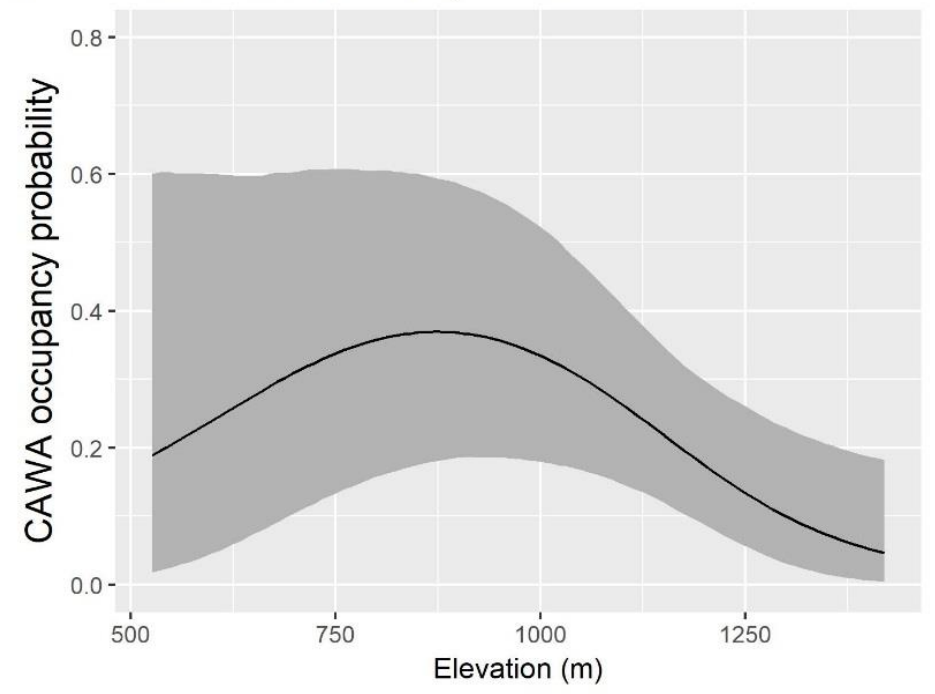

\section{B Conditional on BTBW absence}

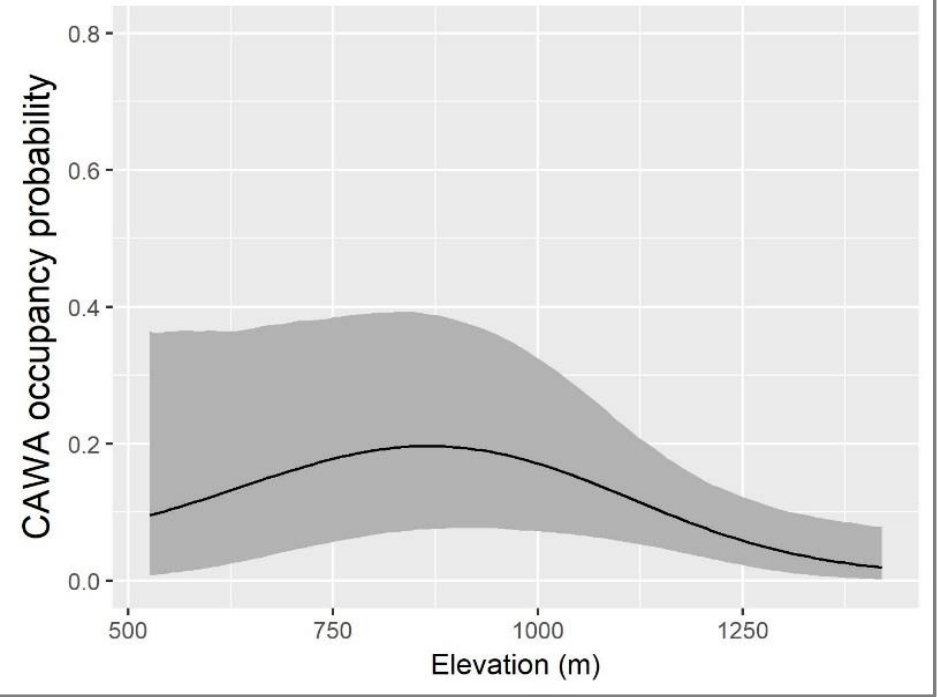

Figure 2.7. Occupancy probability of the Canada Warbler (Cardellina canadensis) conditional on Black-throated Blue Warbler (Setophaga caerulescens) presence (A) and absence (B) in the Monongahela National Forest, West Virginia, 2017 - 2018 obtained from detection/non-detection data at 840 unlimited radius point count surveys. Black lines represent the point estimate, and gray areas represent the $95 \%$ confidence interval. All other continuous covariates were held at their mean and forest type was held at northern hardwood. 

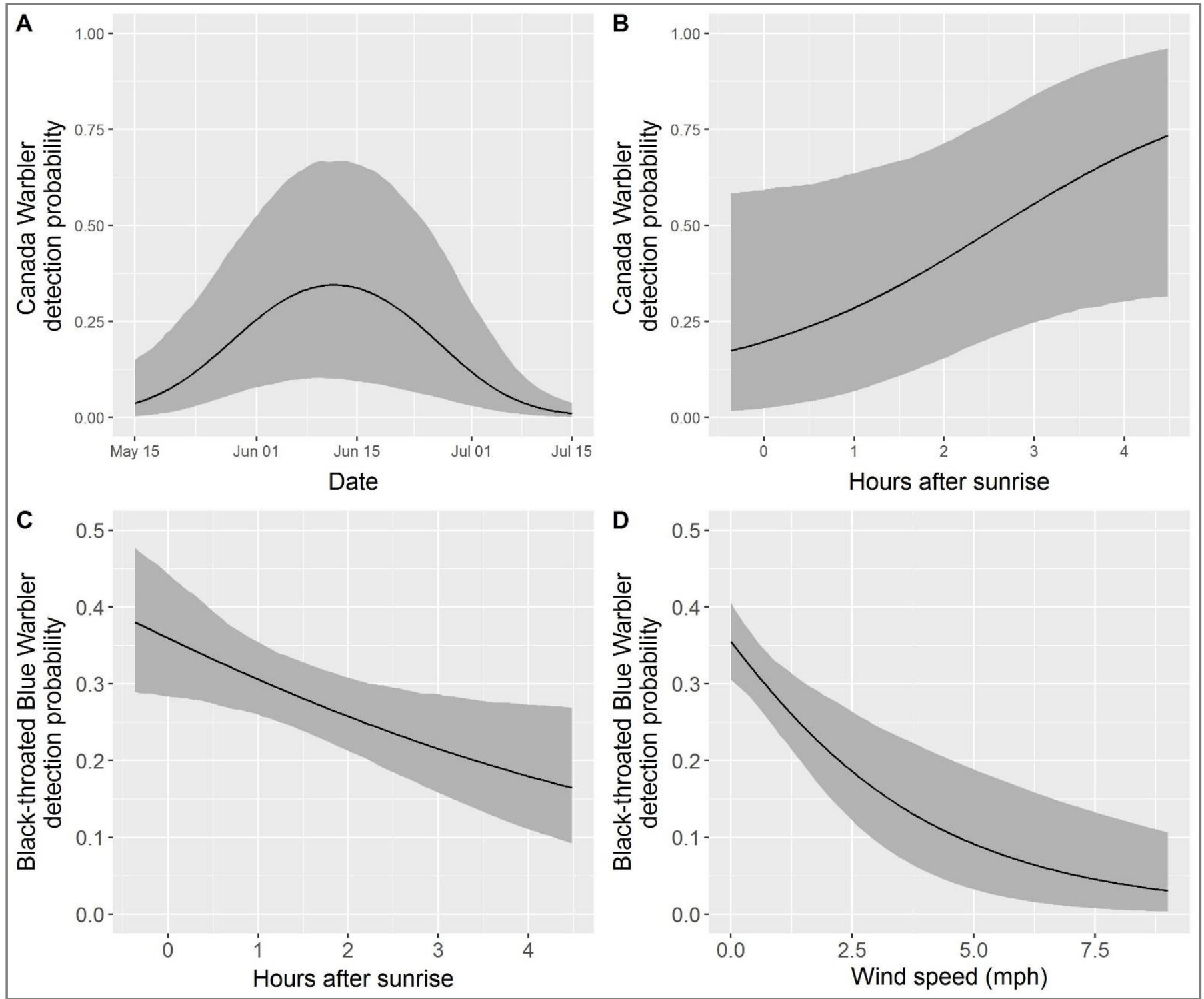

Figure 2.8. Effect of survey date and hours after sunrise on Canada Warbler (Cardellina canadensis) detection probability (AB). Effect of hours after sunrise and wind speed on Black-throated Blue Warbler (Setophaga caerulescens) detection probability (C-D). Detection/non-detection data was obtained from 840 unlimited radius point count surveys in the Monongahela National Forest, West Virginia, 2017 - 2018. Black lines represent the point estimate, and gray areas represent the $95 \%$ confidence interval. For each covariate of interest, all other covariates were held at their mean. 
Table 2.1. Detection and occupancy covariates used to model multi-species occupancy of Canada Warbler (Cardellina canadensis), Black-throated Blue Warbler (Setophaga caerulescens), and Hermit Thrush (Catharus guttatus) in the Monongahela National Forest, West Virginia, 2017-2018. Levels describe the categories for categorical variables and the units for continuous variables. For continuous variables, I report the mean and range, and for categorical variables I report the proportion of point count surveys that fell in each level.

\begin{tabular}{|c|c|c|c|}
\hline Covariate & $\begin{array}{l}\text { Occupancy/ } \\
\text { Detection }\end{array}$ & Levels & Mean (Range) \\
\hline Ordinal day & Detection & Continuous & $168(138-196)$ \\
\hline Hours after sunrise & Detection & Continuous (hours) & $1.45(-0.37-4.48)$ \\
\hline Wind speed & Detection & Continuous (mph) & $0.90(0.00-9.00)$ \\
\hline \multirow[t]{5}{*}{ Sky condition } & Detection & Categorical: & \\
\hline & & 0 - clear & 0.50 \\
\hline & & 1 - partly cloudy & 0.16 \\
\hline & & 2 - cloudy/overcast & 0.27 \\
\hline & & $3-$ fog/mist & 0.07 \\
\hline Elevation & Occupancy & Continuous (meters) & $1023(526-1420)$ \\
\hline Distance to riparian & Occupancy & Continuous (meters) & $355(0.06-1505)$ \\
\hline Distance to stream & Occupancy & Continuous (meters) & $265(0.31-1505)$ \\
\hline Shrub density & Occupancy & Continuous (stems/hectare) & $1861(0-14067)$ \\
\hline Rhododendron density & Occupancy & Continuous (stems/hectare) & $93(0-4431)$ \\
\hline Suppressed tree density & Occupancy & Continuous (trees/hectare) & $115(0-1024)$ \\
\hline Overstory tree density & Occupancy & Continuous (trees/hectare) & $99(0-1443)$ \\
\hline Percent deciduous trees & Occupancy & Continuous & $0.75(0.00-1.00)$ \\
\hline Percent coniferous trees & Occupancy & Continuous & $0.25(0.00-1.00)$ \\
\hline \multirow[t]{5}{*}{ Forest age class } & Occupancy & Categorical: & \\
\hline & & Young harvest (0-19 yr) & 0.07 \\
\hline & & Old harvest (20-40 yr) & 0.07 \\
\hline & & Mature forest (40-120 yr) & 0.80 \\
\hline & & Old-age forest (> $120 \mathrm{yr}$ ) & 0.06 \\
\hline \multirow[t]{5}{*}{ Forest type } & Occupancy & Categorical: & \\
\hline & & Mixed mesophytic & 0.43 \\
\hline & & Oak/pine & 0.23 \\
\hline & & Northern hardwood & 0.23 \\
\hline & & Spruce & 0.09 \\
\hline \multirow[t]{3}{*}{ Year } & Occupancy & Categorical: & \\
\hline & & 2017 & 0.45 \\
\hline & & 2018 & 0.55 \\
\hline
\end{tabular}


Table 2.2. Model selection procedure for multi-species occupancy models of Canada Warbler (Cardellina canadensis), Black-throated Blue Warbler (Setophaga caerulescens), and Hermit Thrush (Catharus guttatus) in the Monongahela National Forest, West Virginia, 2017-2018. Top model weight was 0.95. Covariates used in the global and reduced detection models are in Appendix A. Covariates used in the global and reduced $1^{\text {st }}$-order occupancy models are in Appendix B. Top model results and slope coefficients are in Appendix C.

\begin{tabular}{lrr}
\hline Model & AIC & DAIC \\
\hline $\begin{array}{l}\text { Detection reduced, 1st-order occupancy reduced, pairwise species } \\
\text { dependence }\end{array}$ & 3192.0 & 0 \\
$\begin{array}{l}\text { Detection reduced, 1st-order occupancy reduced, pairwise species } \\
\text { independence }\end{array}$ & 3198.0 & 6.0 \\
$\begin{array}{l}\text { Detection reduced, 1st-order occupancy global, pairwise species } \\
\text { independence }\end{array}$ & 3216.3 & 24.3 \\
$\begin{array}{l}\text { Detection reduced, 1st-order occupancy constant, pairwise species } \\
\text { independence }\end{array}$ & 3614.9 & 422.9 \\
$\begin{array}{l}\text { Detection global, 1st-order occupancy constant, pairwise species } \\
\text { independence }\end{array}$ & 3627.5 & 435.5 \\
\hline
\end{tabular}


Table 2.3. Proportion of point count surveys that Canada Warbler (Cardellina canadensis), Black-throated Blue Warbler (Setophaga caerulescens), and Hermit Thrush (Catharus guttatus) were detected for each year and forest age class. Raw detection/non-detection data was obtained from 840 unlimited radius point count surveys conducted in the Monongahela National Forest, West Virginia, 2017-2018.

\begin{tabular}{lllllllr}
\hline Species & $\mathbf{2 0 1 7}$ & $\mathbf{2 0 1 8}$ & $\begin{array}{l}\text { Young harvest } \\
(\mathbf{0 - 1 9} \mathbf{~ y r})\end{array}$ & $\begin{array}{l}\text { Old harvest } \\
(\mathbf{2 0 - 4 0} \text { yr })\end{array}$ & $\begin{array}{l}\text { Mature } \\
(\mathbf{4 0 - 1 2 0} \text { yr) }\end{array}$ & $\begin{array}{l}\text { Old age } \\
(>\mathbf{1 2 0} \text { yr })\end{array}$ & $\begin{array}{r}\text { All } \\
\text { surveys }\end{array}$ \\
\hline Canada Warbler & 0.07 & 0.07 & 0.04 & 0.05 & 0.07 & 0.08 & 0.07 \\
Black-throated Blue Warbler & 0.34 & 0.40 & 0.55 & 0.20 & 0.37 & 0.34 & 0.37 \\
Hermit Thrush & 0.36 & 0.36 & 0.05 & 0.25 & 0.39 & 0.40 & 0.36 \\
\hline
\end{tabular}




\section{LITERATURE CITED}

Able, K. P., and B. R. Noon. 1976. Avian Community Structure along Elevational Gradients in the Northeastern United States. Oecologia 26:275-294.

Anders, A. D., J. Faaborg, and F. R. Thompson. 1998. Postfledging Dispersal, Habitat Use, and Home-Range Size of Juvenile Wood Thrushes. The Auk 115:349-358.

Anderson, M. D. 2008. Rhododendron maximum. In: Fire Effects Information System. U.S. Department of Agriculture, Forest Service, Rocky Mountain Research Station, Fire Sciences Laboratory. 〈https://www.fs.fed.us/database/feis/plants/shrub/rhomax/all.html〉.

Archaux, F. 2004. Breeding upwards when climate is becoming warmer: No bird response in the French Alps. Ibis 146:138-144.

Archaux, F., and N. Bakkaus. 2007. Relative impact of stand structure, tree composition and climate on mountain bird communities. Forest Ecology and Management 247:72-79.

Auer, S. K., and D. I. King. 2014. Ecological and life-history traits explain recent boundary shifts in elevation and latitude of western North American songbirds. Global Ecology and Biogeography 23:867-875.

Ball, J. R., P. Sólymos, F. K. A. Schmiegelow, S. Hache, J. Schieck, and E. Bayne. 2016. Regional habitat needs of a nationally listed species, Canada Warbler (Cardellina canadensis), in Alberta, Canada. Avian Conservation and Ecology 11:10.

Beckage, B., B. Osborne, D. G. Gavin, C. Pucko, T. Siccama, and T. Perkins. 2008. A rapid upward shift of a forest ecotone during 40 years of warming in the Green Mountains of Vermont. Proceedings of the National Academy of Sciences 105:4197-4202. 
Becker, D. A., P. B. Wood, and P. D. Keyser. 2012. Canada Warbler use of harvested stands following timber management in the southern portion of their range. Forest Ecology and Management 276:1-9.

Both, C., and M. E. Visser. 2000. Breeding territory size affects fitness: an experimental study on competition at the individual level. Journal of Animal Ecology 69:1021-1030.

Brooks, M. 1940. The Breeding Warblers of the Central Allegheny Mountain Region. The Wilson Bulletin 52:249-266.

Brown, J. H., D. W. Mehlman, and G. C. Stevens. 1995. Spatial Variation in Abundance. Ecology 76:2028-2043.

Buckelew, A. R., and G. A. Hall. 1994. The West Virginia Breeding Bird Atlas. The University of Pittsburgh Press, Pittsburgh, PA.

Burnham, K. P., and D. R. Anderson. 2004. Multimodel inference: Understanding AIC and BIC in Model Selection. Sociological Methods and Research 33:261-304.

Van Buskirk, J., R. S. Mulvihill, and R. C. Leberman. 2009. Variable shifts in spring and autumn migration phenology in North American songbirds associated with climate change. Global Change Biology 15:760-771.

Campbell, S. P., J. W. Witham, and M. L. Hunter. 2007. Long-term effects of group-selection timber harvesting on abundance of forest birds. Conservation Biology 21:1218-1229.

Canterbury, G. 2002. Metabolic Adaptation and Climatic Constraints on Winter Bird Distribution. Ecology 83:946-957.

Chace, J. F., S. D. Faccio, and A. Chacko. 2009. Eagle Hill Institute Canada Warbler Habitat Use 
of Northern Hardwoods in Vermont. Northeastern Naturalist 16:491-500.

Clavero, M., D. Villero, and L. Brotons. 2011. Climate Change or Land Use Dynamics : Do We Know What Climate Change Indicators Indicate? PLoS ONE 6.

Clebsch, E. E., and R. T. Busing. 1989. Secondary Succession, Gap Dynamics, and Community Structure in a Southern Appalachian Cove Forest. Ecology 70:728-735.

Clinton, B. D. ., L. R. . Boring, and W. T. Swank. 1994. Regeneration Patterns in Canopy Gaps of Mixed-Oak Forests of the Southern Appalachians : Influences of Topographic Position and Evergreen Understory. The American Midland Naturalist 132:308-319.

Cody, M. L. 1981. Habitat Selection in Birds: The Roles of Vegetation Structure, Competitors, and Productivity. BioScience 31:107-113.

Cody, M. L. 1985. Habitat Selection in Birds. Academic Press, Inc., Orlando, FL.

Cogbill, C. V., and P. S. White. 1991. The Latitude-Elevation Relationship for Spruce-Fir Forest and Treeline along the Appalachian Mountain Chain. Vegetatio 94:153-175.

Committee on the Status of Endangered Wildlife in Canada (COSEWIC). 2008. COSEWIC Assessment and Status Report on the Canada Warbler (Wilsonia canadensis) in Canada.

Crick, H. Q. P., C. Dudley, D. E. Glue, and D. L. Thomson. 1997. UK birds are laying eggs earlier. Nature 388:526-527.

DeGraaf, R. M., and M. Yamasaki. 2003. Options for managing early-successional forest and shrubland bird habitats in the northeastern United States. Forest Ecology and Management 185:179-191.

DeLuca, W. V., and D. I. King. 2017. Montane birds shift downslope despite recent warming in 
the northern Appalachian Mountains. Journal of Ornithology 158:493-505. Springer Berlin Heidelberg.

DeMeo, T. E. 1999. Forest Songbird Abundance and Viability At Multiple Scales on the Monongahela National Forest, West Virginia. Thesis, West Virginia University, Morgantown, WV.

Dirnböck, T., F. Essl, and W. Rabitsch. 2010. Disproportional risk for habitat loss of highaltitude endemic species under climate change. Global Change Biology 17:990-996.

Van Dongen, S., T. Backeljau, E. Matthysen, and A. A. Dhondt. 1997. Synchronization of hatching date with budburst of individual host trees (Quercus robur) in the winter moth (Operophtera brumata) and its fitness consequences. Journal of Animal Ecology 66:113121.

Drapeau, P., A. Leduc, J. Giroux, J. L. Savard, and W. L. Vickery. 2000. Landscape-Scale Disturbances and Changes in Bird Communities of Boreal Mixed-Wood Forests. Ecological Monographs 70:423-444.

Duguay, J. P., P. B. Wood, and J. V. Nichols. 2001. Songbird Abundance and Avian Nest Survival Rates in Forests Fragmented by Different Silvicultural Treatments. Conservation Biology 15:1405-1415.

ESRI. 2018. ArcGIS Desktop: Release 10.3. Environmental Systems Research Institute, Redlands, CA.

Faccio, S. D. 2003. Effects of ice storm-created gaps on forest breeding bird communities in central Vermont. Forest Ecology and Management 186:133-145. 
Farnsworth, G. L., K. H. Pollock, J. D. Nichols, T. R. Simons, J. E. Hines, and J. R. Sauer. 2002. A Removal Model for Estimating Detection Probabilities from Point-Count Surveys. The Auk 119:414-425.

Flockhart, D. T. T., G. W. Mitchell, R. G. Krikun, and E. M. Bayne. 2016. Factors driving territory size and breeding success in a threatened migratory songbird, the Canada Warbler. Avian Conservation and Ecology 11.

Forero-Medina, G., J. Terborgh, S. J. Socolar, and S. L. Pimm. 2011. Elevational ranges of birds on a tropical montane gradient lag behind warming temperatures. PLoS ONE 6:1-5.

Forsman, J. T., J. T. Seppänen, and M. Mönkkönen. 2002. Positive fitness consequences of interspecific interaction with a potential competitor. Proceedings of the Royal Society B 269:1619-1623.

Forsman, J. T., R. L. Thomson, and J. T. Seppänen. 2007. Mechanisms and fitness effects of interspecific information use between migrant and resident birds. Behavioral Ecology 18:888-894.

Foster, J. R., and A. W. D’Amato. 2015. Montane forest ecotones moved downslope in northeastern USA in spite of warming between 1984 and 2011. Global Change Biology $21: 4497-4507$.

Francis, C. M., and F. Cooke. 1986. Differential Timing of Spring Migration in Wood Warblers (Parulinae). The Auk 103:548-556.

Franzreb, K. E., and K. V. Rosenberg. 1997. Are forest songbirds declining? Status assessment from the southern Appalachians and northeastern forests. Pages 264-279 in. 62nd North 
American Wildlife and Natural Resources Conference.

Freeman, B. G., and A. M. Class Freeman. 2014. Rapid upslope shifts in New Guinean birds illustrate strong distributional responses of tropical montane species to global warming. Proceedings of the National Academy of Sciences 111:4490-4494.

Fretwell, S. D., and H. L. J. Lucas. 1970. On territorial behavior and other factors influencing habitat distribution. I. Theoretical development. Acta Biotheoretica 19:16-36.

Gates, J. E., and N. R. Giffen. 1991. Neotropical Migrant Birds and Edge Effects at a ForestStream Ecotone. The Wilson Bulletin 103:204-217.

Gates, J. E., and J. E. McKearnan. 2003. Artificial Nest Predation across Riparian-Upland Forest Ecotones. Southeastern Naturalist 2:301-312.

George, T. L., and S. Zack. 2008. Bird occupancy and richness in ponderosa pine forests with contrasting forest structure and fire history. Canadian Journal of Forest Research 38:936943.

Goodnow, M. L., and L. R. Reitsma. 2011. Nest-site selection in the Canada Warbler (Wilsonia canadensis ) in central New Hampshire. Canadian Journal of Zoology 89:1172-1177.

Gotelli, N. J., G. R. Graves, and C. Rahbek. 2010. Macroecological signals of species interactions in the Danish avifauna. Proceedings of the National Academy of Sciences 107:5030-5035.

Graves, G. R. 1997. Geographic clines of age ratios of Black-throated Blue Warblers (Dendroica Caerulescens). Ecology 78:2524-2531.

Green, A. W., D. C. Pavlacky, and J. T. Luke. 2019. A dynamic multi-scale occupancy model to 
estimate temporal dynamics and hierarchical habitat use for nomadic species. Ecology and Evolution 9:793-803.

Grinde, A. R., and G. J. Niemi. 2016. Influence of landscape, habitat, and species co-occurrence on occupancy dynamics of Canada Warblers. The Condor 118:513-531.

Gross, D. A. 2009. Pennsylvania Boreal Conifer Forests and Their Bird Communities: Past, Present, and Potential. Pages 48-73 in. Proceedings from the Conference on the Ecology and Management of High-Elevation Forests in the Central and Southern Appalachian Mountains.

Hagan, J. M., P. S. Mckinley, A. L. Meehan, and S. L. Grove. 1997. Diversity and Abundance of Landbirds in a Northeastern Industrial Forest. The Journal of Wildlife Management 61:718735.

Hagan, J. M., and A. L. Meehan. 2002. The Effectiveness of Stand-Level and Landscape-Level Variables for Explaining Bird Occurrence in an Industrial Forest. Society of American Foresters 48:231-242.

Hallworth, M., P. M. Benham, J. D. Lambert, and L. Reitsma. 2008a. Canada warbler (Wilsonia canadensis) breeding ecology in young forest stands compared to a red maple (Acer rubrum) swamp. Forest Ecology and Management 255:1353-1358.

Hallworth, M., A. Ueland, E. Anderson, J. D. Lambert, and L. Reitsma. 2008b. Habitat Selection and Site Fidelity of Canada Warblers (Wilsonia Canadensis) in Central New Hampshire. The Auk 125:880-888.

Harding, C., L. Reitsma, and J. D. Lambert. 2017. Guidelines for Managing Canada Warbler 
Habitat in the Northeast and Mid-Atlantic Regions. High Branch Conservation Services, Hartland, VT.

Hart, J. L., M. M. Cowden, S. J. Torreano, and J. P. R. Vestal. 2015. Disturbance, Succession, and Structural Development of an Upland Hardwood Forest on the Interior Low Plateau, Tennessee. Natural Areas Journal 35:557-573.

Hitch, A. T., and P. L. Leberg. 2007. Breeding distributions of North American bird species moving north as a result of climate change. Conservation Biology 21:534-539.

Hobson, K. A., and E. Bayne. 2000. Effects of Forest Fragmentation by Agriculture on Avian Communities in the Southern Boreal Mixedwoods of Western Canada. The Wilson Bulletin 112:373-387.

Holmes, R. T., and T. W. Sherry. 2001. Thirty-Year Bird Population Trends in an Unfragmented Temperate Deciduous Forest. American Ornithological Society 118:589-609.

Holway, D. A. 1991. Nest-Site Selection and the Importance of Nest Concealment in the BlackThroated Blue Warbler. The Condor 93:575-581.

Homer, C. G., J. A. Dewitz, L. Yang, S. Jin, P. Danielson, G. Xian, J. Coulston, N. D. Herold, J. D. Wickam, and K. Megown. 2015. Completion of the 2011 National Land Cover Database for the conterminous United States-Representing a decade of land cover change information. Photogrammetric Engineering and Remote Sensing 81:345-354.

Hunt, A. R., E. M. Bayne, and S. Haché. 2017. Forestry and conspecifics influence Canada Warbler (Cardellina canadensis ) habitat use and reproductive activity in boreal Alberta, Canada. The Condor 119:832-847. 
Jankowski, J. E., C. L. Merkord, W. F. Rios, K. G. Cabrera, N. S. Revilla, and M. R. Silman. 2013. The relationship of tropical bird communities to tree species composition and vegetation structure along an Andean elevational gradient. Journal of Biogeography 40:950-962.

Jennings, S. B., N. D. Brown, and D. Sheil. 1999. Assessing forest canopies and understorey illumination Canopy closure, canopy cover and other measures. Forestry 72:59-73.

Johnson, C., and P. B. Wood. 2017. Monongahela National Forest, WV Avian Point Counts 1993-2014. Unpublished Raw Data.

Kellner, K. 2017. A wrapper around "rjags" to streamline "JAGS" analyses. Available from: https://github.com/kenkellner/jagsUI.

King, D. I., and R. M. Degraaf. 2000. Bird species diversity and nesting success in mature, clearcut and shelterwood forest in northern New Hampshire, USA. Forest Ecology and Management 129:227-235.

Kirchman, J. J., and A. E. Van Keuren. 2017. Altitudinal Range Shifts of Birds At the Southern Periphery of the Boreal Forest: 40 Years of Change In the Adirondack Mountains. The Wilson Journal of Ornithology 129:742-753.

Lambert, J. D., and S. D. Faccio. 2005. Canada Warbler Population Status, Habitat Use, and Stewardship Guidelines for Northeastern Forests. VINS Technical Report 05-4.

Lewis, K. E., C. T. Rota, C. M. Lituma, and J. T. Anderson. 2019. Influence of the Agricultural Conservation Easement Program wetland practices on winter occupancy of Passerellidae sparrows and avian species richness. PLoS ONE 14:1-19. 
Lindsey, R., and L. Dahlman. 2018. Climate Change: Global Temperature. Climate.gov, NOAA. <https://www.climate.gov/news-features/understanding-climate/climate-change-globaltemperature>. Accessed 4 Mar 2019.

Machtans, C. S., and P. B. Latour. 2003. Boreal Forest Songbird Communities of the Liard Valley, Northwest Territories, Canada. The Condor 105:27-44.

Marini, M. Â., and R. B. Cavalcanti. 1993. Habitat and foraging substrate use of three Basileuterus warblers from Central Brazil. Ornitologia Neotropical 4:69-76.

Marshall, M. R., J. A. DeCecco, A. B. Williams, G. A. Gale, and R. J. Cooper. 2003. Use of regenerating clearcuts by late-successional bird species and their young during the postfledging period. Forest Ecology and Management 183:127-135.

Martin, T. E. 2001. Abiotic vs . Biotic Influences on Habitat Selection of Coexisting Species: Climate Change Impacts? Ecology 82:175-188.

Martin, T. E., and J. J. Roper. 1988. Nest Predation and Nest-Site Selection of a Western Population of the Hermit Thrush. The Condor 90:51-57.

Mayfield III, A. E., and R. R. Hicks Jr. 2009. Abundance of Red Spruce Regeneration Across Spruce-hardwood Ecotones at Gaudineer Knob, West Virginia. Pages 113-125 in. Proceedings from the Conference on the Ecology and Management of High-Elevation Forests in the Central and Southern Appalachian Mountains.

Mayor, S. J., R. P. Guralnick, M. W. Tingley, J. Otegui, J. C. Withey, S. C. Elmendorf, M. E. Andrew, S. Leyk, I. S. Pearse, and D. C. Schneider. 2017. Increasing phenological asynchrony between spring green-up and arrival of migratory birds. Scientific Reports 7:1- 


\section{Springer US.}

McCain, C. M., and J.-A. Grytnes. 2010. Elevational Gradients in Species Richness. Encyclopedia of Life Sciences.

McDermott, M. E., and P. B. Wood. 2009. Short- and long-term implications of clearcut and two-age silviculture for conservation of breeding forest birds in the central Appalachians, USA. Biological Conservation 142:212-220.

McDermott, M. E., and P. B. Wood. 2010. Influence of Cover and Food Resource Variation on Post-Breeding Bird Use of Timber Harvests With Residual Canopy Trees. The Wilson Journal of Ornithology 122:545-555.

McDermott, M. E., P. B. Wood, G. W. Miller, and B. T. Simpson. 2011. Predicting breeding bird occurrence by stand- and microhabitat-scale features in even-aged stands in the Central Appalachians. Forest Ecology and Management 261:373-380.

Mehlman, D. W. 1997. Change in Avian Abundance Across the Geographic Range in Response to Environmental Change. Ecological Applications 7:614-624.

Monkkonen, M. 1994. Diversity Patterns in Palaearctic and Nearctic Forest Bird Assemblages. Journal of Biogeography 21:183-195.

Mönkkönen, M., and J. T. Forsman. 2002. Heterospecific attraction among forest birds: a review. Ornithological Science 1:41-51.

Monongahela National Forest. 2005. Forest Trails Shapefile.

Monongahela National Forest. 2011. Monongahela National Forest : Land and Resource Management Plan. U.S. Department of Agriculture. 
Monongahela National Forest. 2017. Timber Sale Areas 1996-2017. Shapefile. U.S. Department of Agriculture.

Monongahela National Forest. 2018a. About the Forest. U.S. Department of Agriculture. <https://www.fs.usda.gov/main/mnf/about-forest>.

Monongahela National Forest. 2018b. MNF Veg Spatial Layer. Shapefile. Unpublished Data. U.S. Department of Agriculture.

Morin, R. S., S. N. Oswalt, R. T. Trotter, and A. M. Liebhold. 2011. Status of Hemlock in the Eastern United States. e-Science Update SRS-038. Asheville, NC: U.S. Department of Agriculture Forest Service, Southern Research Station.

Morrison, M. L. 1982. The Structure of Western Warbler Assemblages : Ecomorphological Analysis of the Black- Throated Gray and Hermit Warblers. The Auk 99:503-513.

Myers, N., R. A. Mittermeier, C. G. Mittermeier, G. A. B. Fonseca, and J. Kent. 2000. Biodiversity hotspots for conservation priorities. Nature 403.

Naiman, R. J., H. Decamps, and M. Pollock. 1993. The Role of Riparian Corridors in Maintaining Regional Biodiversity. Ecological Applications 3:209-212.

NOAA. 2018. Local Climate Data and Plots, Elkins, WV - Monthly Normals/Records. National Oceanic and Atmospheric Administration. <http://www.weather.gov/rlx/climate>. Accessed 4 Mar 2019.

Nowacki, G., R. Carr, and M. Van Dyck. 2009. The Current Status of Red Spruce in the Eastern United States: Distribution, population trends, and environmental drivers. Proceedings from the Conference on the Ecology and Management of High-Elevation Forests in the Central 
and Southern Appalachian Mountains.

Oswalt, S. N., and W. B. Smith. 2014. U.S. Forest Resource Facts and Historical Trends. U.S. Department of Agriculture, Forest Service.

Plummer, M. 2003. JAGS : A Program for Analysis of Bayesian Graphical Models Using Gibbs Sampling. Proceedings of the 3rd International Workshop on Distributed Statistical Computing (DSC 2003), March 20-22, Vienna, Austria. 2003.

R Core Team. 2018. R: A Language and Environment for Statistical Computing. <https://www.rproject.org/>.

Rahbek, C. 1995. The Elevational Gradient of Species Richness : A Uniform Pattern? Ecography $18: 200-205$.

Ralph, C. J., S. Droege, and J. R. Sauer. 1995. Managing and monitoring birds using point counts: stardards and applications. USDA Forest Service General Technical Report PSWGTR-149.

Reitsma, L., M. L. Goodnow, M. T. Hallworth, and C. J. Conway. 2009. Canada Warbler (Cardellina canadensis), version 2.0. In The Birds of North America (A. F. Poole, Editor). Cornell Lab of Ornithology, Ithaca, NY, USA.

Reitsma, L. R., M. T. Hallworth, and P. M. Benham. 2008. Does Age Influence Territory Size, Habitat Selection, and Reproductive Success of Male Canada Warblers in Central New Hampshire? The Wilson Journal of Ornithology 120:446-454.

Ricklefs, R. E. 2013. Habitat-independent spatial structure in populations of some forest birds in eastern North America. Journal of Animal Ecology 82:145-154. 
Rivers, C. T., D. H. Van Lear, B. D. Clinton, and T. A. Waldrop. 1999. Community composition in canopy gaps as influenced by presence or absence of Rhododendron maximum. Pages 57-60 in. Proceedings of the Tenth Biennial Southern Silvicultural Research Conference.

Root, T. 1988. Energy Constraints on Avian Distributions and Abundances. Ecology 69:330339.

Rota, C. T., M. A. R. Ferreira, R. W. Kays, T. D. Forrester, E. L. Kalies, W. J. McShea, A. W. Parsons, and J. J. Millspaugh. 2016. A multispecies occupancy model for two or more interacting species. Methods in Ecology and Evolution 7:1164-1173.

Rota, C. T., R. J. Fletcher, R. M. Dorazio, and M. G. Betts. 2009. Occupancy estimation and the closure assumption. Journal of Applied Ecology 46:1173-1181.

Royle, J. A., and M. Kéry. 2007. A Bayesian State-space Formulation of Dynamic Occupancy Models. Ecology 88:1813-1823.

Ruggiero, A., and B. A. Hawkins. 2008. Why do mountains support so many species of birds? Ecography 31:306-315.

Sabo, S. R. 1980. Niche and Habitat Relations in Subalpine Bird Communities of the White Mountains of New Hampshire. Ecological Monographs 50:241-259.

Sauer, J. R., D. K. Niven, J. E. Hines, D. J. Ziolkowski, K. L. Pardieck, J. E. Fallon, and W. A. Link. 2017. The North American Breeding Bird Survey, Results and Analysis 1966-2015. Version 2.07.2017 USGS Patuxent Wildlife Research Center, Laurel, MD.

Sekercioglu, C. H., S. H. Schneider, J. P. Fay, and S. R. Loarie. 2008. Climate change, elevational range shifts, and bird extinctions. Conservation Biology 22:140-150. 
Shaffer, T. L. 2004. A unified approach to analyzing nest success. Auk 121:525-540.

Sheehan, J., P. B. Wood, D. A. Buehler, P. D. Keyser, J. L. Larkin, A. D. Rodewald, T. B. Wigley, T. J. Boves, G. A. George, M. H. Bakermans, T. A. Beachy, A. Evans, M. E. McDermott, F. L. Newell, K. A. Perkins, and M. White. 2014. Avian response to timber harvesting applied experimentally to manage Cerulean Warbler breeding populations. Forest Ecology and Management 321:5-18. Elsevier B.V.

Shoo, L. P., S. E. Williams, and J.-M. Hero. 2006. Detecting climate change induced range shifts: Where and how should we be looking? Austral Ecology 31:22-29.

Smith, T. M., and H. H. Shugart. 1987. Territory Size Variation in the Ovenbird: The Role of Habitat Structure. Ecology 68:695-704.

Socolar, J. B., P. N. Epanchin, S. R. Beissinger, and M. W. Tingley. 2017. Phenological shifts conserve thermal niches in North American birds and reshape expectations for climatedriven range shifts. Proceedings of the National Academy of Sciences Early Edit:1-6.

Sodhi, N. S., and C. A. Paszkowski. 1995. Habitat Use and Foraging Behavior of Four Parulid Warblers in a Second-Growth Forest. Journal of Field Ornithology 66:277-288.

Sorte, F. A. La, and W. Jetz. 2010. Projected range contractions of montane biodiversity under global warming. Proceedings of the Royal Society B 277:3401-3410.

Species Conservation Profiles. n.d. Partners in Flight. $<$ https://www.partnersinflight.org/species/canada-warbler/>.

Swift, B. L., J. S. Larson, and R. M. Degraaf. 1984. Relationship of Breeding Bird Density and Diversity to Habitat Variables in Forested Wetlands. The Wilson Bulletin 96:48-59. 
Szymkowiak, J., R. L. Thomson, and L. Kuczynski. 2017. Interspecific social information use in habitat selection decisions among migrant songbirds. Behavioral Ecology 28:767-775.

Terborgh, J. 1985. The Role of Ecotones in the Distribution of Andean Birds. Ecology 66:12371246.

The West Virginia Statewide Addressing and Mapping Board. 2004. WVSAMB Color Digital Orthophotos.

Thomas, C. D., and J. J. Lennon. 1999. Birds extend their ranges northwards. Nature 399:213.

Tingley, M. W., and S. R. Beissinger. 2013. Cryptic loss of montane avian richness and high community turnover over 100 years. Ecology 94:598-609.

Tingley, M. W., M. S. Koo, C. Moritz, A. C. Rush, and S. R. Beissinger. 2012. The push and pull of climate change causes heterogeneous shifts in avian elevational ranges. Global Change Biology 18:3279-3290.

Tingley, M. W., D. A. Orwig, R. Field, and G. Motzkin. 2002. Avian response to removal of a forest dominant: Consequences of hemlock woolly adelgid infestations. Journal of Biogeography 29:1505-1516.

Tylianakis, J. M., R. K. Didham, J. Bascompte, and D. A. Wardle. 2008. Global change and species interactions in terrestrial ecosystems. Ecology Letters 11:1351-1363.

U.S. Census Bureau. 2007. TIGER/Line Shapefile. U.S. Department of Commerce: Geography Division.

U.S. Census Bureau. 2018. MAF/TIGER Feature Class Code Definitions. <https://www.census.gov/geo/reference/mtfcc.html>. 
U.S. Fish and Wildlife Service. 2008. Birds of Conservation Concern 2008. United States

Department of Interior, Fish and Wildlife Service, Division of Migratory Bird Management, Arlington, Virginia.

U.S. Geological Survey. 1979. 7.5 minute Digital Elevation Models. U.S. Geological Survey, Reston, VA.

U.S. Geological Survey. 1996. Digital Orthophoto Quarter Quadrangles. US. Geological Survey, Reston, VA.

U.S. Geological Survey. 1998. Instructions for Conducting the North American Breeding Bird Survey. Patuxent Wildlife Research Center.

U.S. Geological Survey - National Geospatial Program. 2018. USGS TNM Hydrography (NHD).

USDA-FSA-APFO Aerial Photography Field Office. 2016. NAIP Digital Ortho Photo Image.

USDA Forest Service: Northern Research Station. 2018. USDA Forest Service, Forest Inventory and Analysis Program. Forest Inventory EVALIDator web-application Version 1.8.0.00. St. Paul, MN: U.S. <http://fsxopsx1056.fdc.fs.usda.gov:9001/Evalidator/evalidator.jsp>. Accessed 12 Mar 2019.

Vanderwel, M. C., J. R. Malcolm, and S. C. Mills. 2007. A meta-analysis of bird responses to uniform partial harvesting across North America. Conservation Biology 21:1230-1240.

Vega Rivera, J. H., W. J. McShea, and J. H. Rappole. 2003. Comparison of Breeding and Postbreeding Movements and Habitat Requirements for the Scarlet Tanager (Piranga olivacea) in Virginia. The Auk 120:632-644.

Vega Rivera, J. H., J. H. Rappole, W. J. McShea, and C. A. Haas. 1998. Wood Thrush 
Postfledging Movements and Habitat Use in Northern Virginia. The Condor 100:69-78.

Vogelmann, J. E., G. Xian, C. Homer, and B. Tolk. 2012. Remote Sensing of Environment Monitoring gradual ecosystem change using Landsat time series analyses : Case studies in selected forest and rangeland ecosystems. Remote Sensing of Environment 122:92-105. Elsevier B.V.

De Wan, A. A., P. J. Sullivan, A. J. Lembo, C. R. Smith, J. C. Maerz, J. P. Lassoie, and M. E. Richmond. 2009. Using occupancy models of forest breeding birds to prioritize conservation planning. Biological Conservation 142:982-991. Elsevier Ltd.

Weakland, C. A., P. B. Wood, and W. M. Ford. 2002. Responses of songbirds to diameter-limit cutting in the central Appalachians of West Virginia, USA. Forest Ecology and Management 155:115-129.

West Virginia Division of Natural Resources. 2015. 2015 West Virginia West Virginia State Wildlife Action Plan.

Wilson, A. M., D. W. Brauning, and R. S. Mulvihill. 2013. Second atlas of breeding birds in Pennsylvania. The Pennsylvania State University Press.

Wilson, H. W., D. Kipervaser, and S. A. Lilley. 2000. Spring Arrival Dates of Maine Migratory Breeding Birds : 1994-1997 vs . 1899-1911. Northeastern Naturalist 7:1-6.

Zipkin, E. F., J. A. Royle, D. K. Dawson, and S. Bates. 2010. Multi-species occurrence models to evaluate the effects of conservation and management actions. Biological Conservation 143:479-484. Elsevier Ltd.

Zlonis, E. J., and G. J. Niemi. 2014. Avian communities of managed and wilderness hemiboreal 
forests. Forest Ecology and Management 328:26-34. 


\section{Appendix A.}

Global and reduced detection models for Canada Warbler (Cardellina canadensis), Black-throated Blue Warbler (Setophaga caerulescens), and Hermit Thrush (Catharus guttatus) in the Monongahela National Forest, West Virginia, 2017-2018. Occupancy was held constant for all species and pairwise species independence was assumed (second-order effects fixed at 0 ).

\begin{tabular}{llll}
\hline Model & Species & Detection Covariates & Form \\
\hline $\begin{array}{l}\text { Reduced detection, } \\
\text { constant occupancy, }\end{array}$ & Canada Warbler & Ordinal day & Quadratic \\
pairwise species independence & & Time after sunrise & Linear \\
& & Wind speed & Linear \\
& Black-throated Blue Warbler & Time after sunrise & Categorical \\
& & Wind speed & Linear \\
& Hermit Thrush & Ordinal day & Linear \\
Global detection, & & & \\
constant occupancy, & Canada Warbler & Ordinal day & Linear/quadratic \\
pairwise species independence & & Time after sunrise & Linear \\
& & Wind speed & Linear \\
& & Sky condition & Categorical \\
& & Ordinal day & Linear/quadratic \\
& Black-throated Blue Warbler & Time after sunrise & Linear \\
& & Wind speed & Linear \\
& & Sky condition & Categorical \\
& & Ordinal day & Linear/quadratic \\
& & Time after sunrise & Linear \\
& & Wind speed & Linear \\
& & Sky condition & Categorical \\
\hline
\end{tabular}




\section{Appendix B.}

Global and reduced $1^{\text {st }}$-order occupancy models for Canada Warbler (Cardellina canadensis), Black-throated Blue Warbler (Setophaga caerulescens), and Hermit Thrush (Catharus guttatus) in the Monongahela National Forest, West Virginia, 2017-2018. The reduced detection model was used (Appendix A.) and pairwise species independence was assumed (second-order effects fixed at 0 ).

\begin{tabular}{|c|c|c|c|}
\hline Model & Species & Occupancy Covariates & Form \\
\hline \multirow[t]{3}{*}{$\begin{array}{l}\text { Reduced occupancy, } \\
\text { reduced detection } \\
\text { pairwise species independence }\end{array}$} & Canada Warbler & $\begin{array}{l}\text { Elevation } \\
\text { Distance to riparian } \\
\text { Rhododendron density } \\
\text { Forest type }\end{array}$ & $\begin{array}{l}\text { Quadratic } \\
\text { Pseudo-threshold } \\
\text { Pseudo-threshold } \\
\text { Categorical }\end{array}$ \\
\hline & Black-throated Blue Warbler & $\begin{array}{l}\text { Year } \\
\text { Elevation } \\
\text { Distance to stream } \\
\text { Shrub density } \\
\text { Rhododendron density } \\
\text { Suppressed tree density } \\
\text { Overstory tree density } \\
\text { Forest type }\end{array}$ & $\begin{array}{l}\text { Categorical } \\
\text { Quadratic } \\
\text { Pseudo-threshold } \\
\text { Linear } \\
\text { Linear } \\
\text { Linear } \\
\text { Linear } \\
\text { Categorical }\end{array}$ \\
\hline & Hermit Thrush & $\begin{array}{l}\text { Elevation } \\
\text { Overstory tree density } \\
\text { Percent conifer trees } \\
\text { Forest age class } \\
\text { Forest type }\end{array}$ & $\begin{array}{l}\text { Linear } \\
\text { Linear } \\
\text { Linear } \\
\text { Categorical } \\
\text { Categorical }\end{array}$ \\
\hline \multirow[t]{3}{*}{$\begin{array}{l}\text { Global occupancy, } \\
\text { reduced detection, } \\
\text { pairwise species independence }\end{array}$} & Canada Warbler & $\begin{array}{l}\text { Year } \\
\text { Elevation } \\
\text { Distance to riparian } \\
\text { Shrub density } \\
\text { Rhododendron density } \\
\text { Suppressed tree density } \\
\text { Overstory tree density } \\
\text { Percent deciduous trees } \\
\text { Forest age class } \\
\text { Forest type }\end{array}$ & $\begin{array}{l}\text { Categorical } \\
\text { Quadratic } \\
\text { Pseudo-threshold } \\
\text { Linear } \\
\text { Pseudo-threshold } \\
\text { Linear } \\
\text { Linear } \\
\text { Linear } \\
\text { Categorical } \\
\text { Categorical }\end{array}$ \\
\hline & Black-throated Blue Warbler & $\begin{array}{l}\text { Year } \\
\text { Elevation } \\
\text { Distance to wetland } \\
\text { Distance to stream } \\
\text { Shrub density } \\
\text { Rhododendron density } \\
\text { Suppressed tree density } \\
\text { Overstory tree density } \\
\text { Percent deciduous trees } \\
\text { Forest age class } \\
\text { Forest type }\end{array}$ & $\begin{array}{l}\text { Categorical } \\
\text { Quadratic } \\
\text { Pseudo-threshold } \\
\text { Pseudo-threshold } \\
\text { Linear } \\
\text { Linear } \\
\text { Linear } \\
\text { Linear } \\
\text { Linear } \\
\text { Categorical } \\
\text { Categorical }\end{array}$ \\
\hline & Hermit Thrush & Year & Categorical \\
\hline
\end{tabular}


Elevation

Distance to stream

Shrub density

Rhododendron density

Suppressed tree density

Overstory tree density

Percent coniferous trees

Forest age class

Forest type
Linear

Linear

Linear

Linear

Linear

Linear

Linear

Categorical

Categorical 


\section{Appendix C.}

Top model results with slope coefficients (log odds ratio) and 95\% confidence intervals in brackets for each covariate included in the multi-species occupancy model for Canada Warbler (Cardellina canadensis), Blackthroated Blue Warbler (Setophaga caerulescens), and Hermit Thrush (Catharus guttatus) in the Monongahela National Forest, West Virginia, 2017-2018 obtained from detection/non-detection data at 840 unlimited radius point count surveys. Log odds ratios for forest type are relative to mixed mesophytic forest, log odds ratios for forest age are relative to mature forest (40-120 years), and log odds ratios for sky condition are relative to clear days.

\begin{tabular}{|c|c|c|c|}
\hline Species & Covariate & Sub-model & $\begin{array}{r}\text { Log odds ratio } \\
{[95 \% \mathrm{CI}]}\end{array}$ \\
\hline \multirow[t]{15}{*}{ Canada Warbler } & Elevation & 1st-order occupancy & $-0.52[-1.09,0.06]$ \\
\hline & Elevation^2 & 1st-order occupancy & $-0.45[-0.91,0.00]$ \\
\hline & Distance to riparian & 1st-order occupancy & $-0.41[-0.73,-0.08]$ \\
\hline & Rhododendron density & 1st-order occupancy & $0.64[0.32,0.95]$ \\
\hline & Forest type: & 1st-order occupancy & \\
\hline & Mesophytic & & $1.67[0.44,2.90]$ \\
\hline & Northern hardwood & & $2.71[1.31,4.11]$ \\
\hline & Spruce & & $1.74[-0.29,3.76]$ \\
\hline & Day & Detection & $-0.47[-1.03,0.09]$ \\
\hline & Day^$^{\wedge}$ & Detection & $-1.22[-1.91,-0.52]$ \\
\hline & Wind speed & & $0.68[-0.03,1.40]$ \\
\hline & Sky condition: & Detection & $0.09[-1.20,1.37]$ \\
\hline & Partly cloudy & & $-0.47[-2.96,2.02]$ \\
\hline & Overcast & & $0.43[-0.64,1.50]$ \\
\hline & Fog/mist & & $0.86[-1.09,2.81]$ \\
\hline \multirow[t]{14}{*}{ Black-throated Blue Warbler } & Year & 1st-order occupancy & $0.35[0.02,0.68]$ \\
\hline & Elevation & 1st-order occupancy & $-0.12[-0.38,0.15]$ \\
\hline & Elevation^2 & 1st-order occupancy & $-0.37[-0.58,-0.16]$ \\
\hline & Distance to stream & 1st-order occupancy & $-0.18[-0.36,0.00]$ \\
\hline & Shrub density & 1st-order occupancy & $0.26[0.06,0.46]$ \\
\hline & Rhododendron density & 1st-order occupancy & $0.23[-0.01,0.47]$ \\
\hline & Suppressed tree density & 1st-order occupancy & $0.17[0.00,0.33]$ \\
\hline & Overstory tree density & 1st-order occupancy & $-0.43[-0.68,-0.18]$ \\
\hline & Forest type: & 1st-order occupancy & \\
\hline & Mesophytic & & $1.69[1.20,2.18]$ \\
\hline & Northern hardwood & & $1.71[1.08,2.34]$ \\
\hline & Spruce & & $1.31[0.51,2.12]$ \\
\hline & Hours after sunrise & Detection & $-0.26[-0.46,-0.06]$ \\
\hline & Wind speed & Detection & $-0.42[-0.67,-0.17]$ \\
\hline \multirow[t]{4}{*}{ Hermit Thrush } & Elevation & 1st-order occupancy & $-0.5[-0.92,-0.08]$ \\
\hline & Overstory tree density & 1st-order occupancy & $1.02[0.77,1.27]$ \\
\hline & Percent conifer trees & 1st-order occupancy & $0.23[0.03,0.43]$ \\
\hline & Forest age: & 1st-order occupancy & $0.30[0.12,0.48]$ \\
\hline
\end{tabular}




\begin{tabular}{lllr} 
& Young harvest $(0-19 \mathrm{yr})$ & & $-1.81[-3.05,-0.56]$ \\
& Old harvest $(20-40 \mathrm{yr})$ & & $-0.58[-1.35,0.18]$ \\
& Old-age forest $(>120 \mathrm{yr})$ & & $0.61[-0.10,1.31]$ \\
& Forest type: & 1st-order occupancy & \\
& Mesophytic & & $0.02[-0.49,0.53]$ \\
& Northern hardwood & & $0.32[-0.29,0.94]$ \\
& Spruce & & $-1.01[-1.80,-0.22]$ \\
& Day & Detection & $0.15[-0.05,0.35]$ \\
CAWA-BTBW interaction & Intercept & 2nd-order occupancy & $0.89[0.14,1.64]$ \\
CAWA-HETH interaction & Intercept & 2nd-order occupancy & $-0.56[-1.28,0.16]$ \\
BTBW-HETH interaction & Intercept & 2nd-order occupancy & $-0.26[-0.64,0.11]$ \\
\hline
\end{tabular}

